\title{
Middle atmosphere response to the solar cycle in irradiance and ionizing particle precipitation
}

\author{
K. Semeniuk ${ }^{1}$, V. I. Fomichev ${ }^{1}$, J. C. McConnell ${ }^{1}$, C. Fu ${ }^{2}$, S. M. L. Melo ${ }^{2}$, and I. G. Usoskin ${ }^{3}$ \\ ${ }^{1}$ Department of Earth and Space Science and Engineering, York University, Toronto, Ontario, Canada \\ ${ }^{2}$ Canadian Space Agency, St.-Hubert, Quebec, Canada \\ ${ }^{3}$ Sodankylä Geophysical Laboratory, University of Oulu, Oulu, Finland
}

Received: 5 October 2010 - Published in Atmos. Chem. Phys. Discuss.: 25 October 2010

Revised: 29 April 2011 - Accepted: 11 May 2011 - Published: 31 May 2011

\begin{abstract}
The impact of $\mathrm{NO}_{\mathrm{x}}$ and $\mathrm{HO}_{\mathrm{x}}$ production by three types of energetic particle precipitation (EPP), auroral zone medium and high energy electrons, solar proton events and galactic cosmic rays on the middle atmosphere is examined using a chemistry climate model. This process study uses ensemble simulations forced by transient EPP derived from observations with one-year repeating sea surface temperatures and fixed chemical boundary conditions for cases with and without solar cycle in irradiance. Our model results show a wintertime polar stratosphere ozone reduction of between 3 and $10 \%$ in agreement with previous studies. EPP is found to modulate the radiative solar cycle effect in the middle atmosphere in a significant way, bringing temperature and ozone variations closer to observed patterns. The Southern Hemisphere polar vortex undergoes an intensification from solar minimum to solar maximum instead of a weakening. This changes the solar cycle variation of the Brewer-Dobson circulation, with a weakening during solar maxima compared to solar minima. In response, the tropical tropopause temperature manifests a statistically significant solar cycle variation resulting in about $4 \%$ more water vapour transported into the lower tropical stratosphere during solar maxima compared to solar minima. This has implications for surface temperature variation due to the associated change in radiative forcing.
\end{abstract}

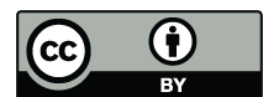

Correspondence to: K. Semeniuk

(kirill@nimbus.yorku.ca)

\section{Introduction}

Although the field of research on the influence of the variability of solar radiation and particle flux on the atmosphere is fast growing, great uncertainty remains concerning impacts and the mechanisms involved. Traditionally, modeling studies of solar variability effects on the climate system have focused on two basic ideas: (1) direct forcing of the troposphere by surface warming associated with changes in the total solar irradiance (TSI) or, in a more complex scenario, modulation of the atmosphere-ocean interactions producing internal oscillations (see for example White et al., 1997; White, 2006); and (2) forcing of the stratosphere associated with changes in ultraviolet (UV) radiation causing an increase in ozone and associated warming during solar maximum conditions. The latter results in changes in the latitudinal distribution of UV heating in the stratosphere which modifies the Eliassen-Palm flux divergence leading to a reduction of the Brewer-Dobson circulation (Kodera and Kuroda, 2002; Kuroda and Kodera, 2002; Kodera and Shibata, 2006). Both (1) and (2) operate at the same time increasing the complexity of the system response. An extensive model based analysis exploring the different effects and its implications is provided by Rind et al. (2008), which clearly demonstrates our current lack of understanding of the details of how each mechanism operates individually and the impacts of coupled processes. Indeed, Kodera et al. (2008) find that $\mathrm{CO}_{2}$ mediated cooling of the stratosphere produces a tropospheric response through a nonlinear interaction with the solar cycle. A review of the current state of understanding of the solar cycle influence on climate is given by Gray et al. (2010).

Published by Copernicus Publications on behalf of the European Geosciences Union. 
Recently, more attention has been devoted to the effects of upper atmosphere $\mathrm{NO}_{\mathrm{x}}$ and $\mathrm{HO}_{\mathrm{x}}$ produced from ionization by energetic particle precipitation (EPP) on stratospheric ozone. As with UV irradiance, the EPP component of the solar cycle has the potential to influence the tropospheric response through dynamical processes in the stratosphere that are sensitive to the ozone distribution (Callis et al., 2001; Shindell et al., 1999). Indeed, Seppälä et al. (2009) find a statistically significant correlation of wintertime polar northern hemisphere surface air temperatures and the Ap index using ERA-40 reanalyses from 1957 to 2002 and ECMWF operational data for subsequent years.

Ionization by energetic particle precipitation in the atmosphere is an ubiquitous feature of the Sun-Earth system. The work by Warneck (1972), Swider and Keneshea (1973) and Crutzen et al. (1975) pioneered research into influence of energetic particle precipitation on the chemistry of the atmosphere through the enhancement of $\mathrm{NO}_{\mathrm{x}}$. Following this early work, Solomon and Crutzen (1981) and Solomon et al. (1981, 1983) pointed out a coupling mechanism whereby thermospheric $\mathrm{NO}_{\mathrm{x}}$ could affect the stratosphere. The Halogen Occultation Experiment (HALOE) instrument on the Upper Atmosphere Research Satellite (UARS), and the subsequent Atmospheric Trace Molecule Spectroscopy (ATMOS) and Polar Ozone and Aerosol Measurement (POAM) experiments provided observational evidence for EPP associated $\mathrm{NO}_{\mathrm{x}}$ enhancement (Callis et al., 1996; Randall et al., 1998, 2001; Rinsland et al., 1996; Russell et al., 1984). However, little effort was devoted to the inclusion of EPP effects in chemistry climate models partly due to complexity and since they were considered to be of secondary importance on climate timescales. This has changed in recent years prompted by conclusive observational evidence of significant $\mathrm{NO}_{\mathrm{x}}$ enhancement in the polar regions, extending to stratospheric altitudes, during major solar proton events (e.g., Siskind, 2000; Randall et al., 2001, 2005; Hauchecorne et al., 2005, 2007; Jackman et al., 2005; López-Puertas et al., 2005). A number of 1, 2 and 3-dimensional model studies, mostly focused on a particular event and sometimes using measured $\mathrm{NO}_{\mathrm{x}}$ enhancement to force the model have been conducted since then (for a literature review see Jackman et al., 2008; Reddmann et al., 2010).

The work of Callis et al. (2001) demonstrates that SPEs are not the only type of EPP that can have a significant impact on ozone in the stratosphere and that auroral zone electron precipitation also needs to be taken into account.

The main difficulty in implementing energetic particle precipitation forcing in general circulation models is the complexity of the $\mathrm{D}$ region ion chemistry. One feasible option is to use parameterizations, relating ionization rates to the production of $\mathrm{NO}_{\mathrm{x}}$ and $\mathrm{HO}_{\mathrm{x}}$ (e.g., Jackman et al., 2008). The inclusion of ionization by energetic particles in global selfconsistent chemistry climate models started with the work of Langematz et al. (2005) and Rozanov et al. (2005), and has varied from from one model to another. For exam- ple, while the WACCM implementation described by Marsh et al. (2007) includes thermospheric $\mathrm{NO}_{\mathrm{x}}$ chemistry explicitly, it does not account for stratospheric production of $\mathrm{NO}_{\mathrm{x}}$ and $\mathrm{HO}_{\mathrm{x}}$ due to penetration of high energy galactic cosmic ray particles (GCR). The implementation in the HAMMONIA model, as described in Schmidt et al. (2006), includes stratospheric NO production by galactic cosmic rays following Heaps (1978) and has the thermospheric NO production based on the scheme of Huang et al. (1998), with the parameters adjusted to reproduce the Student Nitric Oxide Explorer (SNOE) satellite instrument measurements (Barth et al., 2003). In the recent EPP studies using the ECHAM5/MESSy chemistry climate model (CCM) low energy electron precipitation is parameterized in terms of the Ap index and ionization by solar proton events (SPEs) is included in a comprehensive way via an online model (Baumgaertner et al., 2009, 2010).

$\mathrm{HO}_{\mathrm{x}}$ is relatively short-lived (of the order of days) leading mostly to local effects, while $\mathrm{NO}_{\mathrm{x}}$ can lead to both short and long term (order of months) catalytic ozone destruction in the middle atmosphere. A comprehensive study of the short, middle and long term effects of large SPEs in the polar regions has been conducted by Jackman et al. $(2008,2009)$ involving model and measurements. Ozone destruction in the stratosphere can exceed $10 \%$ and last up to 5 months depending of the magnitude of the event. Based on their work it is apparent that CCMs are not able to reproduce all the features found by satellite measurements of atmospheric composition. The reasons for this include the fact that CCMs are not constrained to reproduce the observed meteorology and that there is uncertainty about the ion and neutral chemistry.

The multi-model studies of solar variability effects described by Austin et al. (2008) and the more recent CCMVal2 project (Manzini et al., 2010) noted an improvement of CCMs in the tropical stratosphere ozone response to the solar cycle in irradiance compared to observations. It was hypothesized that the improvement could have resulted from either the use of observed varying sea surface temperature (SST) or use of the full cycle in solar irradiance instead of steady solar maximum or minimum conditions. However, there are still unresolved issues such as the much weaker temperature variation in the tropical stratosphere around and below $10 \mathrm{hPa}$ in most models. The CCMVal projects did not investigate the role of EPP and it remains unclear what direct and indirect role it plays. In spite of the conclusions of Gray et al. (2010), we believe more process oriented model studies are necessary to understand the effects of EPP. The solar cycle signal is weak and is difficult to extract over short periods, such as the UARS record, from the internal variability of the chaotic ocean-atmosphere system.

As noted above, there is a growing body of work into the effects of EPP on the middle atmosphere. However, to the best of our knowledge there is no published analysis focused on the global role of EPP, including galactic cosmic rays, coupled with the transient solar cycle evolution of the 
atmosphere in a chemistry climate model. Previous studies had fixed solar maximum and minimum conditions (Schmidt et al., 2006) or did not include GCR (Marsh et al., 2007). The modulation of the solar irradiance cycle impact on the stratosphere by EPP is the focus of the work presented here.

We conduct pseudo-timeslice ensemble simulations, which include the solar cycle irradiance variation alone and those that also include EPP, using the Canadian Middle Atmosphere Model (CMAM). CMAM is a chemistry climate model which has been modified to include the solar irradiance cycle in the solar heating and photolysis rates as described below. The version of the model used here has a lid at $95 \mathrm{~km}$ and does not have a proper thermosphere. As a result, the thermospheric $\mathrm{NO}_{\mathrm{x}}$ source is not simulated and only partially captured by the constant upper boundary condition. However, this is a process study intended to assess the impact of EPP on CCMs, which typically lack EPP and do not represent the thermosphere (SPARC CCMVal, 2010). Three types of EPP are active in the model domain and were included: auroral zone medium and high energy electrons, SPEs and GCR. Medium and high energy electrons are found to be sufficient to produce $\mathrm{NO}_{\mathrm{x}}$ concentrations in the mesosphere similar to solar minimum conditions, which is a very large increase above the regular model state.

In this study we also deliberately do not allow for interannual SST variation to reduce the uncertainty in the response. A significant part of the interdecadal variability in climate model simulations originates from the low frequency variation of ocean temperatures. In this study we hope to reduce any aliasing of SST variability onto the solar cycle signal. Also, the solar cycle signal in SSTs is weak and not statistically significant (e.g. Roy and Haigh, 2010) so it is not selfevident that indirect EPP effects play a secondary role compared to solar variation of SSTs in the stratospheric response in regions such as the tropics where EPP is small. However, it should be recognized that the comparison of the results of this study with observations is limited since not all processes are included.

The EPP effect on the model chemistry can, to first order, be expressed by the amount of energy deposition, and hence ionization, which results in generation of $\mathrm{NO}_{\mathrm{x}}$ (Porter et al., 1976) and $\mathrm{HO}_{\mathrm{x}}$ (Solomon and Crutzen, 1981). For auroral zone electrons and SPEs, the vertical profile of the energy deposition is inferred from electron and proton fluxes, observed in low earth orbit and in geostationary orbit, respectively. For GCR we use the Usoskin and Kovaltsov (2006) parameterization for ionization, which is also based on observations. More details of the model and EPP parameterizations are given in the next section.

\section{Description of the model and simulations}

The CMAM version used here has a spectral dynamical core with a triangular truncation of 31 spherical harmonics. There are 71 sigma-pressure hybrid levels extending from the sur- face to about $95 \mathrm{~km}$. A non-zonal sponge layer is applied in the upper two pressure scale heights of the model. The radiation scheme of the model takes into account processes which are essential in both the troposphere and middle atmosphere. CMAM is the middle atmosphere version of the CCCma third generation climate GCM, which includes a comprehensive set of physical processes, including an interactive land surface scheme, deep and shallow convection parameterizations, orographic and non-orographic gravity wave drag parameterizations. A more detailed description of the CMAM model and its climatology is given in Scinocca et al. (2008), Beagley et al. (1997) and Fomichev et al. (2004).

The model has a comprehensive middle atmosphere photochemical scheme as well as heterogeneous chemistry on ice and supersaturated ternary solution (STS) polar stratospheric clouds (PSCs) (de Grandpré et al., 1997, 2000) which can capture $\mathrm{NO}_{\mathrm{x}}$ and $\mathrm{HO}_{\mathrm{x}}$ production and decay, as well as interaction with chlorine and bromine chemistry (Melo et al., 2008; Brohede et al., 2008). The heterogeneous chemistry scheme does not include processing on nitric acid trihydrate (NAT) particles as well as the associated denitrification. This is not considered to be a major omission as activation of chlorine on NAT is much less effective than on STS and ice, and denitrification typically contributes less than $30 \%$ to ozone loss (see Hitchcock et al., 2009, and references therein). Reddmann et al. (2010) found that NAT was enhanced by about $5 \%$ in the Antarctic winter of 2004 and Arctic winter of 2004-2005 when there was significant $\mathrm{NO}_{\mathrm{x}}$ production by auroral zone electrons and SPEs. Some underestimation of ozone loss in early spring in response to EPP is expected due to lack of NAT, which typically forms below $25 \mathrm{~km}$. However, as shown in subsequent sections, $\mathrm{NO}_{\mathrm{x}}$ produced by EPP can destroy ozone over most altitudes in the polar stratosphere and at different times of the year depending on EPP type. So the lack of NAT in the model has a secondary impact on the results.

Intrusions of $\mathrm{NO}_{\mathrm{x}}$ into the stratosphere are observed to produce a significant enhancement of $\mathrm{HNO}_{3}$ (Orsolini et al., 2005). The mechanisms by which this occurs are not clear and may be any combination of ion-ion, water ion cluster and heterogeneous reactions on aerosols including possibly sulfate nucleating on meteor smoke (Megner, 2007). For a discussion see Stiller et al. (2005). Since there is no ion chemistry and the sulfate aerosol surface area density is negligible above $30 \mathrm{~km}$ in CMAM, conversion of $\mathrm{N}_{2} \mathrm{O}_{5}$ into $\mathrm{HNO}_{3}$ in the upper stratosphere winter polar region is underestimated. So our simulations do not produce the strong secondary $\mathrm{HNO}_{3}$ maximum in the wake of SPEs or large auroral zone $\mathrm{NO}_{\mathrm{x}}$ intrusions such as observed in February 2004 (e.g, Reddmann et al., 2010). Since $\mathrm{HNO}_{3}$ is a reservoir species for both $\mathrm{HO}_{\mathrm{x}}$ and $\mathrm{NO}_{\mathrm{x}}$, there may be some overestimation of ozone loss through gas phase catalytic cycles in the upper stratosphere.

Tropospheric chemistry in this version of CMAM is limited to gas phase reactions. There is no chemistry for volatile 
organic compounds and wet or dry aerosols. Removal of species is by dry deposition at the surface. There is convective transport of tracers but without wet removal. Surface and lightning emissions of $\mathrm{NO}_{\mathrm{x}}$ are absent. Nevertheless, the tropospheric ozone values in the model do not deviate significantly from observations (de Grandpré et al., 2000). It should be noted that the ozone balance in the troposphere is largely determined by ozone transported from the stratosphere $\left(\sim 500 \mathrm{Mt} \mathrm{yr}^{-1}\right)$ and photochemical net production $\left(\sim 500 \mathrm{Mt} \mathrm{yr}^{-1}\right)$ with loss to surface deposition. Surface emissions and lightning emissions of $\mathrm{NO}_{\mathrm{x}}$ are $\sim 40 \mathrm{Mt} \mathrm{yr}^{-1}$ and $\sim 5 \mathrm{Mt} \mathrm{yr}^{-1}$, respectively (Lamarque et al., 1996). Given that the model ozone in the troposphere is within $10 \%$ of observations any radiative impact on the dynamics and transport is limited. This is borne out by the reasonable climate and sensitivity of the model (Eyring et al., 2006; Karpechko et al., 2010). Neither the lack of wet removal nor additional air quality chemistry in the model should change the fact that GCR leads to a net increase of tropospheric $\mathrm{NO}_{\mathrm{y}}$ and ozone. However, in this study this increase is overestimated due to lack of wet removal. Any effect of GCR on cloud formation is not included as this is at best a weak effect (e.g., Pallé et al., 2004) and another source of uncertainty to be minimized.

Major sudden stratospheric warming (SSW) events are important for $\mathrm{NO}_{\mathrm{x}}$ transport from the upper mesosphere to the stratosphere in the $\mathrm{NH}$ due to the associated intensification of the polar vortex in the mesosphere resulting in more effective polar night confinement (Hauchecorne et al., 2007; Semeniuk et al., 2008; Randall et al., 2009). We used the NAM index method described in McLandress and Shepherd (2009) to determine the SSW frequency for the runs presented here. They are found to occur $50 \pm 5 \%$ of the time. However, major SSWs in the model have highly variable features in different years and are not always effective at organizing $\mathrm{NO}_{\mathrm{x}}$ transport to the stratosphere. In addition, the major SSWs in the model exhibit highly variable clustering and often occur in successive years as opposed to every other year thereby producing multi-year gaps in occurrence. It should be noted that free running model SSWs do not occur at the same time as in observations and there is long term variation of SSW frequency in observations as well (Charlton and Polvani, 2007). Analysis of the impact of EPP on the frequency of occurrence of SSWs and their transport characteristics will be presented in a subsequent paper.

For the simulations conducted for this study SSTs, sea ice and chemical boundary conditions were specified to be repeated 1979 values for the IPCC SRES A1B greenhouse gas (IPCC, 2000) and the WMO Ab halogen (WMO/UNEP, 2003) scenarios. The SSTs and sea ice were taken from one of the ensemble members of the IPCC AR4 simulations using the coupled ocean-atmosphere version of the CCCma GCM on which CMAM is based. These IPCC AR4 simulations were conducted for the SRES A1B scenario.
The choice of 1979 conditions for halogens leads to the absence of a deep chemical ozone hole. However, the impact of this on the results presented here is limited. For 1979 conditions there is a dynamical ozone "hole" in the SH polar region in both the observations and the model. The annual mean total column ozone in the SH polar region exhibits a distinct minimum of about $285 \mathrm{DU}$ in the ground based observations (Fioletov et al., 2002) and 250 DU in the model. A maximum of about $340 \mathrm{DU}$ occurs at $55^{\circ} \mathrm{S}$. This structure persists from year to year in the model and observations, except that in the case of the latter the increasing halogen burden lowers the total column ozone amount globally. The deep dynamical "hole" in the model is partly a consequence of the late break up of the SH polar vortex. The presence of a chemical ozone hole does not significantly change the intensity of SH polar vortex and the transport characteristics in this region. Hence, the sensitivity to EPP investigated here should be relevant for models which have varying chlorine.

Since the $\mathrm{NO}_{\mathrm{x}}$ and $\mathrm{HO}_{\mathrm{x}}$ produced by EPP reacts with $\mathrm{ClO}_{\mathrm{x}}$ to form reservoir species such as $\mathrm{ClONO}_{2}$ and $\mathrm{HOCl}$, there will be reduced gas phase ozone loss through reactive nitrogen, hydrogen and chlorine catalytic cycles under conditions of increased chlorine which has been the case following 1979. However, during polar night conditions, $\mathrm{ClO}_{\mathrm{x}}$ amounts are very low above the PSC region where most of the effect of EPP on ozone occurs (e.g. Vogel et al., 2008).

To investigate the impact of individual EPP types single realization runs without solar cycle irradiance variation were conducted over the 1979 through 2006 period for auroral zone electrons, SPEs, GCR and a reference case without EPP. The results are presented in Sect. 4. To address dynamical variability effects, a three-member ensemble simulation without the solar irradiance cycle but with all three EPP types included was produced and is also presented in Sect. 4. Section 5 presents analysis of the role of EPP in the 11-yr solar cycle impact on the middle atmosphere using ensemble simulations. A three-member ensemble simulation from 1979 through 2006 without EPP but with the solar irradiance cycle is taken as the reference. A three-member ensemble simulation over the same period but with all three types of EPP included together with the solar irradiance cycle is taken as the perturbation. Effects on the long term mean state as well as variation with the solar cycle are considered. The various model experiments are summarized in Table 1.

\subsection{Solar irradiance scheme}

The incident solar radiation at the top of the atmosphere varies on different time scales. Variations in the total solar irradiance (TSI), i.e. the spectrally integrated solar irradiance, over the 11-yr solar cycle are very small (with an amplitude of approximately $0.1 \%$ ). However, as noted above, variations in solar irradiance are spectrally dependent and increase considerably with decreasing wavelength in the ultraviolet (UV) part of the spectrum, reaching several percent 
Table 1. Brief description of the simulations.

\begin{tabular}{lccc}
\hline $\begin{array}{l}\text { Run } \\
(1979-2006)\end{array}$ & $\begin{array}{c}\text { Ensemble } \\
\text { members }\end{array}$ & $\begin{array}{c}\text { EPP } \\
\text { type }\end{array}$ & $\begin{array}{c}\text { Solar } \\
\text { cycle }\end{array}$ \\
\hline Reference & 3 & none & no \\
Auroral Zone & 1 & $\begin{array}{c}\text { Electrons } \\
\text { SPEs }\end{array}$ & no \\
SPEs & 1 & GCR & no \\
GCR & 1 & Electrons+SPEs+GCR & no \\
Combined & 3 & none & yes \\
\hline Solar & 3 & Electrons+SPEs+GCR & yes \\
Solar Combined & 3 & &
\end{tabular}

in ozone absorption bands between 200 and $300 \mathrm{~nm}$ and exceeding $10 \%$ in the molecular oxygen bands at wavelengths shorter than $200 \mathrm{~nm}$ (e.g., Fröhlich and Lean, 2004). To take into account the spectral variability of the solar radiation, both the solar heating and photolysis rates schemes have been modified.

Absorption of solar UV radiation at wavelengths shorter than $300 \mathrm{~nm}$ by ozone and molecular oxygen provides the main contribution to the solar heating of the middle atmosphere (e.g., Fomichev, 2009). This means that in order to simulate effects of solar variability in the middle atmosphere, the spectral resolution of the model radiation scheme should be high enough so that it allows for an adequate description of variations in the spectral solar irradiance (SSI) over the solar cycle evolution (e.g., Egorova et al., 2004; Nissen et al., 2007). However, the shortwave radiation scheme of the CMAM exploits only one spectral band between 250 and $690 \mathrm{~nm}$ and uses TSI as the solar input for solar heating calculations. This approximation reflects the historical focus of numerical global modeling on the troposphere where absorption of solar UV radiation was thought to play only a very minor role, given the much lower intensity in the UV spectral region compared to the visible and near-infrared parts of the solar spectrum.

In order to properly account for solar input in the current study, a scheme allowing for calculation of variability in solar heating due to variations in SSI at wavelengths shorter than $300 \mathrm{~nm}$ has been developed. This scheme takes into account absorption of direct radiation in eight spectral bands between 121 and $300.5 \mathrm{~nm}(121-122,125-152,152-166$, $166-175,175-206,206-242.5,242.5-277.5$, and 277.5$305.5 \mathrm{~nm})$ and agrees very well with the reference line-byline calculations (Fomichev et al., 2010).

Figure 1 presents time series of the solar heating rate deviation from the 1950-2006 mean values at different heights as calculated with the developed scheme. Calculations were done for an equatorial ozone profile and an overhead Sun assuming $24 \mathrm{~h}$ illumination with the use of daily varying SSI provided on the SOLARIS website (2008). Changes in so-

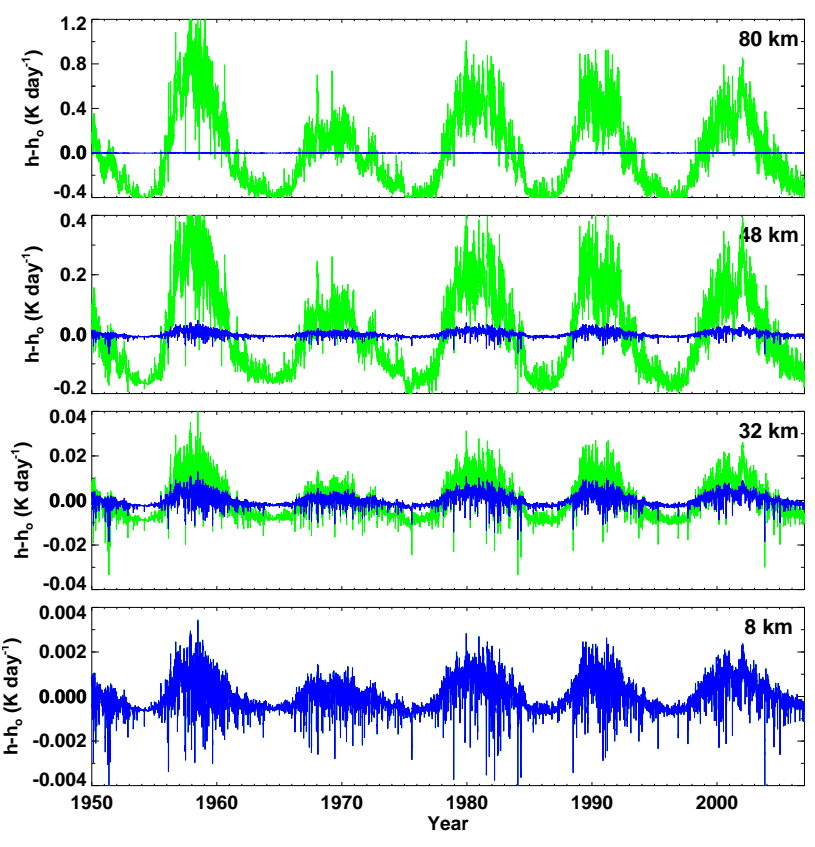

Fig. 1. Time series of the solar heating rate deviation from the 1950-2006 mean values in the troposphere $(8 \mathrm{~km})$, stratosphere $(32 \mathrm{~km})$, near the stratopause $(48 \mathrm{~km})$ and in the upper mesosphere $(80 \mathrm{~km})$. Blue: variability only in TSI is taken into account. Green: variability in SSI is taken into account. An overhead Sun and equatorial ozone profile are considered in calculating the solar heating rates.

lar heating associated with changes in TSI (blue) and in SSI (green) are shown. As seen from Fig. 1, taking into account variability in TSI only provides a reasonable solar heating signal in the troposphere, where absorption in visible and near-infrared regions dominates the heating rates, but significantly underestimates it in the middle atmosphere. In this case the signal is very small (less than $0.0012 \mathrm{~K} \mathrm{day}^{-1}$ from solar minimum to maximum at $8 \mathrm{~km}$ ) and has a relatively weak variation with height. With variability in SSI included, the solar signal considerably increases with height as absorption at shorter wavelengths becomes more important. In this case, the shortwave heating rates between solar minimum and maximum vary by about $0.03,0.3$ and $1 \mathrm{~K} \mathrm{day}^{-1}$ at 32,48 and $80 \mathrm{~km}$ levels, respectively.

To calculate photolysis rates the CMAM chemistry scheme uses a look-up table, which uses solar zenith angle, partial ozone column and geometric height as parameters. Photo-dissociation rates are provided for 165 spectral intervals with a width ranging from 1 to $10 \mathrm{~nm}$ between 121 and $852.5 \mathrm{~nm}$. These spectral ranges and spectral resolution are quite sufficient for the purpose of solar variability studies. For the current study, the photolysis scheme has been modified to calculate the look-up table daily reflecting changes in the SSI. Thus, a reasonable solar forcing is provided in the model. 


\subsection{EPP parameterization}

In these simulations we limit our ionization sources to auroral zone medium and high energy electrons, solar coronal mass ejection protons and galactic cosmic rays. Electron fluxes are measured by NOAA low earth orbit satellites, proton fluxes are measured by the NOAA GOES geostationary satellites, and galactic cosmic ray intensity is measured by surface neutron monitors.

For all EPP types the $\mathrm{NO}_{\mathrm{x}}$ and $\mathrm{HO}_{\mathrm{x}}$ production rates were determined from the energy deposition rate, $E\left(\mathrm{eV} \mathrm{g}^{-1} \mathrm{~s}^{-1}\right)$, following the work of Porter et al. (1976). The ionization rate, $I\left(\mathrm{~cm}^{-3} \mathrm{~s}^{-1}\right)$, is given by

$I=\frac{\rho E}{35.4}$

where $\rho$ is the air density in $\mathrm{g} \mathrm{cm}^{-3}$ and the ionization energy is $35.4 \mathrm{eV}$. The production of $\mathrm{NO}_{\mathrm{x}}$ is given by

$P_{\mathrm{NO}_{\mathrm{x}}}=1.25 \mathrm{I}$

and $45 \%$ of $P_{\mathrm{NO}_{\mathrm{x}}}$ is assumed to produce $\mathrm{N}\left({ }^{4} \mathrm{~S}\right)$ while $55 \%$ is assumed to go into $\mathrm{N}\left({ }^{2} \mathrm{D}\right)$. The latter is added to the production of $\mathrm{NO}$ and $\mathrm{O}$ since the reaction of $\mathrm{N}\left({ }^{2} \mathrm{D}\right)$ with $\mathrm{O}_{2}$ to form these products is rapid compared to the reaction of $\mathrm{N}\left({ }^{4} \mathrm{~S}\right)$ with $\mathrm{O}_{2}$, which is very temperature dependent. The production of $\mathrm{HO}_{\mathrm{x}}$ is given by

$P_{\mathrm{HO}_{\mathrm{x}}}=a I$

where $a(z)$ is a height dependent function that varies from a value of 2 at $40 \mathrm{~km}$ to zero above $90 \mathrm{~km}$ and is an approximation based on the typical variation found in Fig. 2 of Solomon et al. (1981). The actual production rate has a nearly linear dependence on the logarithm of the ionization rate with a negative slope depending on altitude. For example, around $75 \mathrm{~km}$ it falls from 1.93 to 1.3 as the ionization rate increases from 10 to $100000 \mathrm{~cm}^{-3} \mathrm{~s}^{-1}$. In the lower mesosphere and stratosphere the dependence of the production rate on the ionization rate is very small. So the approximation has the greatest effect on auroral zone electron precipitation in our simulations. As shown in later sections, auroral zone $\mathrm{HO}_{\mathrm{x}}$ does not survive transport into the stratosphere due to its short photochemical lifetime so the impact on ozone and hence the dynamics of the middle atmosphere is not important.

It is assumed here that $P_{\mathrm{HO}_{\mathrm{x}}}$ contributes equally to the production of $\mathrm{H}$ and $\mathrm{OH}$. Below $40 \mathrm{~km}, a(z)$ is taken to have a constant value of two. This assumption is a limitation since work with a detailed ion chemistry model (Verronen et al., 2006) indicates that $\mathrm{HNO}_{3}$ is an important direct product through ion-ion recombination reactions with secondary $\mathrm{OH}$ production via photodissociation. As noted by Verronen et al. (2006) assuming a constant $\mathrm{HO}_{\mathrm{x}}$ production leads to an underestimation of $\mathrm{HO}_{\mathrm{x}}$ during sunrise and sunset which also affects ozone loss, but only lasts for a short period outside polar regions.
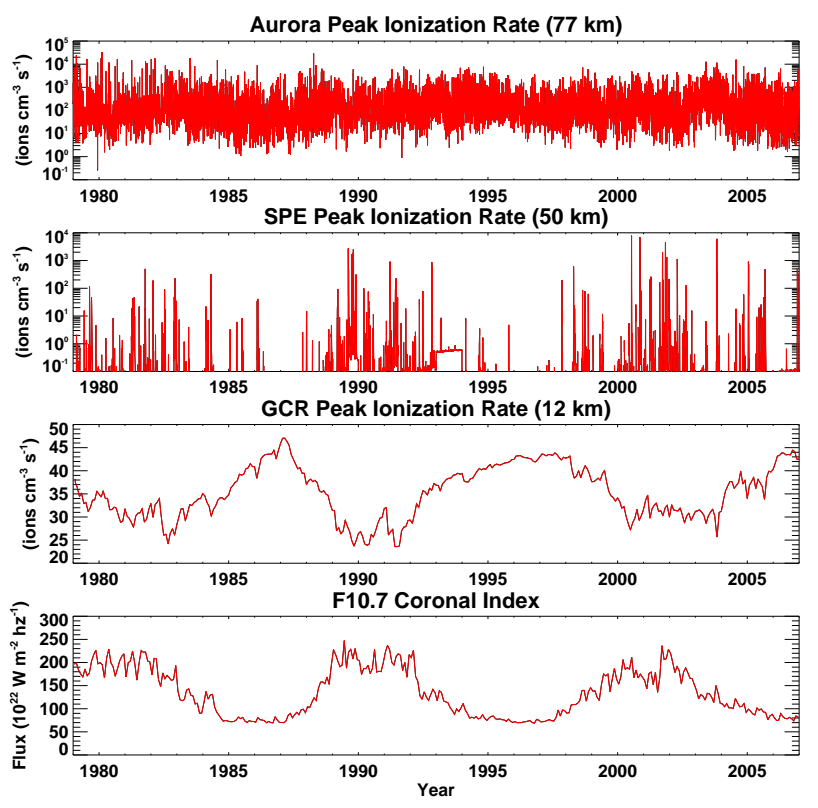

Fig. 2. Timeseries of peak ion pair production for aurora (top panel), SPEs (second panel) and GCR (third panel). Auroral zone electrons and SPEs data is daily but GCR data is monthly. The F10.7 index variation is shown in the bottom panel.

Figure 2 shows the time series of the ion pair production rate for the three types of EPP used in the model along with the F10.7 solar variability index (adjusted Penticton/Ottawa $2800 \mathrm{MHz}$ solar flux, http://www.ngdc.noaa.gov/ $\mathrm{stp} / \mathrm{solar} /$ flux.html). Auroral activity maximizes during the descending stage of the solar cycle. SPEs tend to cluster during solar maximum years when coronal activity is enhanced. GCR is anti-correlated with the solar cycle due to the complex heliospheric modulation driven by solar magnetic activity.

The vertical profiles of the peak ion pair production rate are shown in Fig. 3 based on the parameterizations described below. Auroral zone ionization maximizes in the upper mesosphere and above with a high energy tail that penetrates into the lower mesosphere. SPEs can have maximum ionization below the stratopause depending on the energy spectrum of the solar protons (Jackman et al., 2005). The GCR profiles peak around $13 \mathrm{~km}$ and there is about a factor of two difference between solar maximum and minimum conditions.

\subsubsection{Electron precipitation}

The daily energy deposition is inferred from daily composites of electron flux observations from the Medium Energy Proton and Electron Detector (MEPED) instruments on NOAA low earth orbit satellites in the $30-100 \mathrm{keV}, 100$ $300 \mathrm{keV}$ and 300-1000+ keV channels (Seale and Bushnell, 1987). The first two of these selected channels measure the medium energy electron fluxes and the third channel 
measures the high energy electron fluxes. The MEPED data from 1979 through 2006 was used (NOAA/POES website, 2008). Data gaps were filled using the method of singular spectrum analysis (Kondrashov and Ghil, 2006).

The low energy MEPED channel (under $30 \mathrm{keV}$ ) was not used as electrons with this energy are deposited primarily above $100 \mathrm{~km}$ and the model lid. The thermospheric generation of $\mathrm{NO}_{\mathrm{x}}$ via extreme ultraviolet radiation, $\mathrm{x}$-ray radiation and ionization by low energy EPP is not included in the model. This limitation manifests itself during solar maximum periods when $\mathrm{NO}_{\mathrm{X}}$ increases relative to solar minimum conditions near the winter poles are several times smaller than observed. In observations (Hood and Soukharev, 2006) and model studies which include a more comprehensive thermosphere and low energy electron ionization (Marsh et al., 2007), there is a $\mathrm{NO}_{\mathrm{x}}$ variation of about $100 \%$ during the solar cycle as low as the stratopause.

However, the medium and high energy electrons considered here are sufficient to produce mesospheric $\mathrm{NO}_{\mathrm{x}}$ values typical of solar minimum conditions (not shown). This reflects three constraints on the contribution of the region above the model lid to lower altitudes. Firstly, during descent in the lower thermosphere and upper mesosphere region air parcels experience large meridional excursions through wave action. In the polar region of both hemispheres between 80 and $100 \mathrm{~km}$ there are wintertime zonal wavenumber 2 planetary waves which propagate eastward (Sandford et al., 2008; Tunbridge and Mitchell, 2009). These waves have peak meridional winds of about $20 \mathrm{~m} \mathrm{~s}^{-1}$ and have a two day period but occur for episodes lasting a week or more (Tunbridge and Mitchell, 2009). There are also longer period oscillations peaking above $80 \mathrm{~km}$ at high latitudes in the $\mathrm{NH}$. They are eastward and westward traveling and have a zonal wavenumber 1 structure (Pancheva et al., 2008). The period of these waves is predominantly 16 and 23 days and their peak meridional wind amplitudes exceed $20 \mathrm{~ms}^{-1}$ during major SSW events but are not negligible at other times during winter. They are also very deep with vertical wavelengths in excess of $50 \mathrm{~km}$. It is likely that the $\mathrm{SH}$ has analogous disturbances which reflect stratospheric vortex deformation, but with characteristics reflecting the large interhemispheric difference in polar vortex behaviour. When taken together with the fact that the area of the polar night declines with altitude, these waves will contribute to significant loss of $\mathrm{NO}_{\mathrm{x}}$ through long-distance transport into lower latitudes and photochemical conversion back into $\mathrm{N}_{2}$.

Secondly, the descent of air between 100 and $80 \mathrm{~km}$ in the winter polar regions is frustrated by the fact that in both hemispheres the zonal wind undergoes a reversal in this layer (e.g., McLandress et al., 2006; Liu et al., 2010). Associated with this wind reversal is a layer where the meridional circulation changes sign and the flow is equatorward with little downward descent rather than poleward and downward. These results are model based but there is observational evidence to support them (e.g., Beagley et al., 2000). The large

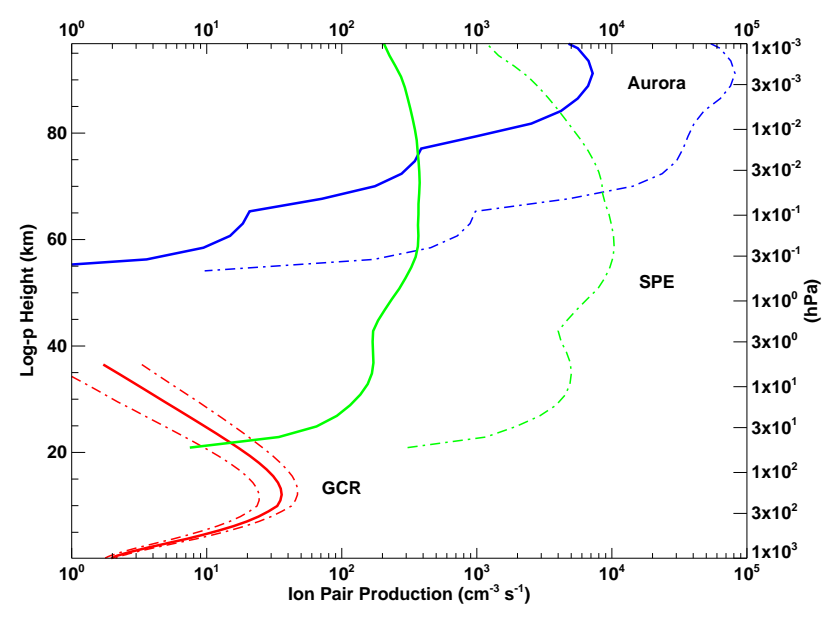

Fig. 3. Vertical pressure profiles of the time mean ion pair production rate for auroral zone electrons (blue), SPEs (green), and GCR (red). The time average for SPEs is done only for the fraction of the time when ionization exceeds 100 pairs $\mathrm{cm}^{-3} \mathrm{~s}^{-1}$ at some altitude. The dash-dot curves represent maximum and minimum ionization for the 1979 through 2006 period. Minimum ionization is significant only for GCR.

wave diffusivity at these altitudes to some extent overcomes this large scale transport reversal and drives downgradient tracer fluxes. However, there is no simple transport conduit linking the low energy auroral region above $100 \mathrm{~km}$ with the mesosphere during winter.

The zonal wind reversals also result in a structure that supports barotropic and baroclinic instability and contributes to the growth of large amplitude Rossby wave disturbances (McLandress et al., 2006). As noted above, this reduces the survival of any thermospheric $\mathrm{NO}_{\mathrm{x}}$ during descent through the MLT.

Thirdly, the density decreases exponentially with height. In the vicinity of the mesopause, between 80 and $90 \mathrm{~km}$, the scale height is about $4 \mathrm{~km}$, so the atmospheric density experiences about a 30-fold reduction between 80 and $100 \mathrm{~km}$. A tracer originating above $100 \mathrm{~km}$ will experience a similar or greater reduction factor in mixing ratio during descent to $80 \mathrm{~km}$ depending on diffusion. Eddy and wave diffusion increases with height due to amplification of waves on account of density decrease. In the mesosphere the wave energy spectrum has a $-5 / 3$ slope (e.g., Koshyk et al., 1999), which indicates a turbulent-like mixing regime. Observations of $\mathrm{NO}_{\mathrm{y}}$ transport (e.g., Urban et al., 2009; Orsolini et al., 2009) indicate that there is attenuation of mixing ratios in descending plumes of air at the poles. Mixing ratio conservation would require a volumetric collapse of descending tracer plumes but instead they disperse.

A vertical energy deposition profile was derived using peak flux values from twelve $30^{\circ}$ longitudinal sectors at each altitude. The average of these twelve peak electron flux 
values was used for subsequent calculations. This approach gives an average daily peak intensity that is biased on the high side. However, for the simulations presented here the peak $\mathrm{NO}_{\mathrm{x}}$ value of $\sim 5 \mathrm{ppmv}$ in the polar regions between 80 and $90 \mathrm{~km}$, agrees well with observations (Randall et al., 2009). A more sophisticated statistical model tying observed electron fluxes on orbit tracks to their spatial and temporal distribution in the auroral oval would be more accurate. The dependence of the flux on energy was approximated by a piece-wise exponential fit following Callis et al. (1998). The energy deposition was obtained using the range-energy expression from Gledhill (1973) and the $80^{\circ}$-isotropic energy distribution function from Rees (1989).

A parameterized auroral oval was used to obtain a 3-D distribution of electron energy deposition from the vertical profile calculated. The auroral oval is a modified version of the scheme from Holzworth and Meng (1975) based on the formulation of Feldstein (1963). The modification for the auroral horizontal distribution, $H$, was as follows:

$$
\begin{aligned}
& H(\phi, \theta)=\left\{\begin{array}{l}
\exp \left(-\left(\left(\theta_{\mathrm{g}}(\phi, \theta)-\theta_{\mathrm{c}}\right) / \delta \theta_{\mathrm{p}}\right)^{2}\right), \text { if } \theta_{\mathrm{g}}>\theta_{\mathrm{c}} \\
\exp \left(-\left(\left(\theta_{\mathrm{g}}(\phi, \theta)-\theta_{\mathrm{c}}\right) / \delta \theta_{\mathrm{e}}\right)^{2}\right), \text { if } \theta_{\mathrm{g}} \leq \theta_{\mathrm{c}}
\end{array}\right. \\
& \theta_{\mathrm{c}}=\theta_{\mathrm{e}}+0.3\left(\theta_{\mathrm{p}}-\theta_{\mathrm{e}}\right) \\
& \delta \theta_{\mathrm{p}}=2\left(\theta_{\mathrm{p}}-\theta_{\mathrm{c}}\right) \\
& \delta \theta_{\mathrm{e}}=\left(\theta_{\mathrm{c}}-\theta_{\mathrm{e}}\right)
\end{aligned}
$$

where $\theta_{\mathrm{e}}$ and $\theta_{\mathrm{p}}$ are the equatorial and polar corrected geomagnetic latitude limits of the auroral oval, respectively, from the Holzworth and Meng (1975) scheme. This modification was made to improve the realism of the auroral oval distribution when compared to the statistical model of the Space Weather Prediction Center of NOAA (see http: //www.swpc.noaa.gov/pmap/index.html). The map from geographic longitude $(\phi)$ and latitude $(\theta)$ on the model grid to corrected geomagnetic latitude $\left(\theta_{\mathrm{g}}(\phi, \theta)\right)$ was calculated offline using an updated version of the GEOCGM program of Tsyganenko et al. (1987).

Hourly values of the auroral electrojet (AE) index (WDC website, 2008) were used to specify the size of the oval using the relation for the $Q$ index from Starkov (1994). The orientation of the oval follows the Sun. The parameterized auroral oval resets $Q$ values to six when they exceed this number, so that more $\mathrm{NO}_{\mathrm{x}}$ is deposited in the polar night than should be during intense geomagnetic storms. In addition, the highest energy electrons are assumed to be distributed in the same auroral oval as the lower energy electrons when in fact relativistic electrons are deposited in the sub-auroral belt (e.g., Brown, 1966). However, the relativistic electrons account for a small fraction of the $\mathrm{NO}_{\mathrm{x}}$ production and this limitation of the scheme is not significant.

\subsubsection{SPES}

For SPEs the daily energy deposition rate vertical profiles were obtained from the dataset of Jackman (2006). The horizontal distribution of the energy deposition was approximated by axially symmetric caps centered on the geomagnetic poles with a diameter of about 60 degrees (Jackman et al., 2005). A smooth Gaussian squared transition was assumed starting with a value of one at $65^{\circ}$ and decreasing to zero at $45^{\circ}$ in geomagnetic coordinates with a $5^{\circ}$ scaling factor to minimize Gibbs fringing since CMAM uses spectral transport.

\subsubsection{GCR}

Ionization effect of GCR was computed using the CRAC:CRII (Cosmic Ray induced Atmospheric Cascade: Application for Cosmic Ray Induced Ionization) model (Usoskin and Kovaltsov, 2006) extended toward the upper atmosphere (Usoskin et al., 2010). The model is based on the full Monte-Carlo simulation of the cosmic ray induced atmospheric cascade and provides computations of the ionization rate in 3-D. The accuracy of the model is within $10 \%$ in the troposphere and lower stratosphere, and up to a factor of two in the mesosphere (Bazilevskaya et al., 2008). The temporal variability of the GCR energy spectrum, which is a result of the solar modulation in the heliosphere, is parameterized via the variable modulation potential, which is computed on a monthly basis using the data from the world network of ground-based neutron monitors (Usoskin et al., 2005). The final time-dependent ionization rate was computed using the following parameters: altitude (quantified via the barometric pressure), geomagnetic latitude (quantified via the geomagnetic cutoff rigidity computed in the framework of IGRF10 model (IAGA/V-MOD website, 2008) and solar activity (quantified via the modulation potential).

\section{Regression model}

Following the analysis in Austin et al. (2008), we use a linear multiple regression model with first order autoregressive, AR(1), error treatment (Tiao et al., 1990) to investigate the solar cycle in key model fields. However, instead of subtracting the mean seasonal variation we include annual and semiannual harmonics. As CMAM simulations do not resolve the QBO and do not contain long term variation of total chlorine, aerosols and sea surface temperatures no fitting is done for these terms for model output. But QBO, equivalent effective stratospheric chlorine (EESC), aerosol and El Niño/Southern Oscillation (ENSO) terms are used when fitting the observational data. Thus, for a timeseries of a field, e.g. ozone, $M$, we have 

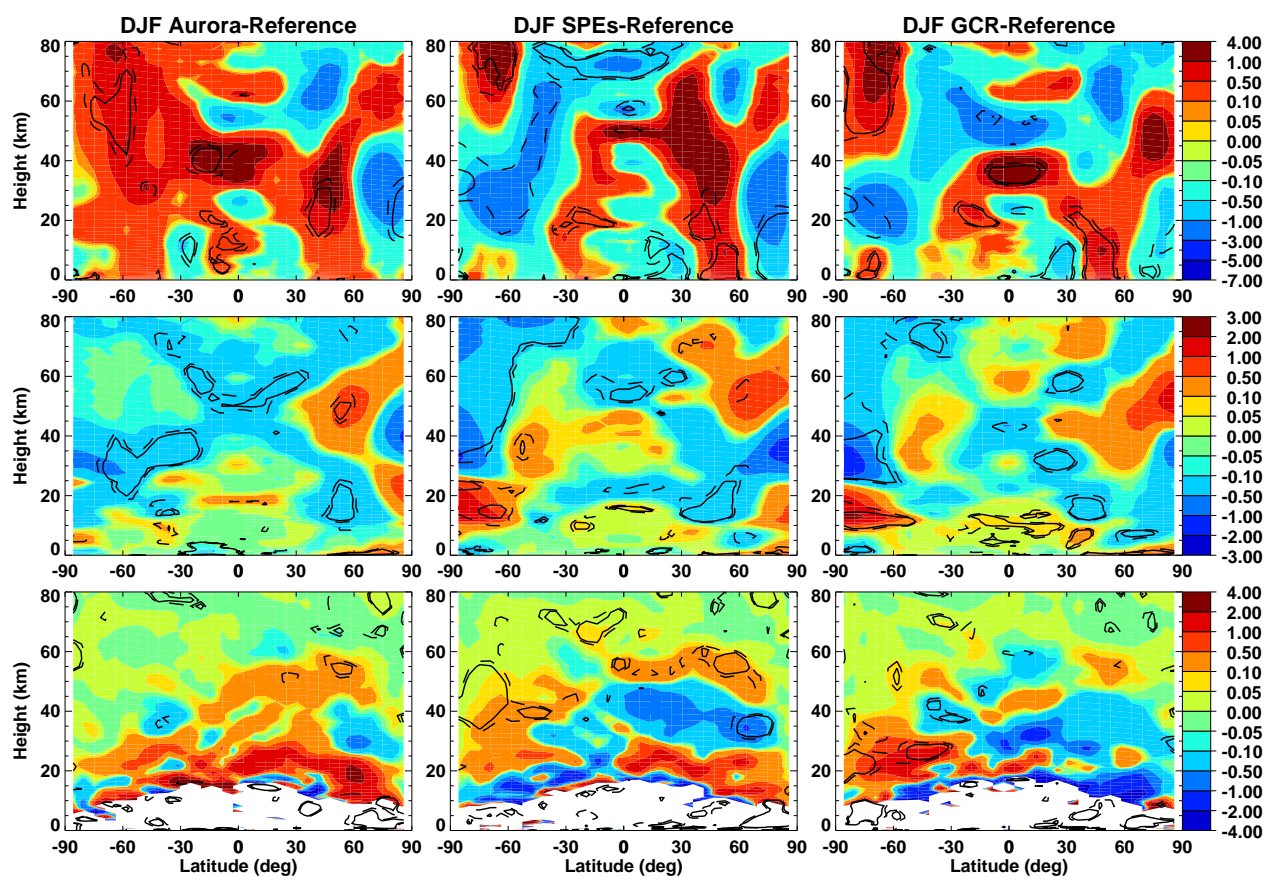

Fig. 4. Run mean, December-February mean differences compared to the reference run for auroral zone electrons (left), SPEs (center) and GCR (right) showing zonal wind (top, $\mathrm{m} \mathrm{s}^{-1}$ ), temperature (middle, K) and mass streamfunction (bottom, $\mathrm{kg} \mathrm{m}^{-1} \mathrm{~s}^{-1}$, values outside the $(-4,4)$ interval not plotted). Solid and dashed contours denote regions with $95 \%$ and $90 \%$ confidence levels, respectively. These two contours are the same for all subsequent figures.

$$
\begin{aligned}
M(t)= & a_{0}+a_{1} \sin \left(\pi \frac{t}{2}\right)+a_{2} \cos \left(\pi \frac{t}{2}\right)+ \\
& a_{3} \sin (\pi t)+a_{4} \cos (\pi t)+b t+ \\
& c S_{\mathrm{F} 10.7}(t)+d_{1} U_{\mathrm{QBO} 1}(t)+d_{2} U_{\mathrm{QBO} 2}(t)+ \\
& e \mathrm{SAD}(t)+f \operatorname{MEI}(t)+g \operatorname{EESC}(t)+\epsilon(t)
\end{aligned}
$$

where $t$ is in seasons (three month means), $S_{\mathrm{F} 10.7}$ is the F10.7 index normalized by 100 , and $U_{\mathrm{QBO} 1}$ and $U_{\mathrm{QBO} 2}$ are based on the $30 \mathrm{hPa}$ Singapore winds as in Randel and $\mathrm{Wu}$ (2007) and represent two orthogonal QBO wind components. The remaining fitting terms are the sulphate surface area density at $60 \mathrm{hPa}, \mathrm{SAD}$ (Hamill et al., 2006), the Multivariate ENSO index, MEI (Wolter and Timlin, 1998) and the EESC (Newman et al., 2007).

The height-latitude distributions of the F10.7 regression coefficient, $c$, are shown in Sect. 5. This coefficient represents the fraction of the timeseries variation that projects onto the F10.7 timeseries. We chose the F10.7 index as a general representation of the solar cycle. The Ap index gives a better fit for the auroral component, as it reflects the variation of the solar wind streams. However, it does not serve the main purpose of this paper, which is to study all main EPP types including SPEs and GCR.

\section{Impact of individual EPP types}

The effect of the three EPP types on the long-term composition and dynamics is presented in this section. These runs are single realizations from the 1979 through 2006 period spanned by the EPP data. This $28 \mathrm{yr}$ period is too short to have a high confidence level for the dynamical response given dynamical variability. However, they do reveal the distribution of the impact on composition and give some idea of the dynamical sensitivity.

\subsection{Electron precipitation}

The run mean, December through February mean (DJF) zonal wind, temperature and the transformed Eulerian mean (TEM) mass streamfunction, which represents the BrewerDobson circulation (Andrews et al., 1987), for the run with auroral zone ionization and the reference run (no ionization, no solar cycle) are shown in Fig. 4 (left panels). For this figure and other figures with 2-D fields in this paper the Studentt test confidence values of $90 \%$ and $95 \%$ are marked by dashed and solid black contours, respectively. Both values are plotted to avoid ambiguity as to which regions are statistically significant since the $95 \%$ value always encompasses a smaller region than the $90 \%$ value. The vertical coordinate in all the figures presented here is geopotential derived geometric height. 

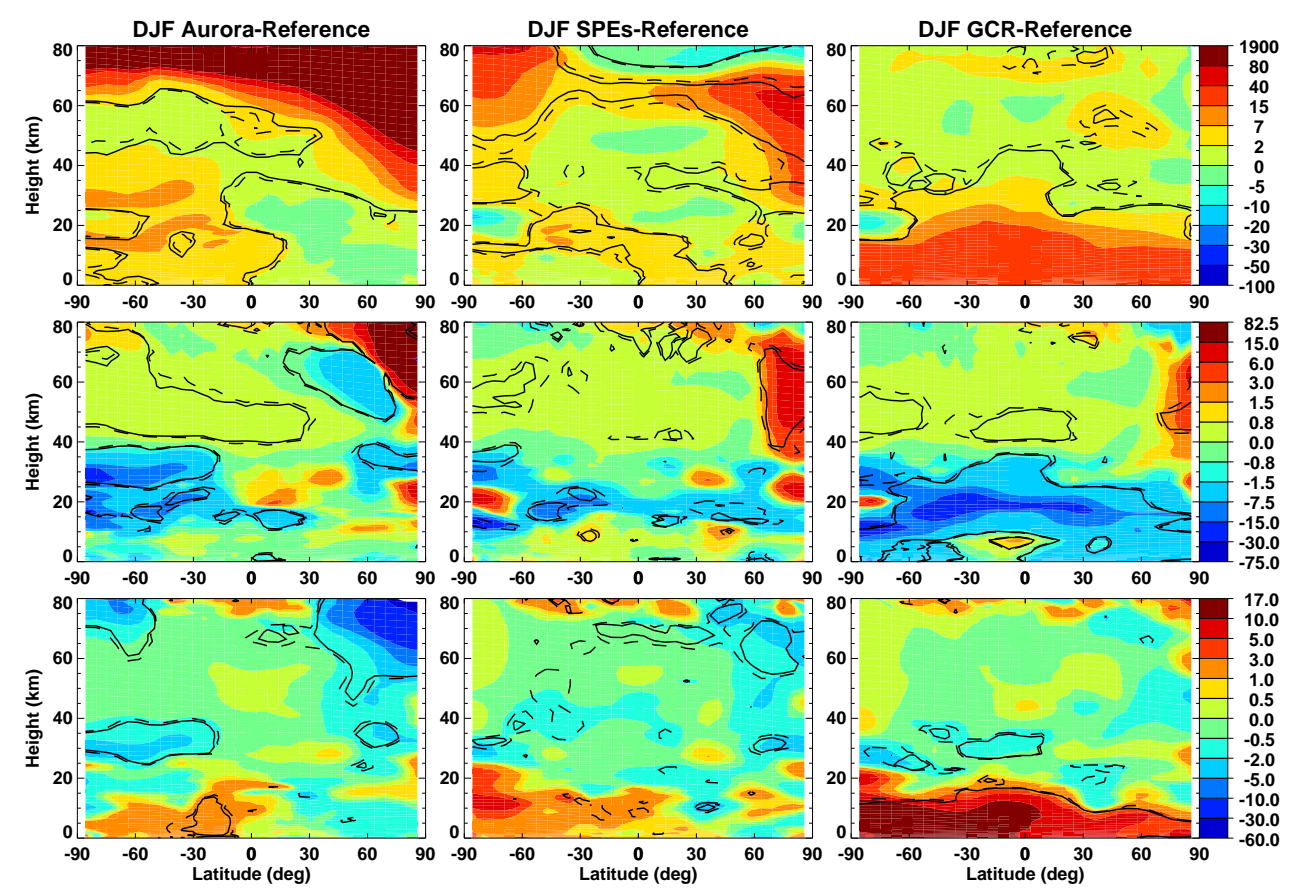

Fig. 5. Run mean, December-February mean $\mathrm{NO}_{\mathrm{y}}$ (top, $\%$ ), $\mathrm{HO}_{\mathrm{x}}$ (middle, \%) and $\mathrm{O}_{3}$ (bottom, \%) differences for auroral zone electrons, SPEs and GCR runs compared to the reference run.

The change in the NH polar vortex shows a statistically significant increase of its diameter in the stratsophere below $30 \mathrm{~km}$. The associated temperature shows a quadrupole structure with significance above $90 \%$ only around $50^{\circ}$ to $60^{\circ} \mathrm{N}$ in the lower stratosphere, where it cools, and in the stratopause region where it warms. The Brewer-Dobson circulation change has three layers between $50^{\circ}$ and $80^{\circ} \mathrm{N}$ with increased strength below $25 \mathrm{~km}$, weakening between 25 and $40 \mathrm{~km}$ and an increase above only to $75^{\circ} \mathrm{N}$. However, the Brewer-Dobson circulation change is not statistically significant. This highlights the limitations of using the Student- $t$ test for the atmosphere, which has non-Gaussian statistics (e.g., Yoden et al., 2002). Presumably there is a unique meridional circulation change associated with the zonal wind change. However, this may not be the case and the lack of statistical confidence could reflect a degeneracy in the dynamical response.

The DJF mean, run mean $\mathrm{NO}_{\mathrm{y}}, \mathrm{HO}_{\mathrm{x}}$ and ozone differences for the run with auroral zone ionization and the reference run are shown in Fig. 5 (left panels). There is a large increase of $\mathrm{NO}_{\mathrm{y}}$ in the winter auroral production zone down to about $30 \mathrm{~km}$. We note that above $40 \mathrm{~km}$ the $\mathrm{NO}_{\mathrm{y}}$ is essentially $\mathrm{NO}_{\mathrm{x}}$. In the summer auroral production zone the increase extends only down to $65 \mathrm{~km}$. The difference in the polar regions between the summer and winter is, of course, that the exposure of $\mathrm{NO}_{\mathrm{x}}$ to sunlight in the polar summer results in its destruction, viz.,

$\mathrm{NO}+h v \rightarrow \mathrm{N}+\mathrm{O}$
$\mathrm{N}+\mathrm{NO} \rightarrow \mathrm{N}_{2}+\mathrm{O}$

which is modulated by reaction with $\mathrm{O}_{2}$ and $\mathrm{OH}$,

$\mathrm{N}+\mathrm{O}_{2} \rightarrow \mathrm{NO}+\mathrm{O}$

$\mathrm{N}+\mathrm{OH} \rightarrow \mathrm{NO}+\mathrm{H}$

There is also a significant increase of $\mathrm{NO}_{\mathrm{x}}$ at all latitudes above $70 \mathrm{~km}$. In the $\mathrm{SH}$ summer at middle and polar latitudes and between the surface and $20 \mathrm{~km}, \mathrm{NO}_{\mathrm{y}}$ increases by over $5 \%$ and this feature is most likely a remnant of downward transport of $\mathrm{NO}_{\mathrm{y}}$ during the previous winter. At these altitudes the photochemical lifetime of $\mathrm{NO}_{\mathrm{y}}$ is long. Also, polar vortex interior air is "fossilized" in the summertime due to weak mixing (Orsolini , 2001; Orsolini et al., 2003). In the Northern Hemisphere during winter, below $40 \mathrm{~km}$, there is a modest decrease of $\mathrm{NO}_{\mathrm{y}}$ in this latitude range (but not statistically significant) which may be associated with a strengthening of the Brewer-Dobson circulation. Since the disturbed state of the winter $\mathrm{NH}$ stratosphere prevents significant transport of $\mathrm{NO}_{\mathrm{y}}$ into this region from above, an increase in transport of low $\mathrm{NO}_{\mathrm{y}}$ air from the tropics could lead to this reduction.

The left central panel for $\mathrm{HO}_{\mathrm{x}}$ shows an increase in both the summer and winter polar mesosphere due to the EPP $\mathrm{HO}_{\mathrm{x}}$ source from water vapour. The largest percentage increase occurs in the winter polar regions partly due to the reduced background $\mathrm{HO}_{\mathrm{x}}$ in winter. Above $70 \mathrm{~km}$ at low and middle latitudes there is no comparable increase of $\mathrm{HO}_{\mathrm{x}}$ as compared to $\mathrm{NO}_{\mathrm{x}}$. The $\mathrm{HO}_{\mathrm{x}}$ source in this region is dominated 
by photolysis of water vapour. Also, to a lesser extent, the difference is because the photochemical lifetime of $\mathrm{HO}_{\mathrm{x}}$ is shorter (under a day in contrast to 5 days for $\mathrm{NO}_{\mathrm{x}}$ ).

In the summer hemisphere, below $40 \mathrm{~km}$ there is a decrease in $\mathrm{HO}_{\mathrm{x}}$. This may be due to changes in the sources and/or sinks of $\mathrm{HO}_{\mathrm{x}}$. As can be seen in the lowest left panel, ozone has also decreased and so one of the sources of $\mathrm{HO}_{\mathrm{x}}$, viz. reaction of $\mathrm{O}\left({ }^{1} \mathrm{D}\right)$ (produced from photolysis of ozone) with $\mathrm{H}_{2} \mathrm{O}, \mathrm{CH}_{4}$ and $\mathrm{H}_{2}$ would decrease. There is also a source from the photolysis of $\mathrm{HNO}_{3}$, which has increased in this region (top left panel, $\mathrm{NO}_{\mathrm{y}}$ is primarily $\mathrm{HNO}_{3}$ at these altitudes). With respect to changes in sinks, the sink via the reaction $\mathrm{OH}+\mathrm{HNO}_{3} \rightarrow \mathrm{H}_{2} \mathrm{O}+\mathrm{NO}_{3}$ has increased as well.

The lowest left panel shows that the largest effect on ozone is in the winter polar region above $50 \mathrm{~km}$. This reflects that auroral zone electron ionization occurs in the upper mesosphere polar regions and the $\mathrm{HO}_{\mathrm{x}}$ produced (see middle left panel) leads to reduction of ozone via

$$
\begin{aligned}
& \mathrm{H}+\mathrm{O}_{3} \rightarrow \mathrm{OH}+\mathrm{O}_{2} \\
& \mathrm{OH}+\mathrm{O} \rightarrow \mathrm{H}+\mathrm{O}_{2} \\
& \text { Net: } \mathrm{O}+\mathrm{O}_{3} \rightarrow 2 \mathrm{O}_{2}
\end{aligned}
$$

and

$$
\begin{aligned}
& \mathrm{O}+\mathrm{HO}_{2} \rightarrow \mathrm{OH}+\mathrm{O}_{2} \\
& \mathrm{O}+\mathrm{OH} \rightarrow \mathrm{H}+\mathrm{O}_{2} \\
& \mathrm{H}+\mathrm{O}_{2}+\mathrm{M} \rightarrow \mathrm{HO}_{2}+\mathrm{M} \\
& \mathrm{Net}: \mathrm{O}+\mathrm{O} \rightarrow \mathrm{O}_{2}
\end{aligned}
$$

This effect can also be seen in the summer polar region above $60 \mathrm{~km}$. There is ozone loss of between 2 and $5 \%$ between 25 and $40 \mathrm{~km}$ in both the winter and summer hemispheres. The additional ozone loss is driven by increases in $\mathrm{NO}_{\mathrm{x}}$ that survived from the previous winter via

$\mathrm{O}+\mathrm{NO}_{2} \rightarrow \mathrm{NO}+\mathrm{O}_{2}$

$\mathrm{NO}+\mathrm{O}_{3} \rightarrow \mathrm{NO}_{2}+\mathrm{O}_{2}$

Net: $\mathrm{O}+\mathrm{O}_{3} \rightarrow 2 \mathrm{O}_{2}$

There is a transition from $\mathrm{O}_{3}$ destruction to production in the lowermost stratosphere and troposphere (Brasseur and Solomon, 2005). Above roughly $20 \mathrm{~km}$ the $\mathrm{NO}_{\mathrm{x}}$ loss cycle (Reactions R12-R14) dominates while below the $\mathrm{O}_{3}$ smog production reactions become important, e.g.

$$
\begin{aligned}
& \mathrm{NO}+\mathrm{HO}_{2} \rightarrow \mathrm{NO}_{2}+\mathrm{OH} \\
& \mathrm{CO}+\mathrm{OH}+\mathrm{O}_{2} \rightarrow \mathrm{CO}_{2}+\mathrm{HO}_{2} \\
& \mathrm{NO}_{2}+h v+\mathrm{O}_{2} \rightarrow \mathrm{NO}+\mathrm{O}_{3} \\
& \mathrm{Net}: \mathrm{CO}+2 \mathrm{O}_{2}+h v \rightarrow \mathrm{CO}_{2}+\mathrm{O}_{3}
\end{aligned}
$$

Thus, the increase in $\mathrm{NO}_{\mathrm{x}}$ below $20 \mathrm{~km}$ leads to an increase of ozone. The decrease in the $\mathrm{HO}_{\mathrm{x}}$ is more than compensated by the increase in $\mathrm{NO}_{\mathrm{x}}$.

The SH winter, June through August (JJA), dynamical difference compared to the reference run is shown in Fig. 6 (left panels). There is a small but statistically significant reduction in the strength of the SH polar vortex (Fig. 6, top left panel) as measured by the reduction in the zonal wind and also by the increase in temperature below $60 \mathrm{~km}$ (Fig. 6, middle left panel). The mass streamfunction shows a statistically significant increase poleward of $60^{\circ} \mathrm{S}$ below $40 \mathrm{~km}$, which is consistent with the increased temperature and weaker zonal wind above $20 \mathrm{~km}$. Consideration of Eliassen-Palm flux divergence (not shown) shows that increased wave drag, i.e. more negative Eliassen-Palm flux divergence, is responsible for the dynamical changes rather than direct radiative effects from chemical constituent changes. Note that in the SH negative anomalies in the mass streamfunction indicate intensification in contrast to the $\mathrm{NH}$ where this applies to positive anomalies due to the change in sign of the Coriolis parameter at the equator. It is also notable that the Brewer-Dobson circulation change in the $\mathrm{SH}$ is hemispheric in scale, as in the $\mathrm{NH}$, in spite of the fact that the ionization impact on composition occurs at high latitudes (see Figs. 5 and 7). The tropospheric response is opposite in sign compared to the $\mathrm{NH}$ and statistically significant.

There is an equatorward shift in the extratropical jet with a weakening in middle latitudes and intensification around $30^{\circ} \mathrm{S}$. A possible explanation for this feature can be inferred from the work of Polvani and Kushner (2002). They demonstrated using a mechanistic model that as the stratospheric polar vortex weakens, the subtropical jet moves equatorward. There was no threshold behaviour in the response, so it is plausible that their results apply to the weak changes seen here.

Figure 7 (left panels) shows the atmospheric chemical difference for the SH winter, JJA. The response reflects differences in transport between the two hemisphere. For example, the penetration of extra $\mathrm{NO}_{\mathrm{x}}$ in the $\mathrm{SH}$ polar winter is more contained within the vortex than for DJF in the NH. In addition, the increase and penetration in the $\mathrm{SH}$ winter extends to $30 \mathrm{~km}$ for an $80 \%$ change compared to $45 \mathrm{~km}$ in the $\mathrm{NH}$ winter. The $\mathrm{SH}$ summer $\mathrm{NO}_{\mathrm{x}}$ is higher than for $\mathrm{NH}$ summer, which reflects the higher amounts in $\mathrm{SH}$ at the end of winter compared to the $\mathrm{NH}$.

The NH polar vortex tends to be weaker and more disturbed compared to the SH vortex due to hemispheric differences in planetary wave forcing (Andrews et al., 1987). So perturbations associated with composition changes, unless they are large, are not likely to alter the NH state significantly. As noted above, the more disturbed $\mathrm{NH}$ vortex results in increased destruction of auroral zone $\mathrm{NO}_{\mathrm{x}}$ by exposure to sunlight during descent as air parcels are transported out of the polar night by planetary wave induced mixing and vortex deformation. So the chemical impact on dynamics is more limited in the $\mathrm{NH}$ compared to the $\mathrm{SH}$.

As expected, there is an increase in $\mathrm{HO}_{\mathrm{x}}$ in the $\mathrm{SH}$ winter polar region above $50 \mathrm{~km}$ as a result of EPP and the small background $\mathrm{HO}_{\mathrm{x}}$ in the reference run. There is also a small enhancement in the $\mathrm{NH}$ summer polar region. In the $\mathrm{NH}$ 

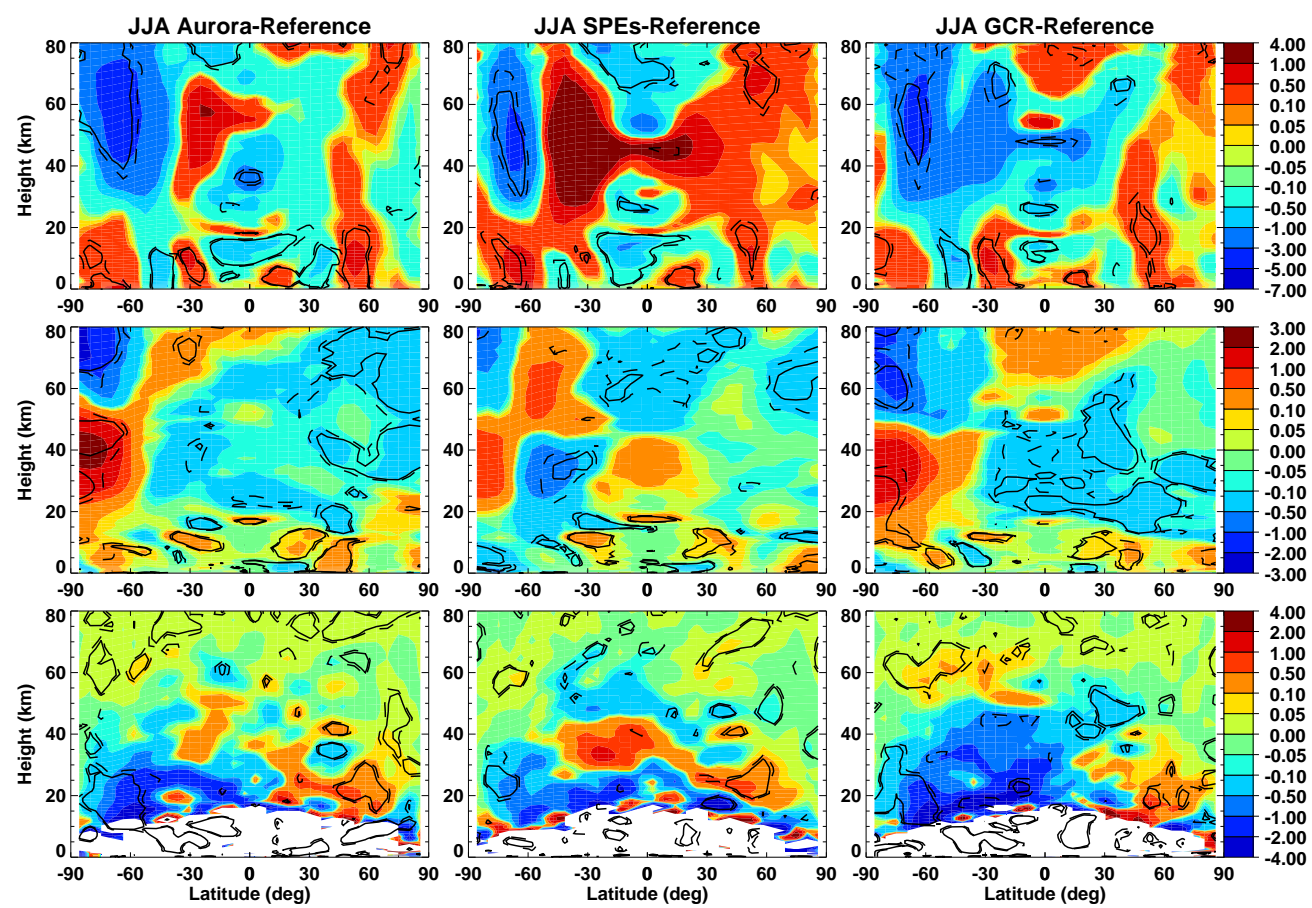

Fig. 6. Run mean, June-August mean differences compared to the reference run for auroral zone electrons (left), SPEs (center) and GCR (right) showing zonal wind (top, $\mathrm{m} \mathrm{s}^{-1}$ ), temperature (middle, $\mathrm{K}$ ) and mass streamfunction (bottom, $\mathrm{kg} \mathrm{m}^{-1} \mathrm{~s}^{-1}$, values outside the $(-4,4$ ) interval not plotted).
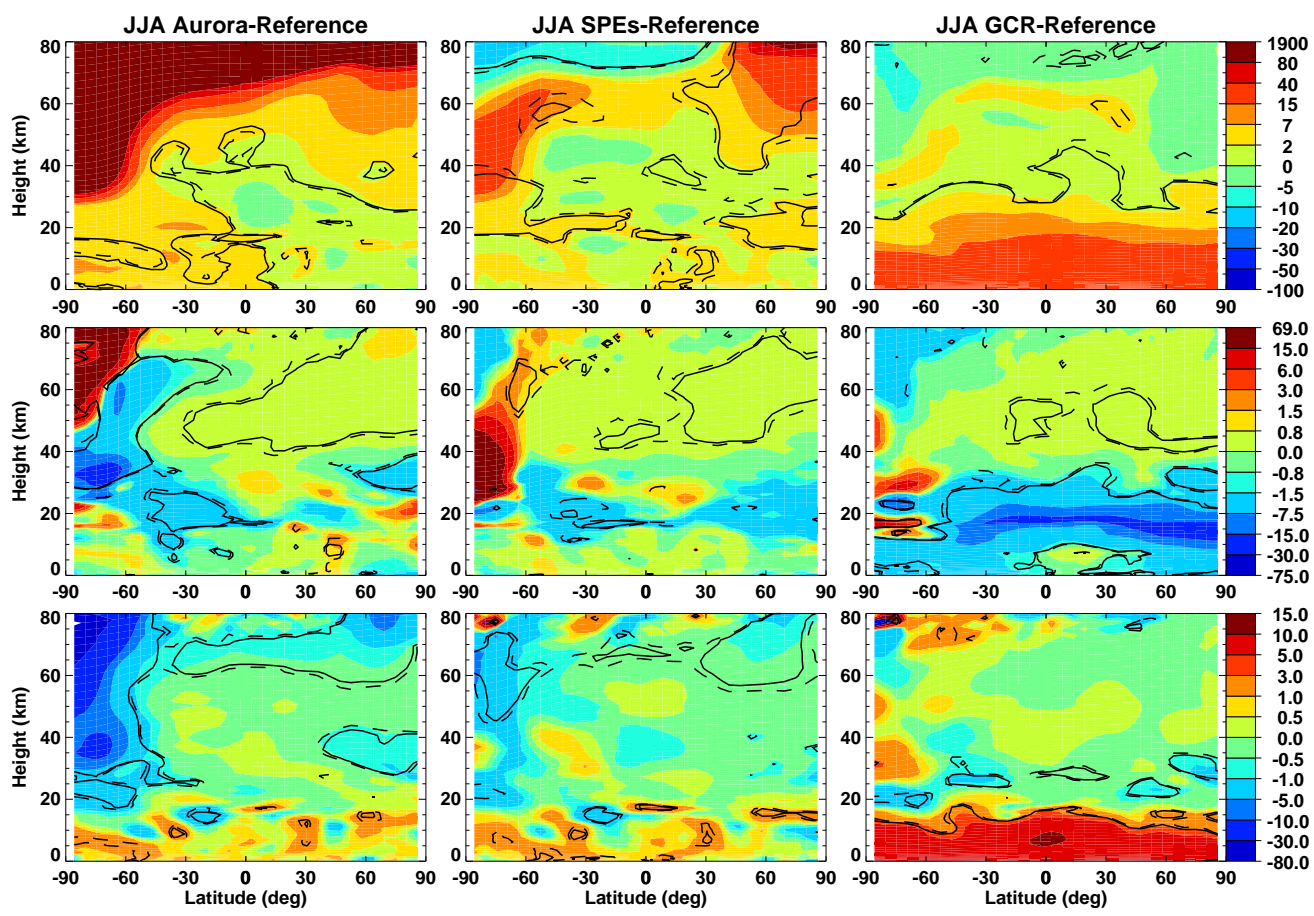

Fig. 7. Run mean, June-August mean compared to the reference run for auroral zone electrons (left), SPEs (center) and GCR (right) showing $\mathrm{NO}_{\mathrm{y}}\left(\right.$ top, \%), $\mathrm{HO}_{\mathrm{x}}$ (middle, \%) and $\mathrm{O}_{3}$ (bottom, \%). 
winter (Fig. 5, left panels), there is a $5 \%$ decrease in $\mathrm{HO}_{\mathrm{x}}$ in mid-latitudes between 50 and $70 \mathrm{~km}$ and $30^{\circ}$ to $75^{\circ} \mathrm{N}$ (Fig. 5 , middle left panel). Another region of decrease in the $\mathrm{NH}$ winter occurs between 30 and $40 \mathrm{~km}$. For the $\mathrm{SH}$ winter, the decrease has strengthened and also has become more extensive in the stratosphere extending below $20 \mathrm{~km}$ (Fig. 7, middle left panel). Above $60 \mathrm{~km}, \mathrm{HO}_{\mathrm{x}}$ is produced by photolysis of $\mathrm{H}_{2} \mathrm{O}$. Below $60 \mathrm{~km}$ it is largely through reaction of $\mathrm{O}\left({ }^{1} \mathrm{D}\right)$ with $\mathrm{H}_{2} \mathrm{O}, \mathrm{CH}_{4}$ and $\mathrm{H}_{2}$. This would suggest that $\mathrm{O}\left({ }^{1} \mathrm{D}\right)$ has decreased in the high latitude stratosphere and lower mesosphere, and to some extent this is reflected by the reduction of ozone in polar regions in $\mathrm{SH}$ winter. Whereas there is a substantial decrease in $\mathrm{HO}_{\mathrm{x}}$ in the $\mathrm{SH}$ winter between 10 and $40 \mathrm{~km}$, there is a much smaller decrease of $\mathrm{HO}_{\mathrm{x}}$ in this altitude range in the $\mathrm{NH}$ winter polar regions. The loss of $\mathrm{HO}_{\mathrm{x}}$ in the winter polar region in the stratosphere is due to reaction with the additional $\mathrm{NO}_{\mathrm{x}}$ transported from the upper mesosphere.

The ozone decrease in both the $\mathrm{NH}$ and $\mathrm{SH}$ polar vortex (Figs. 5 and 7, lower left panels) is caused in the upper regions by $\mathrm{HO}_{\mathrm{x}}$ increases while in the lower regions it is due to increased $\mathrm{NO}_{\mathrm{x}}$ since $\mathrm{HO}_{\mathrm{x}}$ does not survive transport from the mesosphere into the stratosphere. Below $20 \mathrm{~km}$ at all latitudes of the SH in JJA there are regions of enhanced ozone with peak significance values above $90 \%$ but less than $95 \%$. These increases in ozone are compatible with the increase of $\mathrm{NO}_{\mathrm{x}}$ produced by auroral zone electrons of which a fraction is transported to the atmospheric layer below $20 \mathrm{~km}$ and the smog reactions noted above. In addition, there is increased transport of $\mathrm{O}_{3}$ into the lowermost stratosphere and troposphere by the enhanced Brewer-Dobson circulation in the SH (Fig. 6, bottom left panel). It should be noted that these figures are showing percentage differences which can be large due to the typically low ozone values in the troposphere. So even if the ozone anomaly near the pole above $15 \mathrm{~km}$ is negative due to chemical loss, it can be positive in the troposphere due to increased transport.

\subsection{SPES}

The DJF change in the polar vortex shows an increase in diameter in the stratosphere as in the case of auroral zone electrons (Fig. 4, top middle panel). However, the change is only statistically significant below $25 \mathrm{~km}$. There is also a cooling in the lower stratosphere between $30^{\circ}$ and $70^{\circ} \mathrm{N}$. The Brewer-Dobson circulation response has a three layer structure similar to that with the auroral zone case, except the middle layer corresponding to reduced strength is more intense and is statistically significant between 30 and $40 \mathrm{~km}$ poleward of $60^{\circ} \mathrm{N}$. In contrast to the auroral zone response, there is a statistically significant poleward shift of the tropospheric jet structure, with weakening in the subtropics and intensification in middle latitudes. Unlike in the SH winter for auroral zone electrons and SPEs (see below), this tropospheric zonal wind change does not appear to follow the pattern identified by Polvani and Kushner (2002). However, the structure of the stratospheric polar vortex change is more complex and less statistically significant. So it is not immediately apparent which regions are key to mediating the stratosphere-troposphere coupling.

Figure 5 (middle panels) shows the differences in $\mathrm{NO}_{\mathrm{y}}$, $\mathrm{HO}_{\mathrm{x}}$ and ozone for SPEs in DJF. The SPEs $\mathrm{NO}_{\mathrm{x}}$ response pattern is similar to, but much weaker, than that of the auroral zone case for the mesosphere. Even though there is more ionization produced by individual SPEs in the upper stratosphere and lower mesosphere during each event, it is sporadic and averages out to similar or lower values over the duration of the simulation. In addition, the SPEs $\mathrm{NO}_{\mathrm{x}}$ is formed lower in the atmosphere and so a given amount created will appear with a lower mixing ratio near the stratopause as compared to the mesopause. The low values of $\mathrm{NO}_{\mathrm{x}}$ above $70 \mathrm{~km}$ in the $\mathrm{NH}$ are due to both downward transport from the lower thermosphere where the model lid boundary condition is $1 \mathrm{ppmv}$, and the fact that SPEs ionization peaks around $60 \mathrm{~km}$ so there is much less ionization above $70 \mathrm{~km}$ compared to the auroral zone case. The higher values of $\mathrm{NO}_{\mathrm{x}}$ above $70 \mathrm{~km}$ in the summer hemisphere (here the $\mathrm{NH}$ ) are due to the meridional circulation pattern. There is upwelling in the summer polar regions, which lofts the $\mathrm{NO}_{\mathrm{x}}$ in the mesosphere with transport above the mesopause. An $\mathrm{NO}_{\mathrm{y}}$ increase between 2 and $7 \%$ is present in the SH from the surface to $40 \mathrm{~km}$. There is some accumulation above the extratropical tropopause as with the auroral zone case. Between 15 and $25 \mathrm{~km}$ in the $\mathrm{SH}$ polar region the response is negative but with no statistical confidence. This suggests a high level of variability in this region for this season which is likely due to dynamical processes. There is evanescent penetration of Rossby waves above the summertime zero zonal wind line that can extend as high as $25 \mathrm{~km}$ in addition to significant generation of orographic gravity waves by the extreme Antarctic topography (Andrews et al., 1987).

The SPEs $\mathrm{HO}_{\mathrm{x}}$ response shows an increase in the polar lower mesosphere and upper stratosphere since it is being produced in this region in contrast to the auroral zone case, where it is produced above $60 \mathrm{~km}$ and does not survive transport into the stratosphere. Below $40 \mathrm{~km}$ there is a decrease in $\mathrm{HO}_{\mathrm{x}}$ through reaction of $\mathrm{OH}$ with $\mathrm{HNO}_{3}$, which has been augmented. There is also a reduction in ozone, the source of $\mathrm{O}\left({ }^{1} \mathrm{D}\right)$ (and thus $\mathrm{HO}_{\mathrm{x}}$ ), in this region. There is a large negative correlation between the distribution of the $\mathrm{NO}_{\mathrm{y}}$ and $\mathrm{HO}_{\mathrm{x}}$ anomalies between 20 and $40 \mathrm{~km}$ in high latitudes.

The ozone response is concentrated in the polar regions as for the auroral zone case. As expected from the intermittency of SPEs the response is weaker but the difference is not large compared to the impact of auroral zone electrons. There is a roughly $3 \%$ decrease near the winter pole around $30 \mathrm{~km}$. As with the auroral zone case, there is a similar reduction near the summer pole at this height. However, SPEs occur during both summer and winter producing in situ effects not dependent on transport from the upper mesosphere requiring a polar vortex. So this feature is not simply a memory from 
the previous winter and reflects a summertime contribution from SPEs. In the troposphere, there is an increase of ozone which could be due to increased $\mathrm{NO}_{\mathrm{x}}$ but the effects of an increased Brewer-Dobson circulation could also be important. However, the changes are not statistically significant.

From the difference plots in Fig. 6 (middle panels) it can be seen that the JJA SH polar vortex is weakened in high latitudes and also becomes broader judging by the larger increase in the zonal wind equatorward of $60^{\circ} \mathrm{S}$. The peak negative zonal wind anomaly is comparable to the auroral zone case. However, the temperature change is weaker and not statistically significant near the pole but is statistically significant in middle latitudes between 20 and $40 \mathrm{~km}$. There is also a warming in the tropics not present in the auroral zone case in this layer. It is also not statistically significant. This middle latitude cooling and tropical warming reflects the weakening of the residual circulation in middle and low latitudes in this layer of the stratosphere (Fig. 6, lower middle panel). The Brewer-Dobson circulation shows an intensification similar to the auroral zone case in high latitudes below $40 \mathrm{~km}$ with some statistical significance below $30 \mathrm{~km}$. There is also a statistically significant weakening of the circulation between 55 and $65 \mathrm{~km}$. This dynamical pattern is the classical response to a localized wave drag change consisting of a quadrupole temperature anomaly accompanied by a vertical dipolar mass streamfunction anomaly (Haynes et al., 1991). In the troposphere there is a zonal circulation anomaly that resembles the auroral zone case and is opposite in sign to DJF.

For JJA $\mathrm{NO}_{\mathrm{y}}$ and $\mathrm{HO}_{\mathrm{x}}$ changes (Fig. 7, middle panels) the response is almost the mirror of DJF changes (Fig. 5, middle panels). For JJA, the ozone impact is not as pronounced as for the auroral zone case and is only statistically significant between 20 and $30 \mathrm{~km}$ (see lower middle and lower left panels of Fig. 7). This reflects the fact that the SPEs are sporadic. It also suggests that the containment properties of the stronger $\mathrm{SH}$ polar vortex for $\mathrm{NO}_{\mathrm{x}}$ produced by SPEs are less important. The $\mathrm{NO}_{\mathrm{x}}$ production of SPEs occurs in the lower mesosphere and upper stratosphere and is at lower altitudes compared to the auroral zone case, so that $\mathrm{NO}_{\mathrm{x}}$ does not have to survive transport from the upper mesosphere. The JJA vortex response (Fig. 6, top middle panel) suggests that ozone perturbations of a few percent in the polar region between 20 and $30 \mathrm{~km}$ can both induce a weakening of the strength and an increase of the diameter of the SH polar vortex above $25 \mathrm{~km}$.

Vortex variability does play a role in the SPEs case as can be seen by the absence of a significant ozone loss in the $\mathrm{NH}$ summer: any $\mathrm{NO}_{\mathrm{x}}$ produced during the previous winter at higher altitudes experiences greater loss compared to the SH. Between the tropopause and $25 \mathrm{~km}$ during DJF in the SH there is an ozone increase of 3 to $10 \%$ which is statistically significant at the $80 \%$ confidence level (contours not shown). At these heights this increase is likely due to the smog reactions on account of the $\mathrm{NO}_{\mathrm{x}}$ increase (about $5 \%$ ), which more than balances the $\mathrm{HO}_{\mathrm{x}}$ decrease. This summertime ozone increase is smaller in scale in the $\mathrm{NH}$.

\subsection{GCR}

The DJF change in the dynamics induced by GCR is different compared to auroral zone electrons and SPEs (Fig. 4, right panels). There is some increase of the polar vortex diameter below $30 \mathrm{~km}$ but it is not statistically significant. There is no warming near the pole below this altitude as in the other two cases, albeit non-significant. The structure of the BrewerDobson circulation change is quite different, with a general weakening in the $\mathrm{NH}$ stratosphere. Between $30^{\circ}$ and $70^{\circ} \mathrm{N}$ in the lowermost stratosphere and upper troposphere there is a statistically significant temperature change that resembles the SPEs case and which is associated with a poleward shift of the tropospheric jet in the same region. As with the other two EPP types, the stratospheric effect is obscured by $\mathrm{NH}$ vortex variability. Yet there is a coherent response in the troposphere. Assuming the Student-t test is good enough to identify any coherent structure in the stratosphere, if one existed, this suggests that different stratospheric states produce similar tropospheric dynamical changes.

For the stable SH polar vortex regime the impact of GCR is pronounced as opposed to the NH winter. The dynamical response in JJA shows some similarities to the other two EPP types (Fig. 6, right panels). The polar vortex weakens to a similar degree between $60^{\circ} \mathrm{S}$ and $80^{\circ} \mathrm{S}$ above $30 \mathrm{~km}$ and this feature is statistically significant. But the reduction is not associated with a vortex diameter increase and there is a weakening in middle and low latitudes as well. The temperature change in the SH reaches lower latitudes and it appears that the wave drag change is broader meridionally compared to the auroral zone and SPEs cases. The GCR temperature change is most similar to that produced by auroral zone electrons, but with a large region of statistically significant cooling in the tropics and subtropics of the stratosphere. The residual circulation intensification in the $\mathrm{SH}$ extends over the depth of the stratosphere with a $95 \%$ confidence region between the tropopause and $40 \mathrm{~km}$ poleward of $60^{\circ} \mathrm{S}$. GCR is producing a change of the same sign in wave drag over a broader latitude span in spite of being a weaker source of ionization than the other two types of EPP. As shown below, the GCR effect on ozone is not confined to the polar regions or low altitudes. In the troposphere, there is a statistically significant change in the zonal jet structure that is similar to the auroral zone and SPEs cases and is of opposite sign to the DJF response in the NH hemisphere. It appears to be due to weakening of the stratospheric polar vortex, as with the other two EPP types.

The DJF and JJA chemical response to GCR is shown in the right panels of Fig. 5 and Fig. 7, respectively. Due to the low altitude and broader latitude span of GCR energy deposition, the ozone impact is quite different from auroral zone electrons and SPEs. Since GCR peaks around $13 \mathrm{~km}$ with 
a significant tropospheric component, there is up to a $40 \%$ increase in $\mathrm{NO}_{\mathrm{y}}$ and about a $15 \%$ increase in ozone in the troposphere. These values are a reflection of the lack of wet $\mathrm{NO}_{\mathrm{y}}$ removal in the model. However, the additional ozone in the troposphere is very small and rather well mixed so its effect on temperature gradients and hence dynamics is quite limited. Reflecting the fact that there is negligible impact on tropospheric heating rates, there is no change in the cold point tropopause height compared to the reference run except for a small increase in the SH polar region (not shown).

The ionization from GCR above $20 \mathrm{~km}$ is small, nevertheless there is a statistically significant ozone loss between the pole and $50^{\circ} \mathrm{S}$ in a roughly $5 \mathrm{~km}$ layer centered at $20 \mathrm{~km}$ in JJA. No such ozone loss occurs in the winter polar region in DJF, indicating the effect of a more disturbed vortex in the $\mathrm{NH}$ winter. However, in the SH summer there is ozone loss in the polar region between 25 and $30 \mathrm{~km}$, which is associated with enhanced $\mathrm{NO}_{\mathrm{x}}$ in this layer. The $\mathrm{SH}$ summer polar region exhibits dynamical variability around $20 \mathrm{~km}$ which obscures the chemical impact of GCR, much like in the SPEs case.

The situation in the lowermost stratosphere (between the tropopause and $20 \mathrm{~km}$ ) is more complex since this is the region where the transition from ozone production to ozone loss for additional $\mathrm{NO}_{\mathrm{x}}$ occurs (see above). There is poleward and downward transport in the stratosphere which pushes down the GCR induced ozone anomaly in the lowermost stratosphere and brings ozone depleted (number density) air from above $20 \mathrm{~km}$. This transport effect can be seen in the difference in the altitude of the ozone increase between the two hemispheres. There is more diabatic descent in the Northern Hemisphere winter compared to the Southern Hemisphere winter (Andrews et al., 1987) so the region of ozone enhancement does not extend as high into the lowermost stratosphere.

There is a roughly $1 \%$ drop in ozone in middle and low latitudes between 20 and $30 \mathrm{~km}$ in both JJA and DJF where the GCR $\mathrm{NO}_{\mathrm{x}}$ production acts to destroy ozone. As with the auroral zone and SPEs cases there is a loss of $\mathrm{HO}_{\mathrm{x}}$ below $30 \mathrm{~km}$ due to to interactions with $\mathrm{NO}_{\mathrm{x}}$ and $\mathrm{HNO}_{3}$. The difference in the SH middle and low latitude zonal wind change associated with GCR is likely due to the distribution of ozone reduction. The ozone loss around $20 \mathrm{~km}$ in the $\mathrm{SH}$ winter pole region gives rise to a vortex disturbance similar to the other two EPP cases. The loss of ozone between 20 and $30 \mathrm{~km}$ at lower latitudes is likely reducing the radiative equilibrium temperature gradient in this layer in fall and early winter and producing weaker westerlies at these latitudes during JJA (changes in the zonal wind due to thermal wind balance at one height propagate to all heights above). As discussed below this alters the Rossby wave transmission into the SH leading to the hemispheric temperature and circulation changes seen in Fig. 6.

\subsection{Combined EPP effect}

For each of the three EPP simulations conducted there is a reduction in the SH polar vortex strength and a warm temperature anomaly in the polar middle $\mathrm{SH}$ stratosphere, which satisfies thermal wind balance (Fig. 6). This is likely due to the decrease in ozone in the middle to high latitudes between $20 \mathrm{~km}$ and $30 \mathrm{~km}$. As a result, the meridional gradient of the radiative equilibrium temperature is reduced in the polar region from early winter. This modifies the evolution of the polar vortex, which is slightly weaker becoming more prone to Rossby wave penetration and hence additional wave drag (through radiative damping of Rossby waves directly and through redistribution of the wave breaking in the surf zone). The additional Rossby wave drag increases the Brewer-Dobson circulation in the SH winter, which acts to increase dynamical heating in the polar $\mathrm{SH}$ and gives rise to the polar warm temperature anomaly. This picture is supported by analysis of monthly fields of Eliassen-Palm flux divergence, streamfunction and zonal wind (not shown). However, it will become apparent in the next subsection, which presents ensemble runs, that there are other response patterns to EPP which do not conform to this picture.

The timing of the ozone impact on the stratospheric circulation for GCR and SPEs is different from that of the auroral zone case since the latter depends on descent of $\mathrm{NO}_{\mathrm{x}}$ from the upper mesosphere. In the auroral zone case, the polar vortex and Brewer-Dobson circulation are modified when the polar vortex is established and there is downward descent from the mesosphere. For the continuously acting GCR ionization (as opposed to transport dependent auroral zone and intermittent SPEs cases) the ozone reduction in the stratosphere is present through all stages of polar vortex formation and this may explain why it produces a similar dynamical impact to auroral zone electrons even though the ozone impact is weaker in the critical region between $20 \mathrm{~km}$ and $30 \mathrm{~km}$. SPEs can occur at any time of the year so they can influence the vortex evolution from its early onset stage or when it is established, but the impact is large so that the run mean polar vortex response is not negligible. Based on previous work (Jackman et al., 2005, 2009) there is an ozone memory that extends the period of the SPEs impact from several months to over a year below $10 \mathrm{hPa}$.

To assess the linearity of the addition of the individual EPP effects we compare differences from the reference run for the sum of the individual runs to a run with all three EPP types combined in Figs. 8 and 9. The combined impact on the chemical composition is essentially additive as seen by the similarity of the magnitudes in the top and bottom panels of Fig. 8. However, for the ozone field this is not true at high latitudes in the stratopshere, where the ozone in the combined run is about a third smaller than when the individual runs are summed. So there is some positive feedback on ozone reduction from the dynamics. 

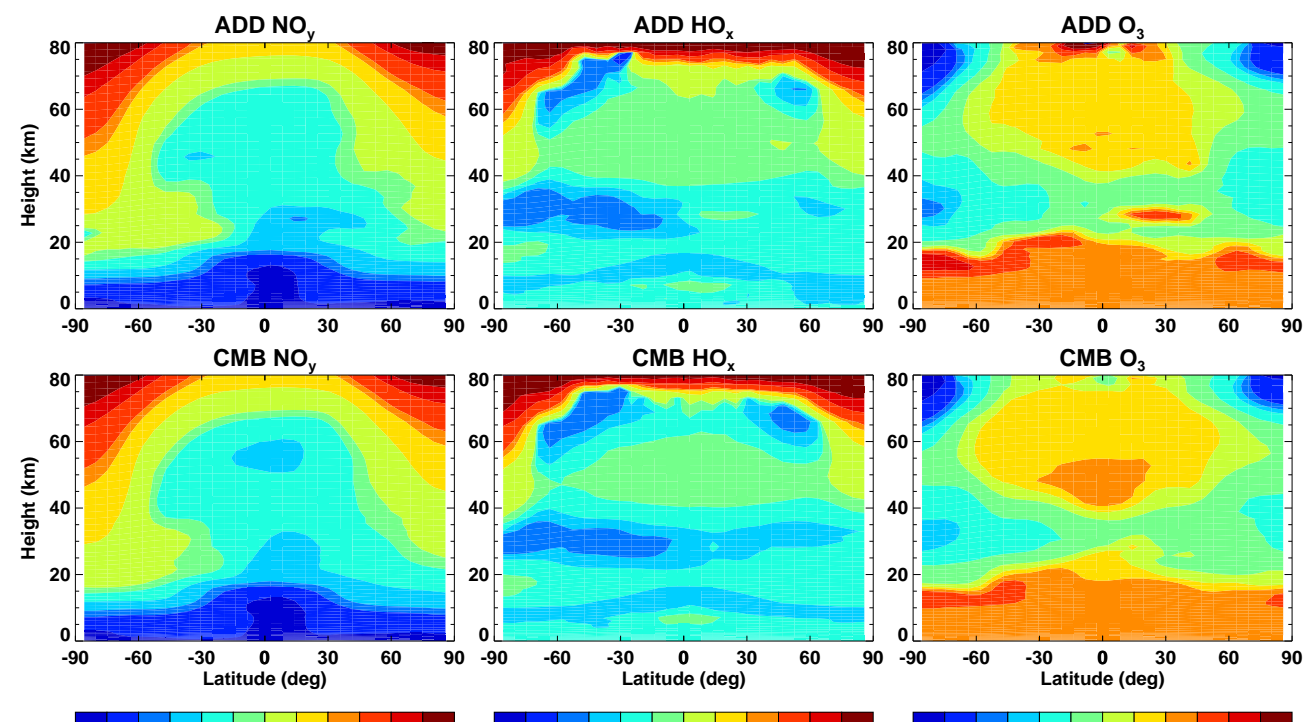

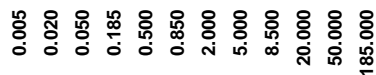
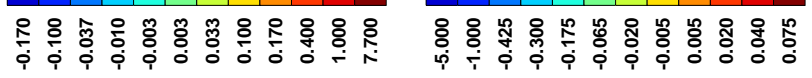

Fig. 8. Run mean, annual mean difference from the reference run for $\mathrm{NO}_{\mathrm{y}}$ (left, ppbv), $\mathrm{HO}_{\mathrm{x}}$ (middle, ppbv) and $\mathrm{O}_{3}$ (right, ppmv). Top panels: sum for the individual auroral zone electrons, SPEs and GCR runs. Bottom panels: combined EPP run.
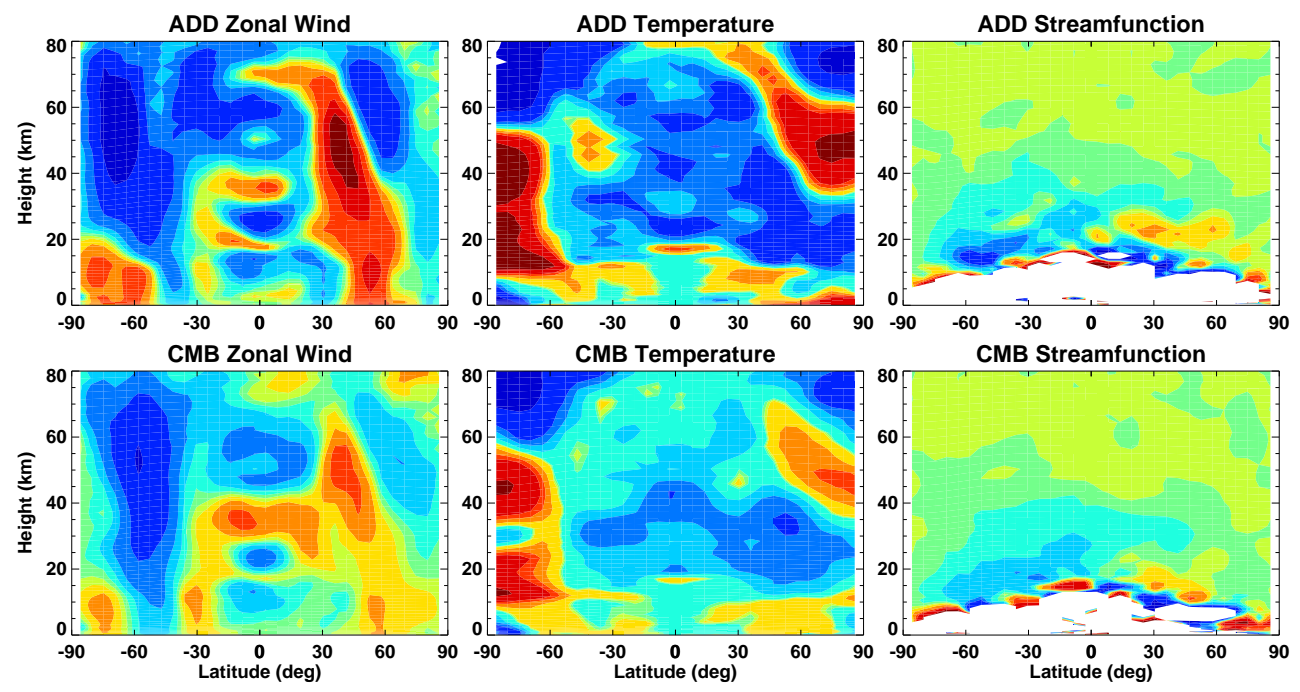

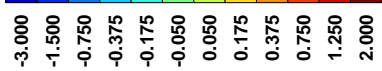

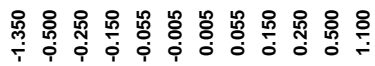

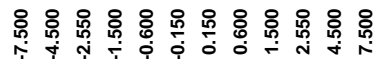

Fig. 9. Run mean, annual mean difference from the reference run for zonal wind (left, $\mathrm{m} \mathrm{s}^{-1}$ ), temperature (middle, $\mathrm{K}$ ) and mass streamfunction (right, $\mathrm{kg} \mathrm{m}^{-1} \mathrm{~s}^{-1}$, values outside the $(-9,9)$ interval not plotted). Top panels: sum for the auroral zone electrons, SPEs and GCR runs. Bottom panels: combined run. 

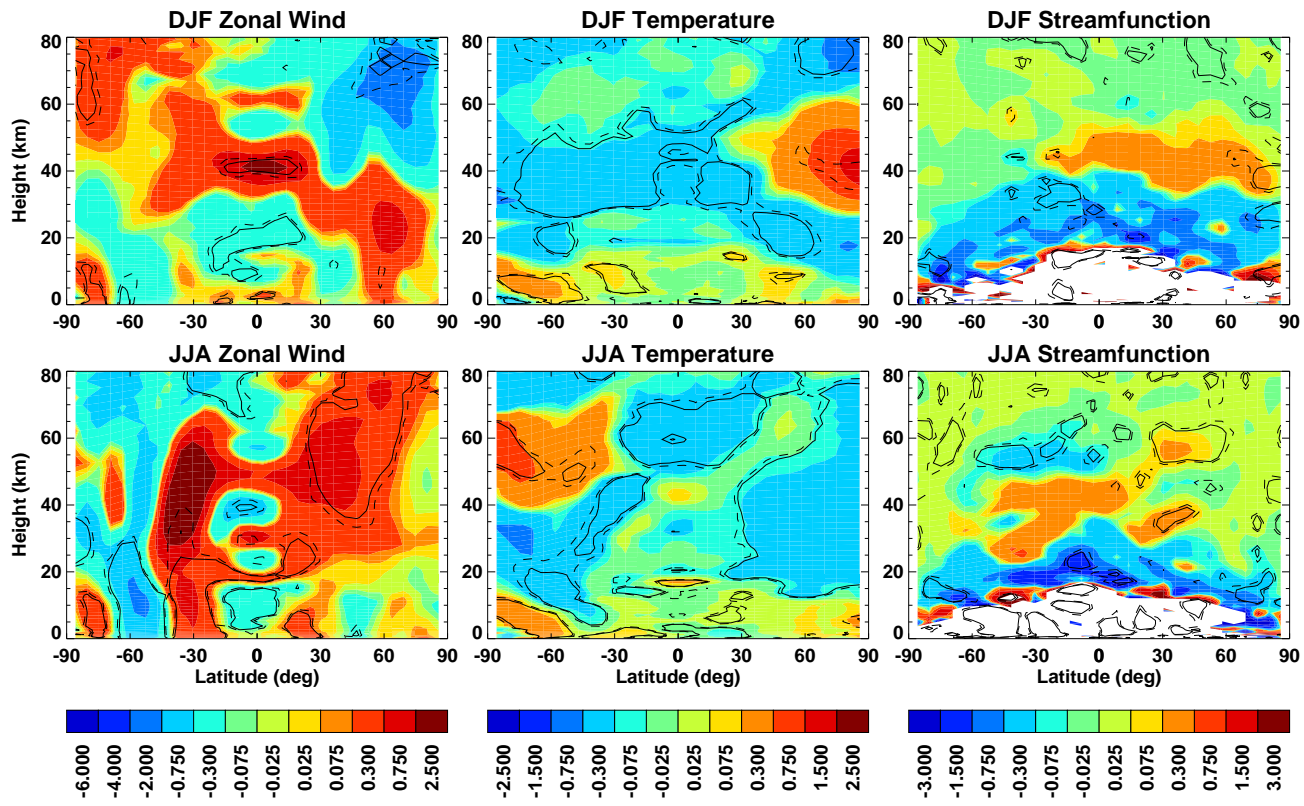

Fig. 10. December-February run mean, ensemble mean (top) and June-August run mean, ensemble mean (bottom) difference of the combined EPP ensemble run from the reference ensemble run for zonal wind (left, $\mathrm{m} \mathrm{s}^{-1}$ ), temperature (center, $\mathrm{K}$ ), and mass streamfunction (right, $\mathrm{kg} \mathrm{m}^{-1} \mathrm{~s}^{-1}$, values outside the $(-4,4)$ interval not plotted).

The dynamical response (Fig. 9) is not additive since the response for each of the individual EPP types is comparable to the response of all three combined. This results in the larger values in the top panels compared to the bottom panels in Fig. 9. It appears that the ozone reduction between 20 and $30 \mathrm{~km}$ is the common factor in the influence of the EPP types on SH polar vortex evolution. The three EPP types also act out of phase. GCR and SPEs are about $180^{\circ}$ out of phase with each other and auroral zone electron precipitation is $90^{\circ}$ out of phase with both (Fig. 2). This, together with the fact that the ozone perturbations are small, implies that the ozone reduction with all three types of EPP present is not different by a large factor between 20 and $30 \mathrm{~km}$. So the magnitude of the dynamical perturbation from the ozone loss in this region is comparable for each of the individual EPP simulations and the combined EPP simulation, although the structure differs. This is supported by the weak non-additivity of the ozone field seen in Fig. 8 (right panels), which indicates that the nonlinear dynamical response to the ozone perturbations saturates with a low amplitude as seen in the small change in the zonal winds (within $\pm 5 \mathrm{~m} \mathrm{~s}^{-1}$ ) and temperatures (within $\pm 2 \mathrm{~K}$ ). The ozone perturbation from the combination of the three EPP types is not sufficiently large to drive the system out of this low amplitude regime.

\subsection{Combined EPP ensemble run}

In order to get a more quantitative estimate of the sensitivity of the middle atmosphere to EPP, two additional simulations with all three EPP types combined were produced giving a three member ensemble. The reference run was also extended into an ensemble with two more 28 -yr realizations. The run mean, ensemble mean differences are shown in Figs. 10 and 11.

There is no longer a statistically significant wintertime zonal wind response in both hemispheres (Fig. 10, left panels). However, in the SH the JJA zonal wind below $20 \mathrm{~km}$ and in the troposphere shows a statistically significant difference pattern that resembles the one identified by Polvani and Kushner (2002). This tropospheric change in the zonal wind was apparent in the runs for the individual EPP types as well. In the ensemble run, the SH polar vortex showed some degree of weakening below $30 \mathrm{~km}$ in all members. The NH DJF change in the troposphere is showing some significance at the $90 \%$ level and is opposite in sign to the SH JJA response, as seen in the individual runs. The $\mathrm{NH}$ winter response in the troposphere is difficult to relate to changes in the stratospheric vortex, which is more variable. The run mean, ensemble mean shows the stratospheric NH winter vortex intensifying around $60^{\circ} \mathrm{N}$ and poleward below $30 \mathrm{~km}$ in contrast to the individual case runs where it weakened poleward of $60^{\circ} \mathrm{N}$ below this height. The only common element appears to be a region of cooling in the middle latitude stratosphere below $30 \mathrm{~km}$ with a thin layer of warming around the tropopause. 

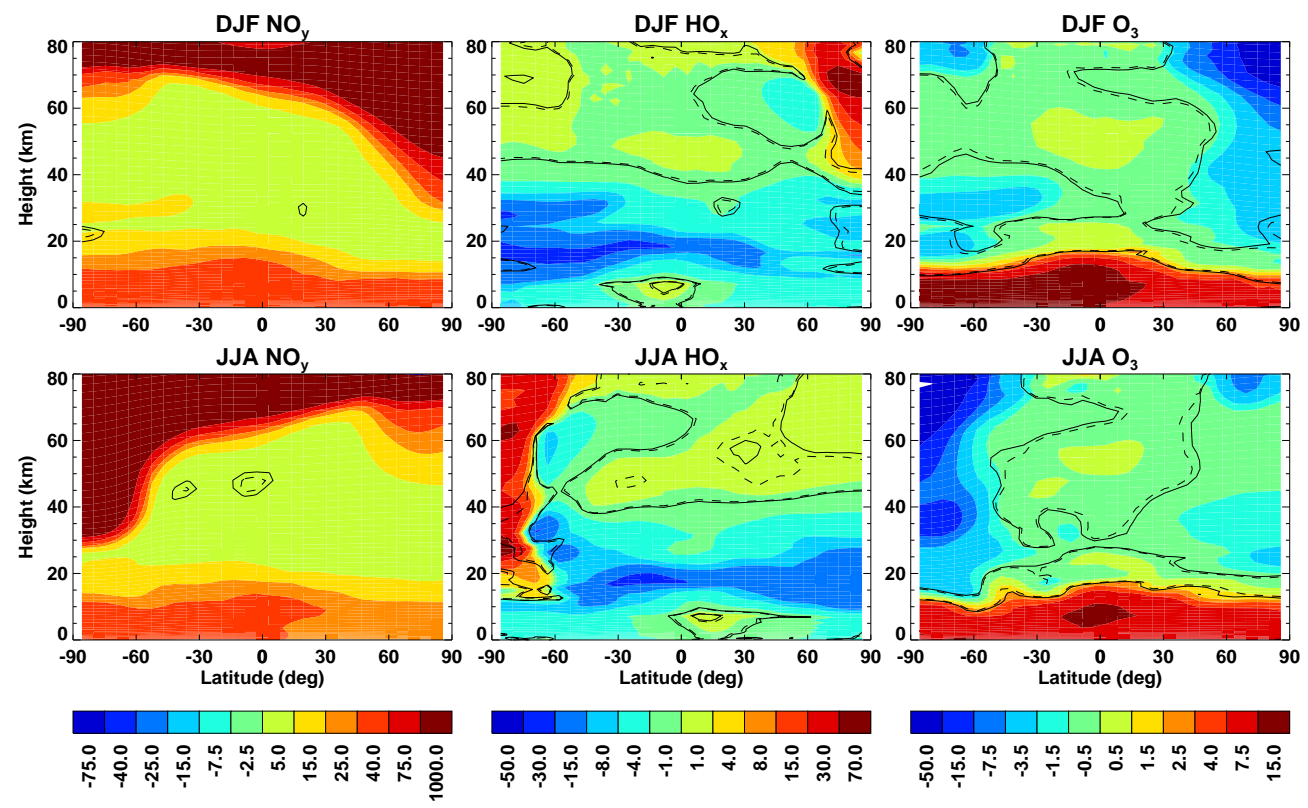

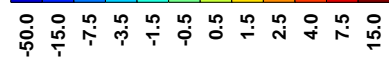

Fig. 11. December-February run mean, ensemble mean (top) and June-August run mean, ensemble mean (bottom) difference of the combined EPP ensemble run from the reference ensemble run for $\mathrm{NO}_{\mathrm{y}}\left(\right.$ left, \%), $\mathrm{HO}_{\mathrm{x}}$ (center, \%) and $\mathrm{O}_{3}$ (right, \%).

The SH JJA temperature anomaly structure is different from the individual EPP run cases. It is colder between 20 and $40 \mathrm{~km}$ and warmer between 40 and $60 \mathrm{~km}$. The individual EPP cases had a warming between 20 and $50 \mathrm{~km}$ with a cooling above. However, there is a significant warming between 5 and $15 \mathrm{~km}$ in the $\mathrm{SH}$ polar region that is associated with the weakening of the $\mathrm{SH}$ polar vortex above through thermal wind balance. The Brewer-Dobson circulation undergoes an intensification in the lowermost $\mathrm{SH}$ stratosphere which is consistent with the temperature increase. But between 20 and $40 \mathrm{~km}$ the Brewer-Dobson circulation weakens at the pole and in middle latitudes (Fig. 10, bottom right panel). This behaviour is similar to the SPEs case.

In contrast to the dynamical response, the chemical response is statistically significant and consists of a superposition of the chemical patterns from each of the individual EPP types (Fig. 11). This is consistent with the linearity test from Sect. 4.4.

The combined effect of the three particle precipitation types does not increase the significance level since there is no unique response pattern in the middle atmosphere. A comparison of two of the combined EPP ensemble members for JJA is presented in Figs. 12 and 13, showing differences from the ensemble mean reference run. The $\mathrm{SH}$ middle atmosphere can respond to combined EPP forcing either through a weakening of the polar vortex, associated with a warming in the polar stratosphere, and more intense Brewer-Dobson circulation (Fig. 12, top panels), or vice versa (Fig. 12, bottom panels). However, the strong vortex case has a rather complicated structure with a weakening of the vortex closer to the pole between 20 and $40 \mathrm{~km}$. This results in a similar zonal wind anomaly pattern for both cases between the surface and $20 \mathrm{~km}$ and in agreement with the findings of Polvani and Kushner (2002).

There are differences in the ozone field (Fig. 13, right panels), for the case with a weakened polar vortex (top panel) compared to the strengthened polar vortex case (bottom panel). Higher ozone values are present between 30 and $50 \mathrm{~km}$ in middle and low latitudes for the weakened polar vortex case. The two vortex regimes differentiate starting in May (not shown). The differences in the ozone field are not particularly striking, which highlights the sensitivity to initial conditions in the nonlinear dynamics of the atmosphere. However, the results change when the solar cycle in irradiance is included, as addressed in the next section.

\section{Combined solar variability and EPP ensemble runs}

Here we present results of ensemble simulations which include the solar irradiance cycle. Two ensembles of three members each with and without combined EPP were produced. Each ensemble member was $28 \mathrm{yr}$ in duration using the same EPP forcings as the runs in the previous section. The ensemble with solar variability only is used as the reference ensemble for the following analysis instead of the reference ensemble used in Sect. 4 which lacks the solar irradiance cycle. 

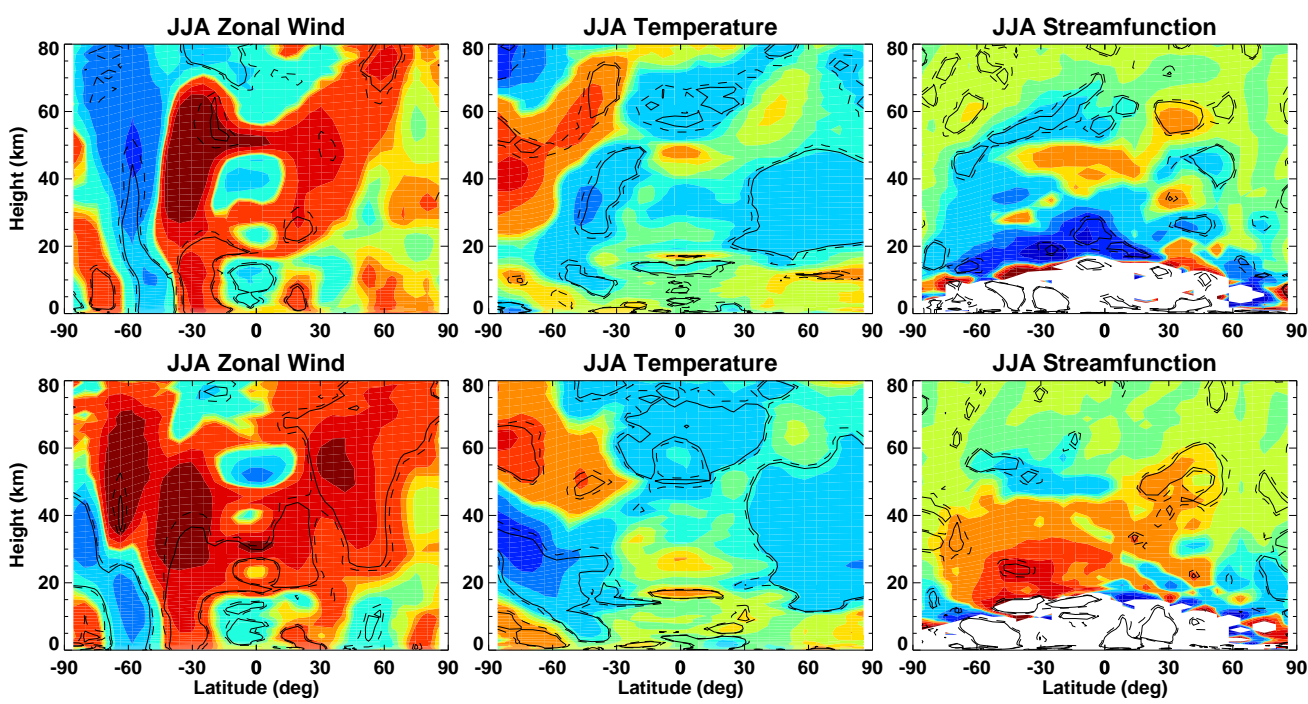

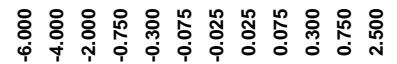

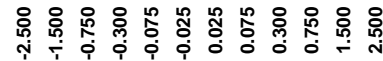

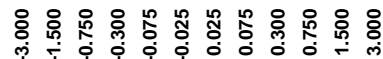

Fig. 12. June-August run mean difference from the ensemble reference run of zonal wind (left, $\mathrm{m} \mathrm{s}^{-1}$ ), temperature (center, $\mathrm{K}$ ) and mass streamfunction (right, $\mathrm{kg} \mathrm{m}^{-1} \mathrm{~s}^{-1}$ ) for two of the combined EPP ensemble members. Top, weak vortex case. Bottom, strong vortex case.
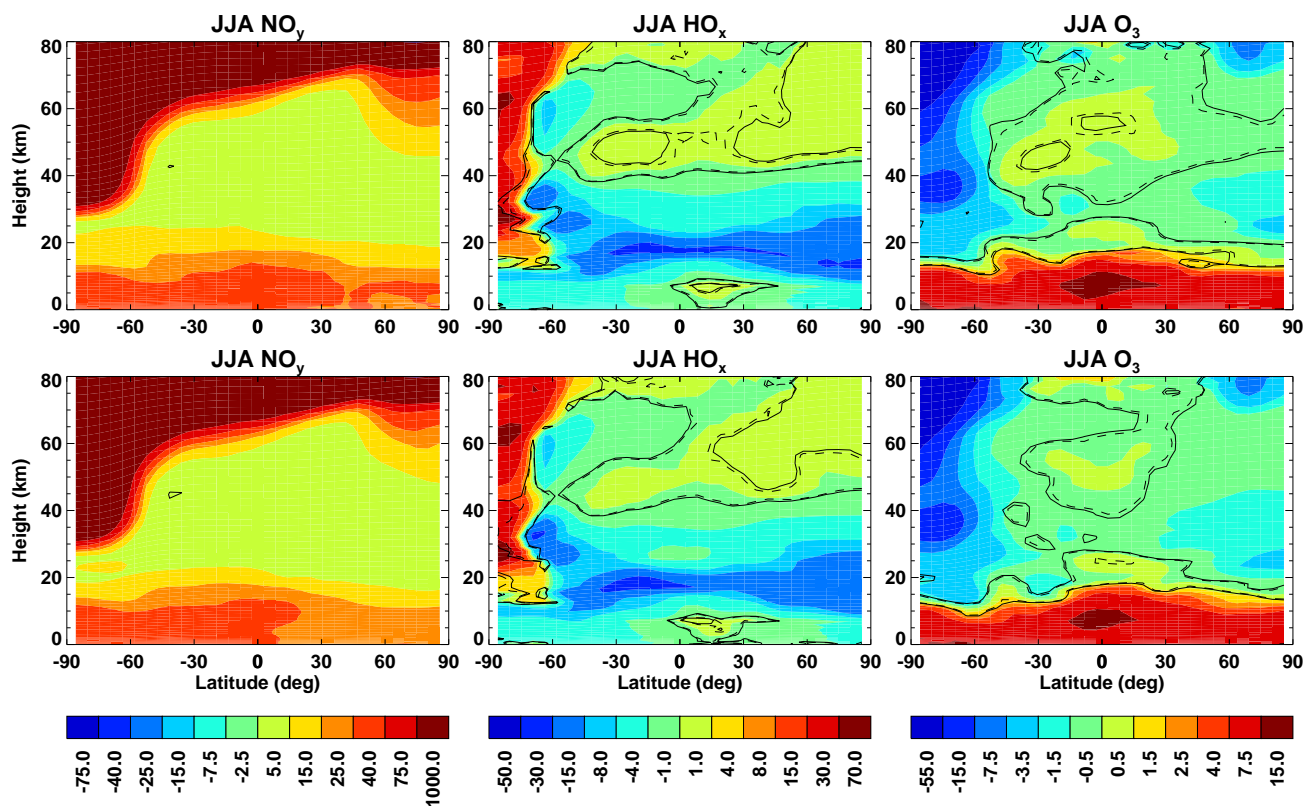

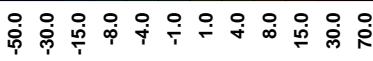

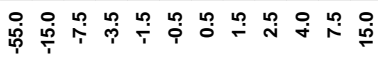

Fig. 13. As in Fig. 12 but for $\mathrm{NO}_{\mathrm{y}}\left(\right.$ left, \%), $\mathrm{HO}_{\mathrm{x}}($ center, $\%)$ and $\mathrm{O}_{3}$ (right, \%). 

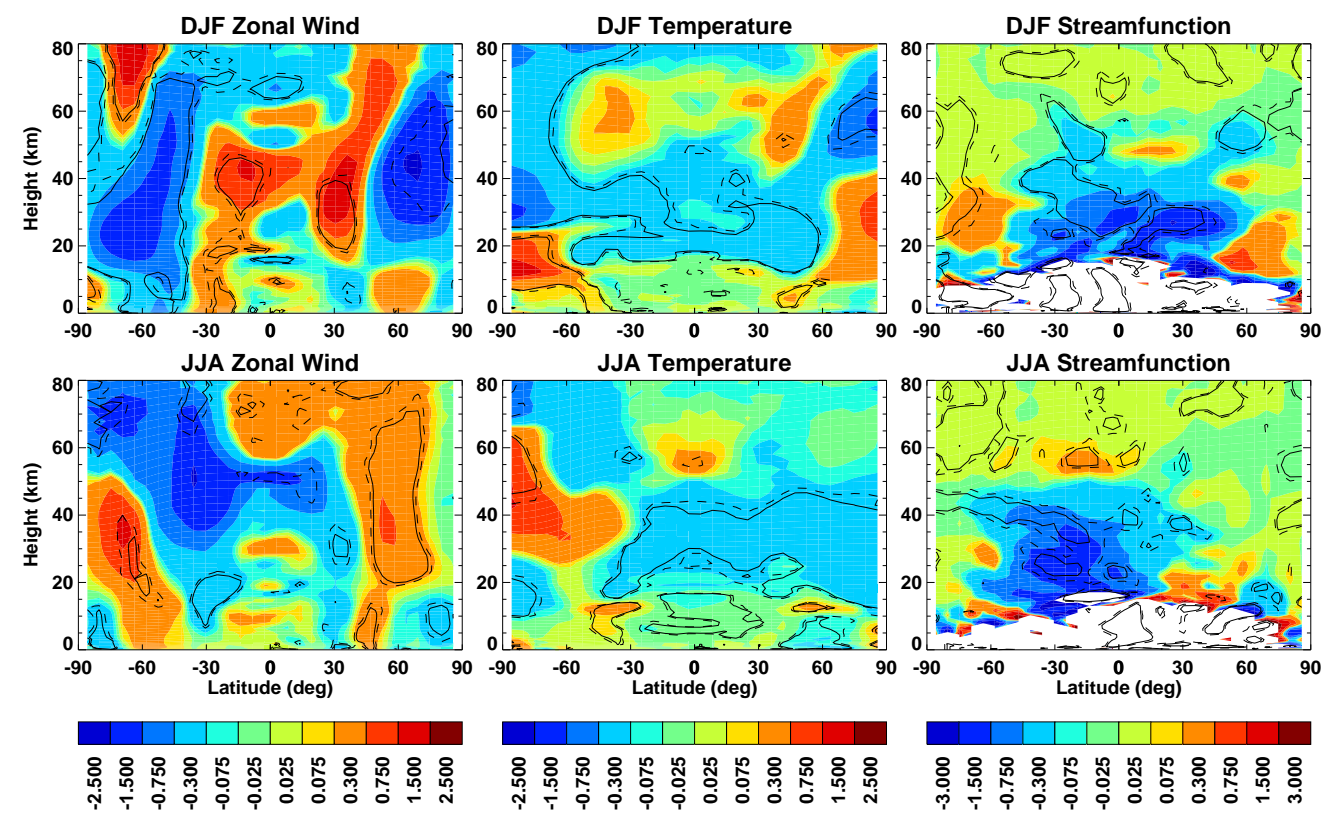

Fig. 14. December-February run mean, ensemble mean (top) and June-August run mean, ensemble mean (bottom) difference of the solar variability combined with EPP ensemble run from the solar variability only ensemble run for zonal wind (left, $\mathrm{m} \mathrm{s}^{-1}$ ), temperature (center, $\mathrm{K}$ ), and mass streamfunction (right, $\mathrm{kg} \mathrm{m}^{-1} \mathrm{~s}^{-1}$, values outside the $(-4,4)$ interval not plotted).

\subsection{Long-term differences between the ensemble runs}

The dynamical run mean, ensemble mean difference between the reference solar cycle ensemble average and the combined solar cycle and EPP ensemble average is shown in Fig. 14. In DJF the zonal wind experiences an intensification around $30^{\circ} \mathrm{N}$ over the depth of the stratosphere and there is a less statistically significant weakening between 20 and $60 \mathrm{~km}$ poleward of $50^{\circ} \mathrm{N}$. The wind change is associated with a quadrupole temperature anomaly which extends from the tropopause well into the mesosphere in middle and high latitudes. In the stratosphere there is a high latitude warming and a low latitude cooling with a reversed pattern in the mesosphere. However, the stratospheric warming lobe of the quadrupole is not statistically significant and the only lobe which shows no region with significance over $90 \%$. The DJF Brewer-Dobson circulation weakens in the NH between the tropopause and $40 \mathrm{~km}$ in low and middle latitudes and has regions of intensification in the high latitude stratosphere. In the stratopause and lower mesosphere the Brewer-Dobson circulation weakens, which is consistent with the temperature anomaly structure.

In the tropics there is a region of weak cooling between 15 and $25 \mathrm{~km}$ which extends into middle latitudes of both hemispheres. This feature appears to reflect the change in ozone (see Fig. 17 discussed below) as does the dipole anomaly in high latitudes in the SH during summer.

In JJA the response pattern in the SH is generally opposite in sign to the DJF response in the NH. The SH polar vortex

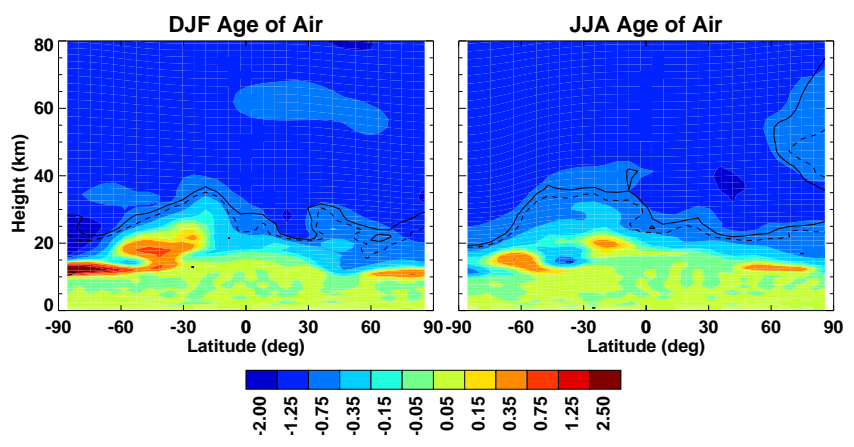

Fig. 15. Run mean, ensemble mean difference (\%) between the two ensembles shown in Fig. 14 for age of air.

undergoes a small intensification poleward of about $50^{\circ} \mathrm{S}$ as well as a reduction around $30^{\circ} \mathrm{S}$. The high latitude temperature cools between the tropopause and $30 \mathrm{~km}$ and warms above extending to $65 \mathrm{~km}$. The Brewer-Dobson circulation intensifies in the middle and low latitudes of the SH. Poleward of $60^{\circ} \mathrm{S}$ there is a weakening below $35 \mathrm{~km}$ which shows only a very small region of statistical significance near the pole. In the upper high latitude stratosphere there is a statistically significant intensification. The Brewer-Dobson circulation change is consistent with the zonal wind and temperature change even though the levels of statistical significance are quite different.

The tropical cooling extends from $25 \mathrm{~km}$ to the stratopause in JJA, but around $20 \mathrm{~km}$ the change is no longer as large as 

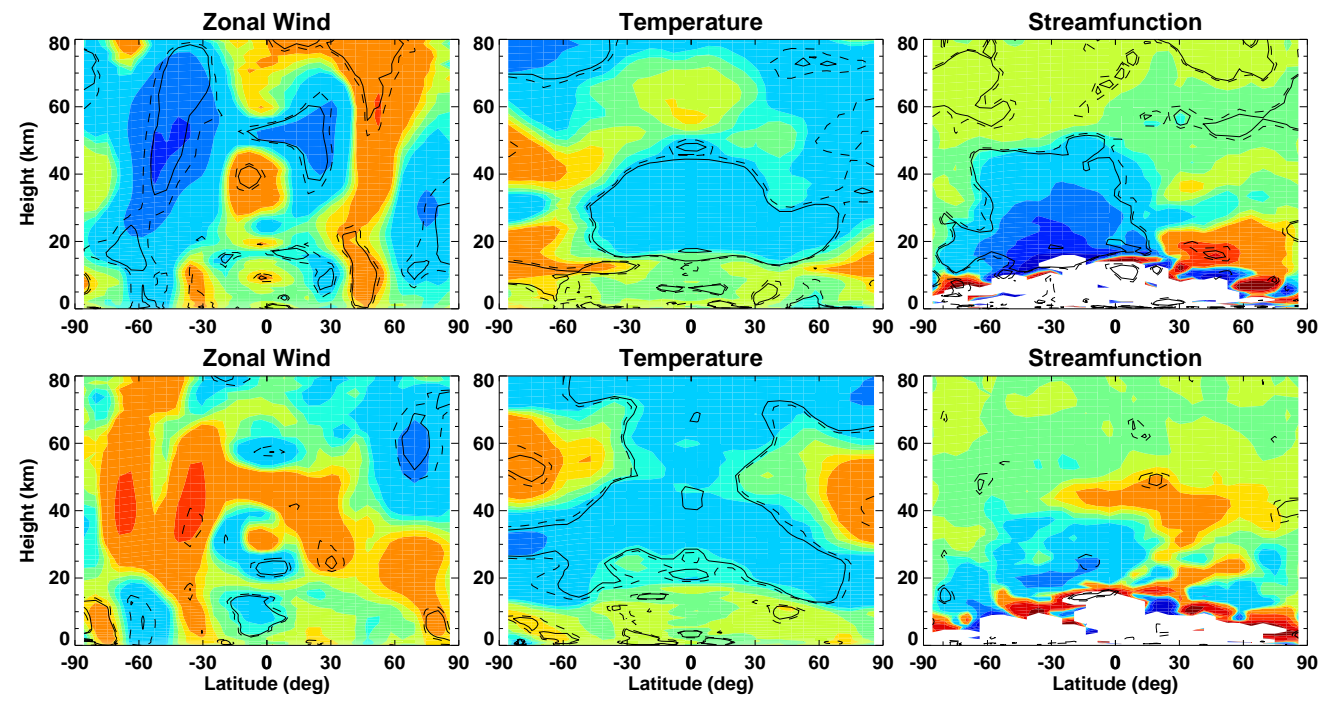

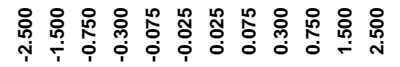

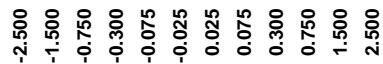

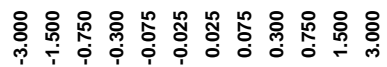

Fig. 16. Comparison of run mean, ensemble mean, annual mean difference from the reference ensembles of zonal wind (left, $\mathrm{ms}^{-1}$ ), temperature (middle, $\mathrm{K}$ ) and mass streamfunction (right, $\mathrm{kg} \mathrm{m}^{-1} \mathrm{~s}^{-1}$ ). Top panels are for solar variability with EPP ensemble vs. solar variability only ensemble. Bottom panels are for the Sect. 4 ensembles without the solar cycle in irradiance: the combined EPP ensemble vs. the reference ensemble.
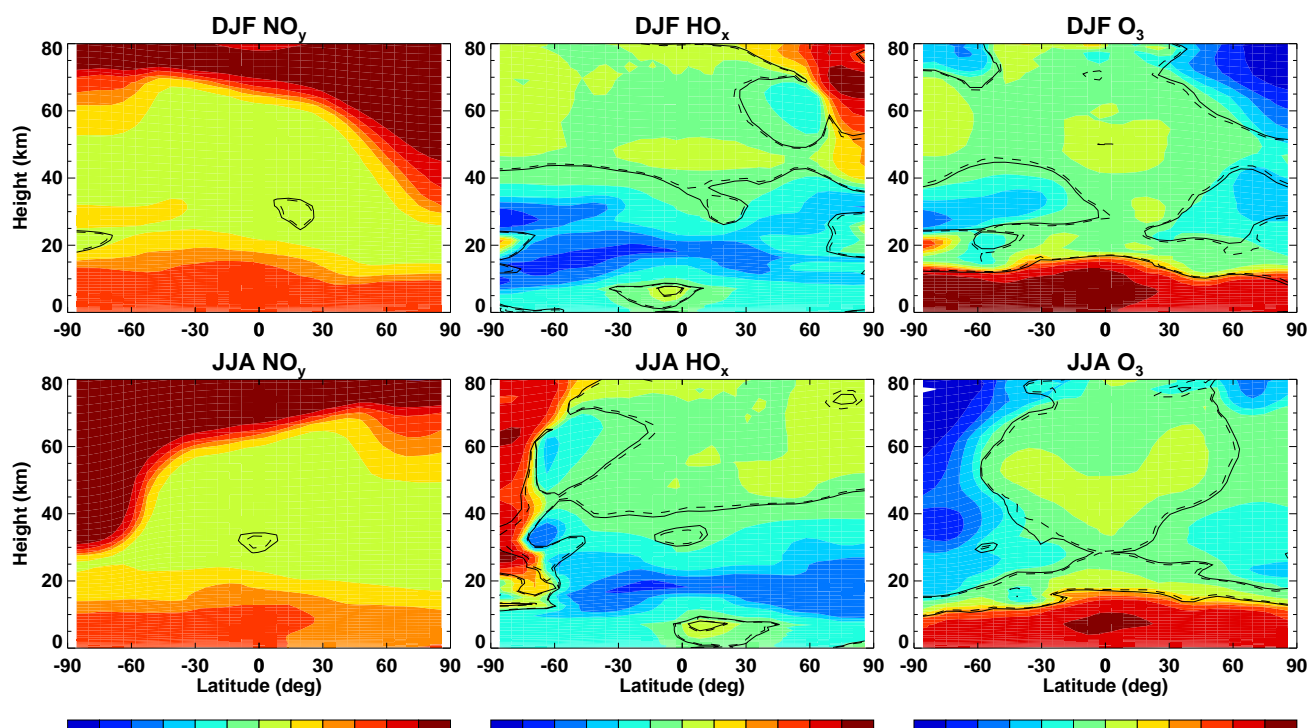

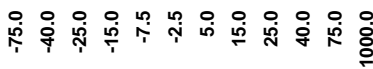

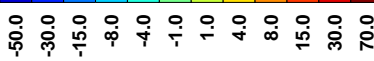

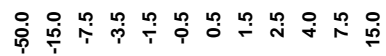

Fig. 17. Run mean, ensemble mean differences between the two ensembles shown in Fig. 14 for $\mathrm{NO}_{\mathrm{y}}(\mathrm{left}, \%), \mathrm{HO}_{\mathrm{x}}(\mathrm{center}, \%)$ and $\mathrm{O}_{3}$ (right, \%). 


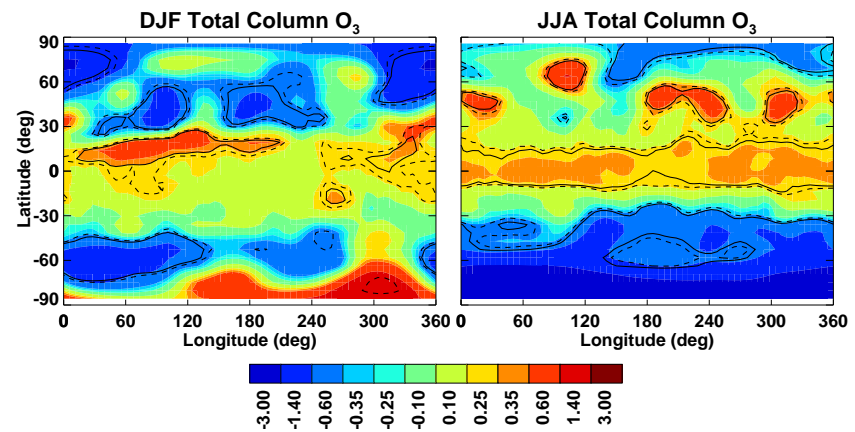

Fig. 18. Run mean, ensemble mean difference (\%) between the two ensembles shown in Fig. 14 for total column ozone.

in DJF and is not statistically significant. In this layer, there is a weak positive ozone anomaly compared to a negative anomaly in DJF (Fig. 17).

The age of air (Fig. 15) is reduced by over $1 \%$ in most of the stratosphere in both DJF and JJA, which shows that there is an overall intensification of tropical upwelling due to EPP. However, there are differences in the lower tropical stratosphere between the two seasons. In JJA in the SH there is an increase in the age of air between $15^{\circ}$ and $30^{\circ} \mathrm{S}$ in the TTL. No such feature is present in the NH in DJF.

In the SH in DJF there is a dipole feature around $20 \mathrm{~km}$ between the pole and $30^{\circ} \mathrm{S}$. It should be stressed that Rossby wave mixing does not shut down completely during summer in the stratosphere. Rossby waves continue to break around the zero wind line and there is an evanescent penetration of vorticity above the zero wind line as high as $25 \mathrm{~km}$. The age of air pattern in the model indicates that there is an exchange of air parcels from the polar region to middle latitudes since there is a negative age of air anomaly near the pole of about $-2 \%$ and and a positive anomaly in middle latitudes of about $0.75 \%$. The age of air near the poles is typically higher than in middle latitudes in the lower stratosphere in all seasons. However, in summer it is not being replenished in the polar region via descent so this would make any mixing with middle latitude air more apparent than in winter.

In the SH lowermost stratosphere there are also regions of increased age of air in JJA. The Brewer-Dobson circulation anomaly in the SH is associated with increased descent in the middle latitude stratosphere in both seasons below $30 \mathrm{~km}$. In JJA the circulation anomaly has a two layer structure in the low latitude SH stratosphere with a local maximum around $20 \mathrm{~km}$. So it appears that parcels with higher values of age of air are being brought down from the upper middle latitude SH stratosphere and injected in the lower stratosphere. A fraction of these air parcels is transported into the tropical lower stratosphere likely due to Rossby wave mixing in the surf zone.

The above response pattern of the dynamics differs from the case presented in Fig. 10. Without solar variability, the
SH polar vortex weakens between 20 and $40 \mathrm{~km}$ in the presence of EPP and there is no cooling in the tropics in JJA. There is no statistically significant zonal wind response in the NH winter stratosphere as well. The difference in the Brewer-Dobson circulation is more striking in the annual mean (Fig. 16). In the presence of solar variability (top panels) there is a long term intensification in the $\mathrm{SH}$, which is reflected in a weakening of the zonal wind. Due to EPP the age of air decreases by about $1.3 \%$ in the middle atmosphere with solar variability compared to $0.8 \%$ without (not shown). Thus, it can be inferred that the solar cycle changes the dynamical sensitivity of the atmosphere to EPP.

The $\mathrm{NO}_{\mathrm{y}}, \mathrm{HO}_{\mathrm{x}}$ and ozone run mean, ensemble mean differences are shown in Fig. 17 and are very similar to the runs without the solar cycle discussed in Sect. 4 (compare Fig. 17 with Fig. 11). The solar cycle variation in the composition of the middle atmosphere is small, so the EPP perturbation is acting on a similar basic state. There are negative ozone anomalies that penetrate into the tropics in both hemispheres below $30 \mathrm{~km}$ during the two seasons. These are due to middle and high latitude ozone depletion by EPP and transport by mixing in the surf zone. At these altitudes the photochemical lifetime of ozone is several months with the lowest values in the tropics. Around $20 \mathrm{~km}$ in the tropics there is a difference in the sign of the ozone anomaly between DJF and JJA albeit not statistically significant. Tropical upwelling is weaker in JJA compared to DJF due to interhemispheric differences in wave driving and hence Brewer-Dobson circulation intensity. So it is possible that GCR ozone production in the TTL in JJA is able to overcome the increased tropical upwelling between the two ensembles noted above.

The total column ozone difference (Fig. 18) shows a decrease up to $4 \%$ in the winter polar regions. In the $\mathrm{NH}$, the ozone column reduction is concentrated between $60^{\circ} \mathrm{E}$ and $60^{\circ} \mathrm{W}$, while in the $\mathrm{SH}$ the reduction occurs at all longitudes. This reflects the more zonally symmetric structure of the SH polar vortex. In the tropics, there is an increase of about $0.3 \%$. The tropical increase is associated with GCR. The positive impact of GCR on total column ozone at high latitudes (not shown) is overwhelmed by the effect of auroral zone electrons and SPEs. This can also be inferred from Figs. 5 and 7, which show significant reductions in polar ozone above $15 \mathrm{~km}$.

\subsection{Solar cycle regression analysis}

To analyze the solar cycle effect for runs with and without EPP, we regress the results of the ensemble runs against the F10.7 index. Use of this index is motivated by the fact that previous studies have been based on it (e.g., Austin et al., 2008) and that it captures the overall evolution of the solar cycle. The Ap index is more appropriate for auroral zone precipitation as it reflects geomagnetic activity but it does not suit GCR or SPEs. 


\subsubsection{Latitude-altitude response}

The F10.7 index annual mean regression coefficient for zonal mean temperature, ozone, zonal wind, TEM mass streamfunction, Eliassen-Palm flux divergence, age of air and water vapour is shown in Figs. 19-21. Without EPP there is a warm temperature anomaly in the $\mathrm{SH}$ polar stratosphere with an associated reduction in the strength of the $\mathrm{SH}$ polar vortex (Fig. 19, top panels). The weaker vortex facilitates a Brewer-Dobson circulation increase (Fig. 20, top left) due to additional wave drag (Fig. 20, top right). However, the statistically significant region is below $25 \mathrm{~km}$. The $\mathrm{SH}$ warm temperature anomaly appears to be due to the ozone buildup in this region (Fig. 21, top middle). The diabatic circulation increase is hemispheric in scale and results in increased tropical upwelling and some reduction in the age of air in the $\mathrm{SH}$ between 20 and $40 \mathrm{~km}$ (Fig. 21, top left).

Inclusion of EPP leads to a strikingly different response pattern. The zonal wind variation with the solar cycle in the SH changes sign (Fig. 19, bottom left). This is associated with a weakening of the Brewer-Dobson circulation in the stratosphere (Fig. 20, bottom left) and an increase in the age of air with increased solar activity (Fig. 21, bottom left). In the upper SH stratosphere the wave drag now weakens with increased solar activity and this is statistically significant in low and middle latitudes (Fig. 20, bottom right). This explains the statistically significant change in the BrewerDobson circulation above $25 \mathrm{~km}$. However, between 20 and $30 \mathrm{~km}$ in low and middle latitudes of the $\mathrm{SH}$ there is a region where the sign of the wave drag variation with solar activity does not change in the presence of EPP and has a high statistical significance. The origin of this feature is not clear and requires additional analysis. The addition of EPP also leads to a wave drag response in the tropical transition layer (TTL) between 15 and $20 \mathrm{~km}$ not seen in the solar cycle only ensemble. There is a weakening during solar maximum conditions or, equivalently, a strengthening during solar minimum conditions which occurs in both hemispheres and maximizes between $20^{\circ}$ and $30^{\circ}$ from the equator. How the high and middle latitude dynamical changes or perhaps GCR effects at lower latitudes result in a wave drag response in the TTL in both hemispheres is a question that cannot be answered here but is worthy of additional analysis.

The change in the dynamical response induced by EPP in the SH is due to its effect on high latitude ozone. The statistically significant buildup of ozone with increasing solar activity near the SH pole in the solar cycle ensemble (Fig. 21, top middle) is not present with EPP (Fig. 21, bottom middle). This is reflected in the SH stratosphere temperature field where the warm anomaly in middle and high latitudes disappears in the presence of EPP (Fig. 19, top right vs. bottom right), in better agreement with observations (Keckhut et al., 2005). The polar ozone buildup with increasing solar activity in the absence of EPP modifies the evolution of the polar vortex during the initial stages of its development so as to make it weaker around $60^{\circ} \mathrm{S}$ by reducing the meridional temperature gradient. In the presence of EPP there is much less ozone increase in the sub-polar latitude band and the $\mathrm{SH}$ polar vortex intensifies during solar maxima (Fig. 19, bottom left).

In the $\mathrm{NH}$, the high latitude ozone increase with solar activity is also removed by EPP. However, the change is not as extensive as in the $\mathrm{SH}$ and there is little difference in the temperature response below $30 \mathrm{~km}$ poleward of $40^{\circ} \mathrm{N}$ (Fig. 19, bottom right). Above $30 \mathrm{~km}$ the temperature is decoupled from the ozone at high latitudes. Presumably, the large difference in polar transport and mixing between the two hemisphere is playing a role.

An interesting effect of inclusion of EPP is the formation of a region with weak ozone response to the solar cycle around $30 \mathrm{~km}$ near the equator (Fig. 21, bottom middle). This feature is present in observations (Soukharev and Hood, 2006), although in these simulations it is not as pronounced. Analysis of the diabatic vertical wind in the tropics (not shown) suggests that there is an increase in the tropical upwelling above $30 \mathrm{~km}$ during solar maxima which offsets the buildup of ozone at its mixing ratio peak, which is at $30 \mathrm{~km}$. The enhanced vertical transport is associated with enhanced horizontal transport of ozone to middle latitudes, counteracting the increased photochemical production of ozone.

Another significant feature associated with EPP is the increase in $\mathrm{H}_{2} \mathrm{O}$ around the tropopause level and in the lowermost stratosphere during solar maximum years (Fig. 21, bottom right). This is driven by the warming temperatures in the cold trap region (Fig. 19, bottom middle) in the EPP ensemble. Without EPP there is a cooling in the TTL (Fig. 19, top middle). The source of the TTL temperature variation with the solar cycle and EPP is the increased Brewer-Dobson circulation during solar minimum years. The presence of a positive ozone anomaly in the TTL region is consistent with reduced upwelling, which is apparent in the age of air increase in the same region (Fig. 19, bottom left). Partly, this is related to the large, positive vertical gradient of ozone in this region. But also, vertical upwelling is associated with horizontal transport so a weakening of the Brewer-Dobson circulation reduces the loss of ozone to middle latitudes. The $\mathrm{H}_{2} \mathrm{O}$ increase itself leads to additional radiative warming in the TTL. The relative warming of the TTL during solar maximum years is not associated with enhanced GCR ozone production since it is in the minimum stage of its cycle when the associated ozone production below $20 \mathrm{~km}$ is the lowest.

\subsubsection{Temporal and spatial profiles}

Here the two solar variability ensembles are compared for zonal and global mean total column ozone and tropical mean vertical profiles of the fields presented in the previous subsection.

The annual mean, global mean total column ozone variation due to the solar cycle is shown in Fig. 22. EPP can offset 

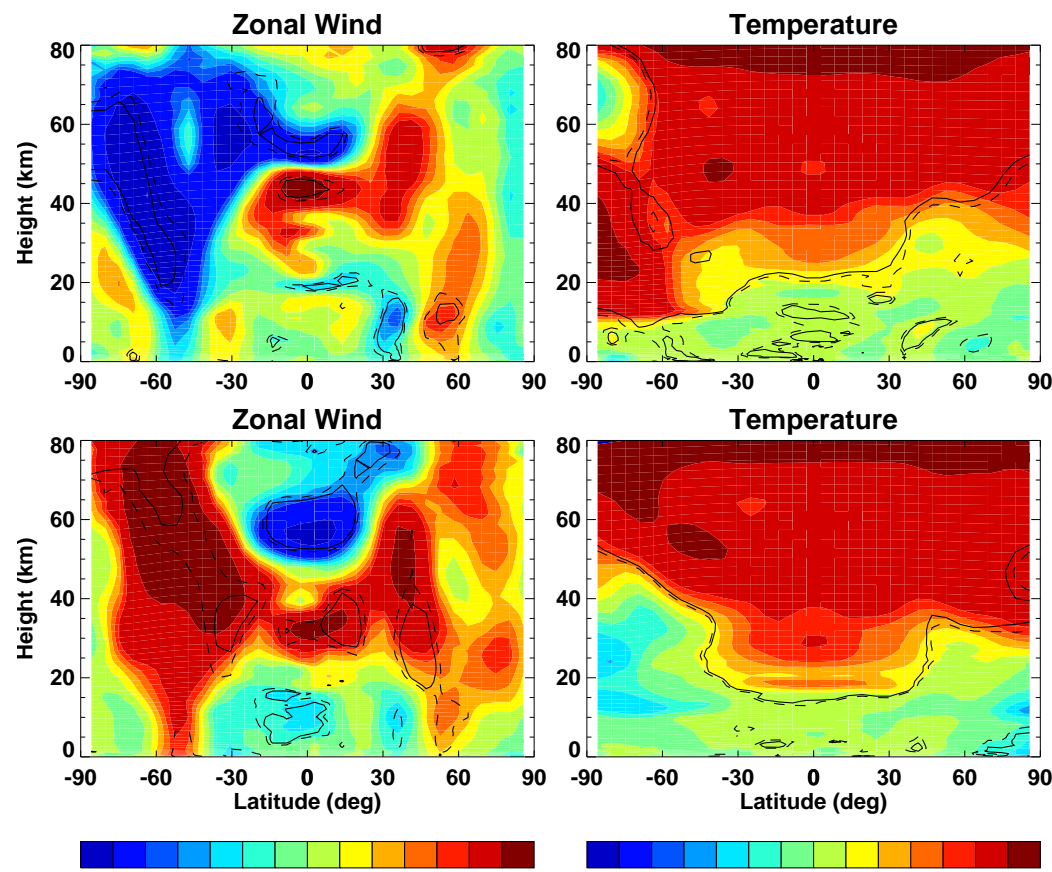

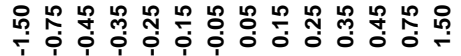

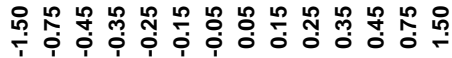

Fig. 19. Latitude-altitude dependence of the annual mean regression coefficient for the solar variability only ensemble mean (top) and for the combined solar variability and EPP ensemble mean (bottom): zonal wind (left, $\mathrm{m} \mathrm{s}^{-1}$ per 100 units of F10.7) and zonal mean temperature (right, K per 100 units of F10.7).
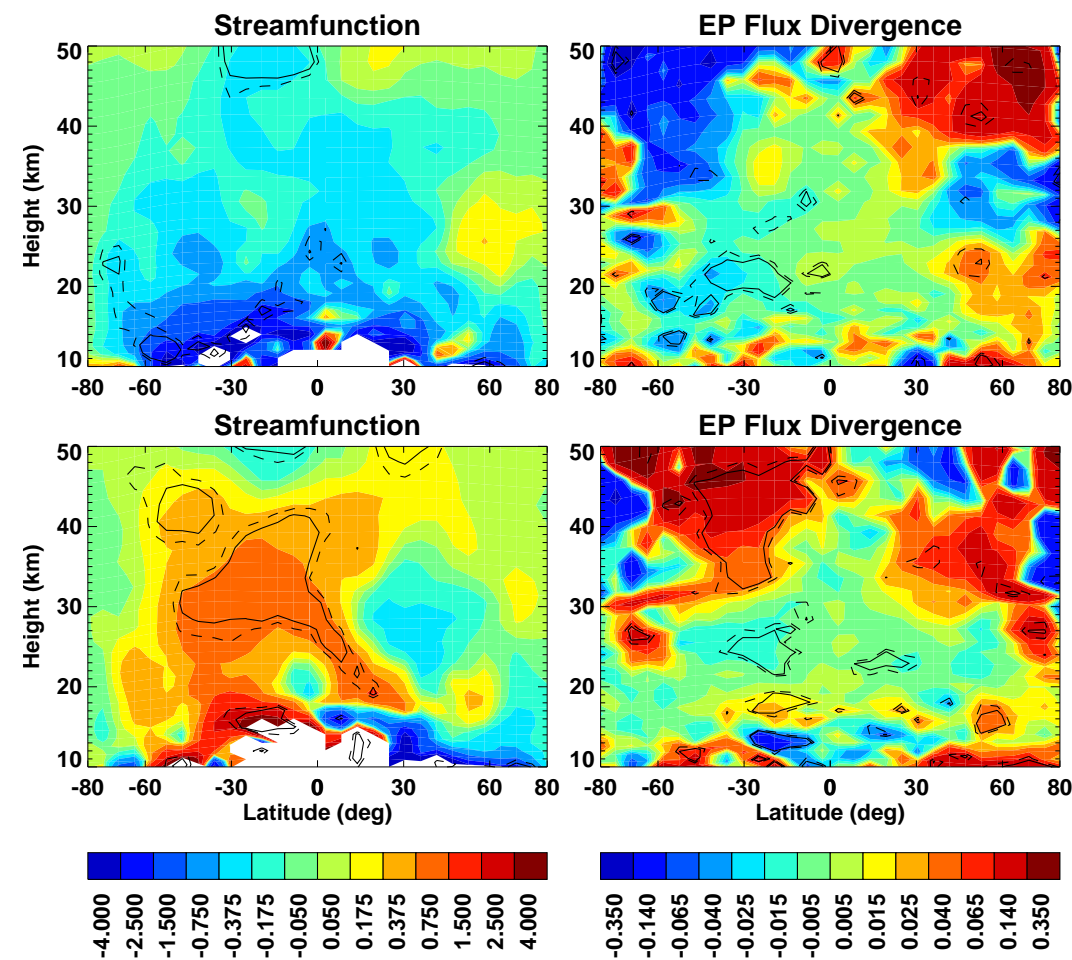

Fig. 20. Latitude-altitude dependence of the annual mean regression coefficient for the solar variability only ensemble mean (top) and for the combined solar variability and EPP ensemble mean (bottom): mass streamfunction (left, $\mathrm{kg} \mathrm{m}^{-1} \mathrm{~s}^{-1}$ per 100 units of F10.7, values outside the $(-5,5)$ interval are not plotted) and Eliassen-Palm flux divergence (right, $\mathrm{m} \mathrm{s}^{-2}$ per 100 units of F10.7). 

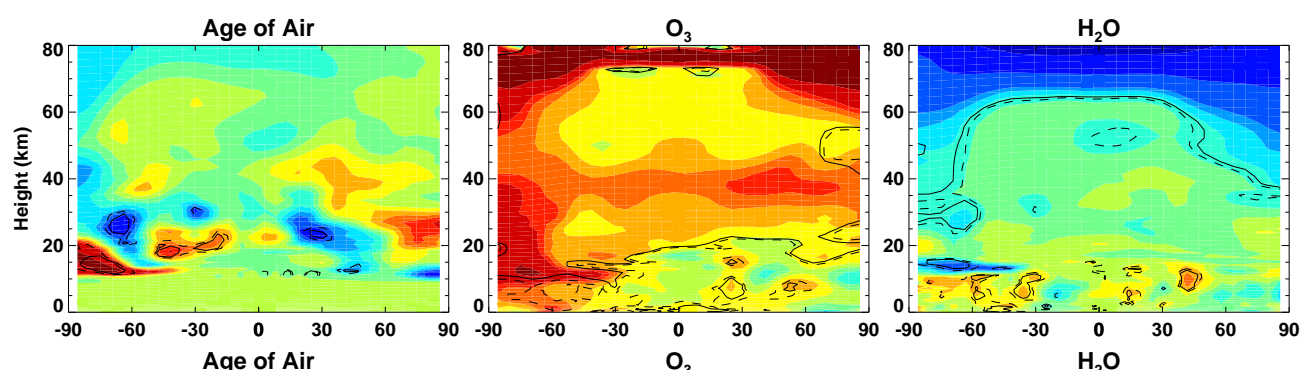

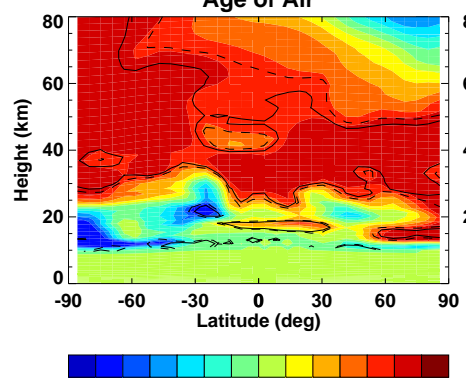

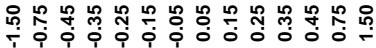

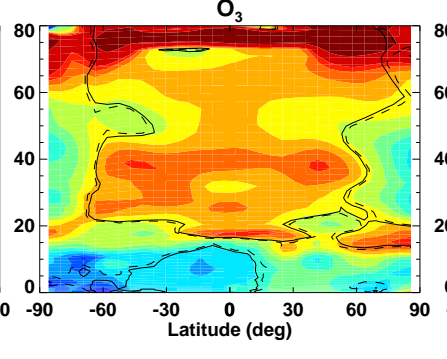

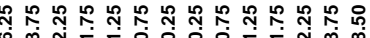

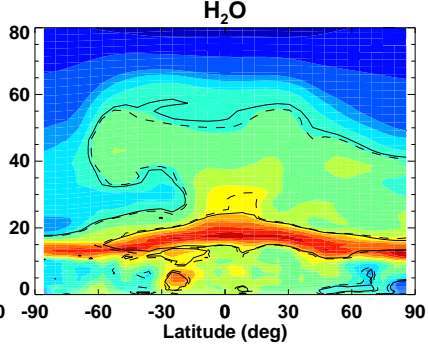

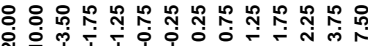

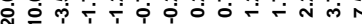

Fig. 21. As in Fig. 19 but for age of air (left), $\mathrm{O}_{3}$ (middle), and $\mathrm{H}_{2} \mathrm{O}$ (right). Differences in $\%$.

some of the solar cycle variation, as seen during the solar maximum around 1990. The observed total column was also relatively lower during this solar maximum. The EESC term should have removed most of the long term variation due to halogen loading so this must be due to other processes. The activity of SPEs combined with auroral zone electron precipitation was highest during the peak of the 1990 solar maximum (see Fig. 2). This is reflected in an increased total column of $\mathrm{NO}_{\mathrm{y}}$ (not shown) which contributes to the reduction of ozone.

A major difference between the model results and observations is the range of global mean total ozone column variation with the solar cycle. Observations range from -6 to $5 \mathrm{DU}$ but the model ranges from -4 to $3 \mathrm{DU}$. There is much more interannual variation in the observations. Some of this is related to volcanic activity, in particular the minimum in 1992 following the Pinatubo eruption in 1991. The SAD term in the regression model cannot remove the volcanic signal completely since there is a long ozone memory below $25 \mathrm{~km}$. The interannual variability in the observations is also due to dynamics. For example, the amount of ozone loss at high latitudes due to heterogeneous chemistry depends on the dynamical state of the polar vortex and there is less PSC formation when the vortex is more disturbed, in both hemispheres. The lack of interannual variation of SSTs in the model reduces dynamical variability in the stratosphere (e.g. Douville, 2009). If a 1-2-1 filter is applied to the observed global mean total column ozone data, across years but keeping the month of the year fixed, then the range becomes -5 to $4 \mathrm{DU}$.

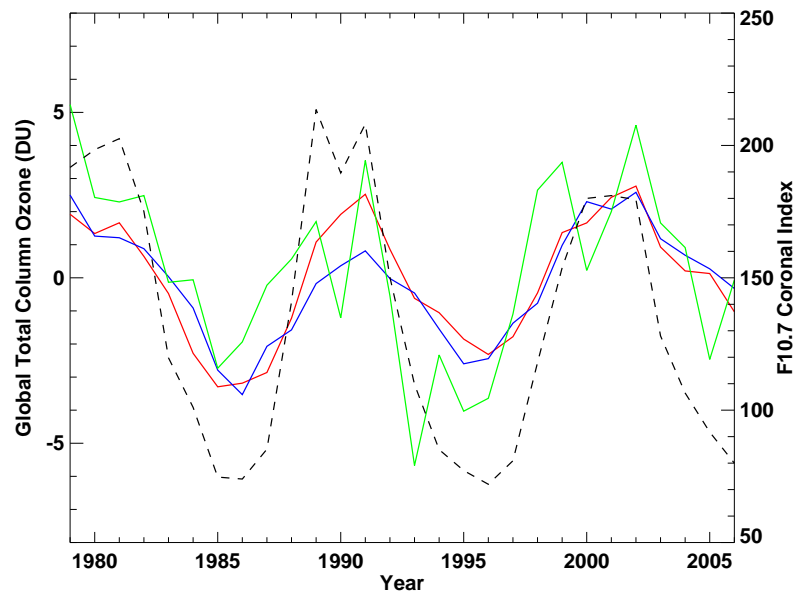

Fig. 22. Annual mean, global mean timeseries of the total column $\mathrm{O}_{3}$ regression fit consisting of the $\mathrm{F} 10.7$ index term and the residual term for the solar variability ensemble without EPP (red), the solar variability ensemble with EPP (blue) and observed total column ozone data from Fioletov et al. (2002) (green). The F10.7 index is also shown (dashed).

Figure 23 presents the zonal mean total column ozone variation with latitude. The high latitude effect of EPP is most apparent in the SH where the maximum in total column ozone variation near the pole is removed and is lower than in the ground based observations (Fioletov et al., 2002, latest data provided courtesy of V. Fioletov). This may reflect an overly stable SH polar vortex in CMAM. In the $\mathrm{NH}$ 
the variation is underestimated in the model since the model $\mathrm{NH}$ polar vortex is too leaky compared to the real atmosphere. For a discussion of Arctic vortex transport isolation see Müller et al. (2005). However, the version of CMAM used in the present study has a vertical diffusion on tracers that is ten times smaller than in the version discussed in this reference.

Comparing to other models from the CCMVal-1 intercomparison (see Fig. 8 in Austin et al., 2008), the high latitude response in the SH is too large for most models without EPP. Those models without EPP which lie closer to observations have a much higher variability in the response compared to the results presented here. The WACCM response in this region is similar to the CMAM solar variability ensemble with EPP (Fig. 23, blue curve). This indicates that EPP is an important factor in the high latitude SH ozone solar cycle variation.

Figure 24 (top left) compares the ozone regression coefficient averaged from $25^{\circ} \mathrm{S}$ to $25^{\circ} \mathrm{N}$ for the two solar variability ensemble runs and satellite observations (McLinden et al., 2009). As noted above, the model has an ozone solar cycle response minimum around $30 \mathrm{~km}$ with EPP. It is not as deep as in the observations but similar to other models even though we do not have SST imposed variability (Austin et al., 2008). The model study of Matthes et al. (2010) identifies the QBO as an important factor in the tropical stratosphere below $10 \mathrm{hPa}$ for the solar cycle response of ozone. During solar maxima, QBO east phases are associated with enhanced ozone whereas QBO west phases have reduced ozone due to differences in the Brewer-Dobson circulation. However, the origin of the ozone response minimum seen in observations at $10 \mathrm{hPa}$ remains unexplained.

An important source of solar cycle variability that is missing in models without GCR occurs in the tropics, namely the catalytic gas phase destruction via $\mathrm{NO}_{\mathrm{x}}$ between 20 and 30 $\mathrm{km}$. Values of ozone in this layer of the tropics are lower during solar minima due to increased GCR activity compared to solar maxima. This amplifies the solar cycle ozone variation in this layer. The model ozone response in this layer at low latitudes is statistically significant.

The ozone solar cycle response minimum around $10 \mathrm{hPa}$ is made more apparent in the presence of EPP due to the direct chemical effect of GCR and the indirect effect of the three types of EPP on dynamics. There are changes in tropical upwelling and its vertical structure, which involve and intensification of the upwelling at and above $30 \mathrm{~km}$ during solar maxima (not shown). In spite of the fact that the direct effect of auroral zone electrons and SPEs on the tropics is limited due to the high latitude confinement of $\mathrm{NO}_{\mathrm{x}}$ production, the polar vortex perturbations have a global Brewer-Dobson circulation impact that acts to magnify the tropical signal of EPP.

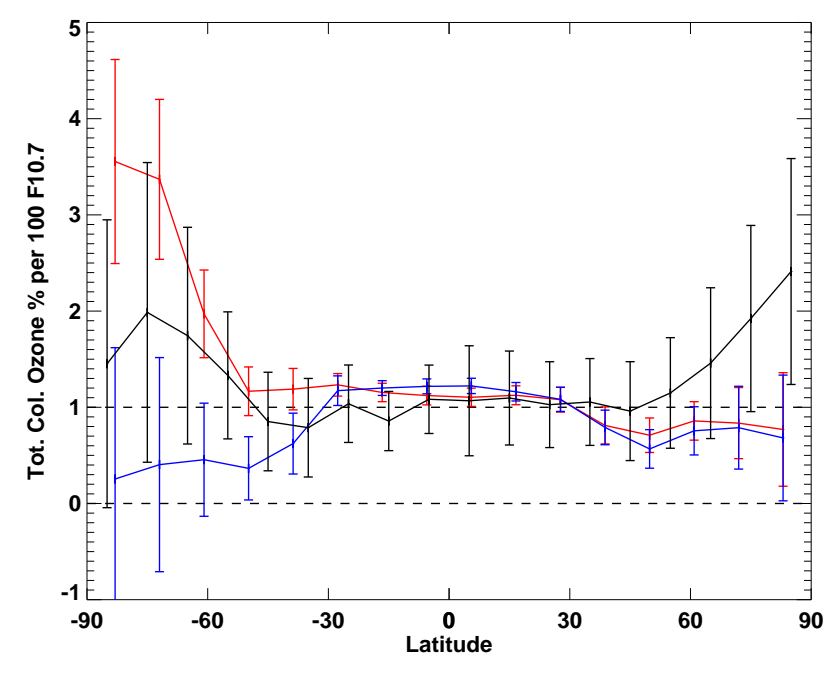

Fig. 23. Zonal mean total column $\mathrm{O}_{3}$ regression fit against the $\mathrm{F} 10.7$ index for the ensemble without EPP (red) and the ensemble with EPP (blue). Regression of observed total column ozone from Fioletov et al. (2002) is also shown (black). The column $\mathrm{O}_{3}$ response is in $\%$ per 100 units of F10.7. Error bars are $\pm 2 \sigma$. The two dashed lines show the $0 \%$ and $1 \%$ levels.

The difference between the two ensembles is highlighted further in the remaining panels of Fig. 24. EPP increases the temperature in the stratosphere tropics due to the reduction in the strength of the Brewer-Dobson circulation during solar maxima relative to solar minima. Below $10 \mathrm{hPa}$ there is much better agreement with observations from the SSU and MSU instruments (Fig. 24, top right). We use channels MSU4, SSU15X, SSU25, SSU26, SSU36X and SSU47X (see caveats in Randel et al., 2009). In our simulations the temperature minimum around $10 \mathrm{hPa}$ is absent without EPP and when it is included, the minimum is not as deep as in models with QBO and variable SSTs (Austin et al., 2008; SPARC CCMVal, 2010). The model average between 10 and $30 \mathrm{hPa}$ is significantly below observations in both CCMVal intercomparisons.

The weakening of the Brewer-Dobson circulation during solar maxima leads to an increase in the age of air (Fig. 24, bottom left). The warming of the TTL in the EPP ensemble results in an increase in the water vapour entering the stratosphere (Fig. 24, bottom right). The inclusion of the solar cycle in most models analyzed by Austin et al. (2008) did not result in any systematic increase in water vapour variation below $20 \mathrm{~km}$ (see their Fig. 13) as in our results. However, the only model with upper atmosphere EPP included in addition to the solar cycle, WACCM (Marsh et al., 2007), did have a variation of $1.5 \%$ in $\mathrm{H}_{2} \mathrm{O}$ per 100 units $\mathrm{F} 10.7$ at $20 \mathrm{~km}$.

The tropical mean age of air does not show any significant solar cycle dependence in the ensemble without EPP. This differs from the results shown in Fig. 14 of Austin et al. (2008). The solar variability without EPP ensemble had two 

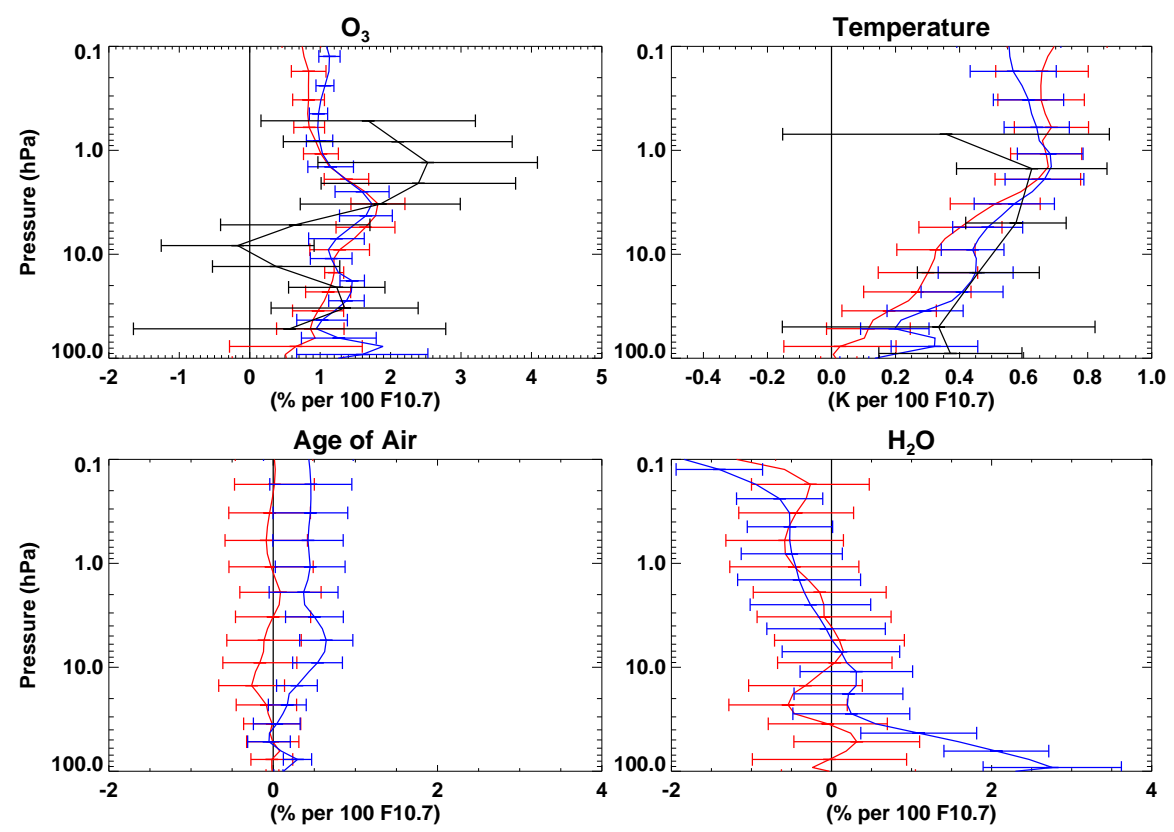

Fig. 24. Tropical average over $25^{\circ} \mathrm{S}-25^{\circ} \mathrm{N}$ of ozone, temperature, age of air and water vapour regression fits to the F10.7 index for the ensemble without EPP (red) and the ensemble with EPP (blue). Regression fits for observed ozone (SAGE corrected SBUV, McLinden et al., 2009) and SSU/MSU temperature (Randel et al., 2009) are also shown (black). Horizontal axis values are \% per 100 units of F10.7 except for temperature which is in K. Error bars are $\pm 2 \sigma$.

members opposing the third giving an insignificant response in the mean. It is possible that three ensemble members is not enough. However, this different behaviour between ensemble members indicates that the dynamical response is not unique. This may no longer be the case if observed or interactive SSTs were used in the model, in which case they may force the middle atmosphere into a response pattern where the age of air increases from solar minimum to solar maximum.

\section{Discussion and conclusions}

The results of our simulations show that addition of EPP to a chemistry climate model makes significant and persistent changes in the natural state of the middle atmosphere. In particular, both auroral zone electrons and SPEs produce annual mean reductions of ozone in the polar regions of the stratosphere in the $3-10 \%$ range depending on location. This is in spite of the fact that auroral zone ionization peaks above $70 \mathrm{~km}$ and SPEs are very intermittent and is consistent with the results of previous studies (Callis et al., 1996; Jackman et al., 2009). There is comparable ozone loss in winter and summer in the polar regions between 20 and $30 \mathrm{~km}$. The $\mathrm{NO}_{\mathrm{y}}$ produced by EPP survives following the break up of the polar vortex (Orsolini et al., 2003) and continues to destroy ozone catalytically. GCR induces a $1 \%$ ozone loss in middle latitudes between 20 and $30 \mathrm{~km}$ in addition to indirect ozone loss in this region due to transport of ozone depleted air in the polar vortices and mixing into lower latitudes. These chemical effects of EPP translate into dynamical effects due to the importance of ozone for radiative transfer.

GCR increases $\mathrm{NO}_{\mathrm{y}}$ by over $10 \%$ in the lowermost stratosphere. The $\mathrm{NO}_{\mathrm{y}}$ of CMAM and other models in this region is lower than in observations (Brohede et al., 2008). So this EPP source together with auroral zone electrons and SPEs helps to explain part of the deficit.

The long-term mean effect of EPP in the simulations with transient solar forcing presented here is to increase the Brewer-Dobson circulation and tropical upwelling. This reduces the age of air by 1 to $2 \%$ in the middle and upper stratosphere. The Brewer-Dobson circulation response varies with the solar cycle; it is weaker during solar maximum years compared to solar minimum years. This behaviour is tied to the EPP modification of the polar vortices through the change in high latitude ozone and hence the radiative equilibrium temperature around the terminator. A reduced meridional gradient of the radiative equilibrium temperature in the $60^{\circ}$ to $80^{\circ}$ latitude region leads to a slightly weaker polar vortex and hence more Rossby wave penetration which can be explained by the Charney-Drazin criterion (Andrews et al., 1987). This results in more Rossby wave drag in the stratosphere (especially the $\mathrm{SH}$ ) and thus a stronger Brewer-Dobson circulation. However, the details of this process are subtle and the simulations with combined EPP excluding the solar cycle (Sect. 4) show that the dynamical response can be in the 
opposite sense as well (weaker Brewer-Dobson circulation and stronger polar vortex).

The regression analysis shows that EPP has a significant impact on the $\mathrm{SH}$ zonal wind variation with the solar cycle. Without EPP the zonal wind becomes weaker during solar maximum years, which does not fit in the idealized picture of Kodera and Kuroda (2002). EPP removes this disagreement. In the NH, the EPP does not alter the basic response of the polar vortex to the solar cycle in the model since it is in a more disturbed regime compared to the $\mathrm{SH}$ and the impact of EPP on the ozone evolution in the NH is weaker. The missing thermospheric $\mathrm{NO}_{\mathrm{x}}$ source in this study is not likely to undermine the pattern of the response. The enhancement during solar maximum near the poles would act to increase the ozone loss below $30 \mathrm{~km}$ with a distribution reinforcing the loss due to existing EPP in the model.

The absence of a well developed Antarctic ozone hole with the choice of chemical boundary conditions in the model is likely to be of secondary importance. EPP generated $\mathrm{NO}_{\mathrm{x}}$ results in some chlorine sequestration in reservoir species and leads to a relative ozone increase below $23 \mathrm{~km}$. However, the ozone increase occurs at too low an altitude to offset most of the loss in the critical region between 20 and $30 \mathrm{~km}$, so the dynamical sensitivity shown here would still be present. Since there is little impact on the transport characteristics of the SH winter circulation, the high latitude ozone anomaly seen in the regression analysis (Fig. 21) would not disappear. This anomaly originates from ozone produced at altitudes higher than the ozone hole. Also, the ozone hole is a temporally limited feature which occurs in Antarctic spring and so is not particularly relevant for the evolution of the SH polar vortex in late fall and winter. Consequently, we believe that without EPP the sensitivity of the SH polar vortex to the solar cycle would still be in the opposite sense as inferred by Kodera and Kuroda (2002).

In the presence of EPP and the associated correction of the $\mathrm{SH}$ polar vortex response to the solar cycle, there is a more pronounced Brewer-Dobson circulation reduction during solar maximum years compared to solar minimum years due to the intensification of the polar vortices and reduced Rossby wave penetration and associated drag. As a result, there is a tropical temperature increase which results from reduced upwelling, and hence reduced adiabatic cooling, in the TTL. So the cold trap warms during solar maximum years, which leads to an increase of $\mathrm{H}_{2} \mathrm{O}$ in the tropopause and lowermost stratosphere of up to $4 \%$. Analysis of the tropical tropopause height based on the cold point diagnostic (not shown) indicates that there is no significant change in height due to GCR. Tropospheric ozone variation during the solar cycle induced by GCR is less than $3 \%$ (Fig. 21, lower middle panel) and there are only small regions with statistically significant variation in tropospheric temperature, which itself is small (Fig. 19, lower right panel). Thus, direct GCR effects on tropopause height are not playing a role in the water vapour variation.
The $\mathrm{H}_{2} \mathrm{O}$ variation in the TTL region and the lowermost stratosphere will have an effect on the surface temperature through radiative forcing (Solomon et al., 2010). This water vapour variation just above the tropopause may be an additional driver for the solar response at the surface. However, an explicit evaluation would require simulations with an interactive ocean. To the best of our knowledge, this EPP effect on surface temperatures has not been suggested before. This mechanism can affect decadal surface temperature trends reflecting variations in the solar cycle.

A feature of these results, which has been noted before (e.g., Kodera, 2006), is that high latitude changes in Rossby wave drag are associated with tropical circulation changes. This can be seen in the pole to pole change in the age of air. However, the tropical response cannot be explained simply by the non-local nature of the diabatic streamfunction (Eliassen, 1951). Some of the low latitude Brewer-Dobson circulation variation from solar minima to solar maxima is due to Rossby wave propagation changes induced by variation of the polar vortices. But there are also sources associated with the subtropical jets such as synoptic scale Rossby waves and mountain wave drag (McLandress and Shepherd, 2009). There is a localized change of Eliassen-Palm flux divergence in the TTL which contributes to the solar cycle variation in temperature (Fig. 20).

Variation of TTL temperatures and tropical ozone is also induced by interannual variation of SSTs (Schmidt, 2010), an effect which is not included in this study. SSTs change the tropopause height as well as the forcing of planetary Rossby waves so they can significantly influence the middle atmosphere circulation (see Rind et al., 2008, and references therein). The results presented here indicate that EPP has a dynamical signature which may mimic that of SSTs for the tropical ozone variability. In particular, the solar cycle ozone response minimum around $10 \mathrm{hPa}$ is made more prominent through the direct chemical effect of GCR on ozone below $10 \mathrm{hPa}$ and indirect dynamical effect of all EPP types on the Brewer-Dobson circulation. Whether EPP and SSTs act through a similar response mode of the stratosphere and how they interact needs further investigation. However, EPP cannot be ignored as a factor in the tropical solar cycle signal in ozone, temperature and water vapour.

Acknowledgements. The authors would like to thank the Natural Sciences and Engineering Research Council of Canada, the Canadian Foundation for Climate and Atmospheric Sciences and the Canadian Space Agency for support. Computing for this work was supported by the Canadian Foundation for Infrastructure, the Canadian Space Agency and the Ontario Innovation Trust.

Edited by: P. Haynes 


\section{References}

Andrews, D. G., Holton, J. R., and Leovy, C. B.: Middle atmosphere dynamics, Academic Press, Toronto,489 pp., 1987.

Austin, J., Tourpali, K., Rozanov, E., Akiyoshi, H., Bekki, S., Bodeker, G., Brühl, C., Butchart, N., Chipperfield, M., Deushi, M., Fomichev, V. I., Giorgetta, M. A., Gray, L., Kodera, K., Lott, F., Manzini, E., Marsh, D., Matthes, K., Nagashima, T., Shibata, K., Stolarski, R. S., Struthers, H., and Tian, W.: Coupled chemistry climate model simulations of the solar cycle in ozone and temperature, J. Geophys. Res., 113, D11306, doi:10.1029/2007JD009391, 2008.

Barth, C. A., Mankoff, K. D., Balley, S. M., and Solomon, S. C.: Global observations of nitric oxide in the thermosphere, J. Geophys. Res., 108, 1027, doi:10.1029/2002JA009458, 2003.

Baumgaertner, A. J. G., Jöckel, P., and Brühl, C.: Energetic particle precipitation in ECHAM5/MESSy1 - Part 1: Downward transport of upper atmospheric $\mathrm{NO}_{\mathrm{x}}$ produced by low energy electrons, Atmos. Chem. Phys., 9, 2729-2740, doi:10.5194/acp-92729-2009, 2009.

Baumgaertner, A. J. G., Jöckel, P., Riede, H., Stiller, G., and Funke, B.: Energetic particle precipitation in ECHAM5/MESSy - Part 2: Solar proton events, Atmos. Chem. Phys., 10, 7285-7302, doi:10.5194/acp-10-7285-2010, 2010.

Bazilevskaya, G. A., Usoskin, I. G., Flückiger, E. O., Harrison, R. G., Desorgher, L., Bütikofer, R., Krainev, M. B., Makhmutov, V. S., Stozhkov, Y. I., Svirzhevskaya, A. K., Svirzhevsky, N. S., and Kovaltsov, G. A.: Cosmic ray induced ion production in the atmosphere, Space Sci. Rev., 137, 149-173, doi:10.1007/s11214-008-9339-y, 2008.

Beagley, S. R., de Grandpré, J., Koshyk, J. N., McFarlane, N. A., and Shepherd, T. G.: Radiative-dynamical climatology of the first-generation Canadian Middle Atmosphere Model, Atmos.Ocean, 35, 293-331, 1997.

Beagley, S. R., McLandress, C., Fomichev, V. I., and Ward, W. E.: The extended Canadian middle atmosphere model, Geophys. Res. Lett., 27, 2529-2532, doi:10.1029/1999GL011233, 2000.

Brasseur, G. P. and Solomon, S.: Aeronomy of the middle atmosphere, Springer, 644 pp., The Netherlands, 2005.

Brohede, S., McLinden, C. A., Urban, J., Haley, C. S., Jonsson, A. I., and Murtagh, D.: Odin stratospheric proxy $\mathrm{NO}_{y}$ measurements and climatology, Atmos. Chem. Phys., 8, 5731-5754, doi:10.5194/acp-8-5731-2008, 2008.

Brown, R. R.: Electron precipitation in the auroral zone, Space Sci. Rev., 5, 311-387, doi:10.1007/BF02653249, 1966.

Callis, L. B., Baker, D., Natarajan, M., Blake, J., Mewaldt, R., Selesnick, R., and Cummings, J.: A 2D model simulation of downward transport of $\mathrm{NO}_{\mathrm{y}}$ into the stratosphere: Effects on the 1994 austral spring $\mathrm{O}_{3}$ and $\mathrm{NO}_{\mathrm{y}}$, Geophys. Res. Lett., 23, 1905-1908, doi:10.1029/96GL01788, 1996.

Callis, L. B., Natarajan, M., Lambeth, J. D., and Baker, D. N.: Solar atmospheric coupling by electrons (SOLACE) 2. Calculated stratospheric effects of precipitating electrons, 1978-1988, J. Geophys. Res., 103, 28421-28438, doi:10.1029/98JD02407, 1998.

Callis, L. B., Natarajan, M., and Lambeth, J. D.: Solar-atmosphere coupling by electrons (SOLACE): 3. Comparisons of simulations and observations, 1979-1997, issues and implications, J. Geophys. Res., 106, 7523-7539, doi:10.1029/2000JD900615, 2001.

Charlton, A. J. and Polvani, L. M.: A new look at stratospheric sud- den warmings. Part I: Climatology and modeling benchmarks, J. Clim., 20, 449-469, 2007.

Crutzen, P. J., Isaksen, I. S. A., and Reid, G. C.: Solar proton events: Stratospheric sources of nitric oxide, Science, 189, 457458, 1975.

de Grandpré, J., Sandilands, J. W., McConnell, J. C., Beagley, S. R., Croteau, P. C., and Danilin, M. Y.: Canadian Middle Atmosphere Model: preliminary results from the chemical transport module, Atmos.-Ocean, 35, 385-431, 1997.

de Grandpré, J., Beagley, S. R., Fomichev, V. I., Griffioen, E., McConnell, J. C., and Medvedev, A. S.: Ozone climatology using interactive chemistry: Results from the Canadian Middle Atmosphere Model, J. Geophys. Res., 105, 26475-26491, doi:10.1029/2000JD900427, 2000.

Douville, H.: Stratospheric polar vortex influence on Northern Hemisphere winter climate variability, Geophys. Res. Lett., 36, L18703, doi:10.1029/2009GL039334, 2009.

Egorova, T., Rozanov, E., Manzini, E., Haberreiter, M., Schmutz, W., Zubov, V., and Peter, T.: Chemical and dynamical response to the 11-year variability of the solar irradiance simulated with a chemistry-climate model, Geophys. Res. Lett., 31, L06119, doi:10.1029/2003GL019294, 2004.

Eliassen, A.: Slow thermally or frictionally controlled meridional circulation in a circular vortex, Astrophys. Norv., 5, 19-60, 1951.

Eyring, V., Butchart, N., Waugh, D. W., Akiyoshi, H., Austin, J., Bekki, S., Bodeker, G. E., Boville, B. A., Brühl, C., Chipperfield, M. P., Cordero, E., Dameris, M., Deushi, M., Fioletov, V. E., Frith, S. M., Garcia, R. R., Gettelman, A., Giorgetta, M. A., Grewe, V., Jourdain, L., Kinnison, D. E., Mancini, E., Manzini, E., Marchand, M., Marsh, D. R., Nagashima, T., Newman, P. A., Nielsen, J. E., Pawson, S., Pitari, G., Plummer, D. A., Rozanov, E., Schraner, M., Shepherd, T. G., Shibata, K., Stolarski, R. S., Struthers, H., Tian, W., and Yoshiki, M.: Assessment of temperature, trace species, and ozone in chemistry-climate model simulations of the recent past, J. Geophys. Res., 111, D22308, doi:10.1029/2006JD007327, 2006.

Eyring, V., Waugh, D. W., Bodeker, G. E., Cordero, E., Akiyoshi, H., Austin, J., Beagley, S. R., Boville, B. A., Braesicke, P., Brühl, C., Butchart, N., Chipperfield, M. P., Dameris, M., Deckert, R., Deushi, M., Frith, S. M., Garcia, R. R., Gettelman, A., Giorgetta, M. A., Kinnison, D. E., Mancini, E., Manzini, E., Marsh, D. R., Matthes, S., Nagashima, T., Newman, P. A., Nielsen, J. E., Pawson, S., Pitari, G., Plummer, D. A., Rozanov, E., Schraner, M., Scinocca, J. F., Semeniuk, K., Shepherd, T. G., Shibata, K., Steil, B., Stolarski, R. S., Tian, W., and Yoshiki, M.: Multimodel projections of stratospheric ozone in the 21st century, J. Geophys. Res., 112, D16303, doi:10.1029/2006JD008332, 2007.

Feldstein, Y. I.: On morphology and auroral and magnetic disturbances at high latitudes, Geomagn. Aeron., 3, 227-239, 1963.

Fioletov, V. E., Bodeker, G. E., Miller, A. J., McPeters, R. D., and Stolarski, R.: Global and zonal total ozone variations estimated from groundbased and satellite measurements: 1964-2000, J. Geophys. Res., 107, 4647, doi:10.1029/2001JD001350, 2002.

Fomichev, V. I.: The radiative energy budget of the middle atmosphere and its parameterizations in general circulation models., J. Atmos. Sol.-Terr. Phys., 71, 1577-1585, doi:10.1016/j.jastp.2009.04.007, 2009.

Fomichev, V. I., Fu, C., de Grandpré, J., Beagley, S. R., Ogibalov, V. P., and McConnell, J. C.: Model thermal response to minor 
radiative energy sources and sinks in the middle atmosphere, J. Geophys. Res., 109, D19107, doi:10.1029/2004JD004892, 2004.

Fomichev, V. I., Forster, P. M., Cagnazzo, C., Jonsson, A. I., Langematz, U., Rozanov, E., Falaleeva, V., Fomin, B., Gillett, N., Iacono, M., Karpechko, A., Li, J., Lemennais, P., Mayer, B., Mlawer, E., Morgenstern, O., Myhre, G., Oberländer, S., Portmann, R., and Sigmond, M.: Chapter 3: Radiation, in: SPARC CCMVal Report on the Evaluation of Chemistry-Climate Models, edited by Eyring, V., Shepherd, T. G., and Waugh, D. W., SPARC, Toronto, Ontario, Canada, Tech. Rep. WCRP132/WMO/TD-1526/SPARC Rep. 5, 2010.

Fröhlich, C. and Lean, J.: Solar radiative output and its variability: evidence and mechanisms, Astron. Astrophys. Rev., 12, $273-$ 320, doi:10.1007/s00159-004-0024-1, 2004.

Gledhill, J. A.: The range-energy relation for $0.1-600 \mathrm{keV}$ electrons, J. Phys. A: Math, Nucl. Gen., 6, 1420-1428, 1973.

Gray, L. J., Beer, J., Geller, M., Haigh, J. D., Lockwood, M., Matthes, K., Cubasch, U., Fleitmann, D., Harrison, G., Hood, L., Luterbacher, J., Meehl, G. A., Shindell, D., van Geel, B., and White, W.: Solar influences on climate, Rev. Geophys., 48, RG4001, doi:10.1029/2009RG000282, 2010.

Hamill, P., Brogniez, C., Antua, J. C., Baumgardner, D., Bevilacqua, R., Bingen, C., Bodeker, G., David, C., Deshler, T., Fussen, D., Hervig, M., Hostettler, C. A., Mergenthaler, J., Peter, T., Raga, G. B., Thomason, L., and Wilson, J. C.: Chapter 4: Stratospheric aerosol record and climatology, in: Assessment of Stratospheric Aerosol Properties (ASAP), edited by: Thomason, L. and Peter, T., 107-176, SPARC, Toronto, Ontario, Canada, Tech. Rep. WCRP-124/WMO/TD-1295/SPARC Rep. 4, 2006.

Hauchecorne, A., Bertaux, J.-L., Dalaudier, F., Cot, C., Lebrun, J.C., Bekki, S., Marchand, M., Kyrölä, E., Tamminen, J., Sofieva, V., Fussen, D., Vanhellemont, F., d'Andon, O. F., Barrot, G., Mangin, A., Théodore, B., Guirlet, M., Snoeij, P., Koopman, R., de Miguel, L. S., Fraisse, R., and Renard, J.-B.: First simultaneous global measurements of nighttime stratospheric $\mathrm{NO}_{2}$ and $\mathrm{NO}_{3}$ observed by Global Ozone Monitoring by Occultation of Stars (GOMOS)/Envisat in 2003, J. Geophys. Res., 110, D18301, doi:10.1029/2004JD005711, 2005.

Hauchecorne, A., Bertaux, J.-L., Dalaudier, F., Russell III, J. M., Mlynczak, M. G., Kyrölä, E., and Fussen, D.: Large increase of $\mathrm{NO}_{2}$ in the north polar mesosphere in January-February 2004: Evidence of a dynamical origin from GOMOS/ENVISAT and SABER/TIMED data, Geophys. Res. Lett., 34, L03810, doi:10.1029/2006GL027628, 2007.

Haynes, P. H., Marks, C. J., McIntyre, M. E., Shepherd, T. G., and Shine, K. P.: On the "downward control" of extratropical diabatic circulations by eddy-induced mean zonal forces, J. Atmos. Sci., 48, 651-678, 1991.

Heaps, M.: Parameterization of the cosmic ray ion-pair production rate above $18 \mathrm{~km}$, Planet Space Sci., 26, 513-517, 1978.

Hitchcock, P., Shepherd, T. G., and McLandress, C.: Past and future conditions for polar stratospheric cloud formation simulated by the Canadian Middle Atmosphere Model, Atmos. Chem. Phys., 9, 483-495, doi:10.5194/acp-9-483-2009, 2009.

Holzworth, R. H. and Meng, C.-I.: Mathematical representation of the auroral oval, Geophys. Res. Lett., 2, 377-380, doi:10.1029/GL002i009p00377, 1975.

Hood, L. L. and Soukharev, B. E.: Solar induced variations of odd nitrogen: Multiple regression analysis of UARS HALOE data,
Geophys. Res. Lett., 33, L22805, doi:10.1029/2006GL028122, 2006.

Huang, T. Y. W., Brasseur, G. P., and Coauthors: Description of the SOCRATES - A chemical dynamical radiative two-dimensional model., Tech. Rep. NCAR/TN-440+EDD, NCAR, Boulder, CO, 94 pp., 1998.

IAGA/V-MOD website:http://www.ngdc.noaa.gov/IAGA/vmod, last access: 15 July, 2008.

IPCC: Special Report on Emission Scenarios, Technical report, Intergovernmental Panel on Climate Change, Cambridge University Press, Cambridge, UK, 599 pp., 2000.

Jackman, C. H.: Ionization rates for 1963-2005 from solar proton events, unpublished technical note, available at: http://www.geo. fu-berlin.de/en/met/ag/strat/forschung/SOLARIS/Input_data, 2006.

Jackman, C. H., DeLand, M. T., Labow, G. J., Fleming, E. L., Weisenstein, D. K., Ko, M. K. W., Sinnhuber, M., Anderson, J., and Russell, J. M.: The influence of the several very large solar proton events in years 2000-2003 on the neutral middle atmosphere, Adv. Space Res., 35, 445-450, 2005.

Jackman, C. H., Marsh, D. R., Vitt, F. M., Garcia, R. R., Fleming, E. L., Labow, G. J., Randall, C. E., López-Puertas, M., Funke, B., von Clarmann, T., and Stiller, G. P.: Short- and medium-term atmospheric constituent effects of very large solar proton events, Atmos. Chem. Phys., 8, 765-785, doi:10.5194/acp-8-765-2008, 2008.

Jackman, C. H., Marsh, D. R., Vitt, F. M., Garcia, R. R., Randall, C. E., Fleming, E. L., and Frith, S. M.: Long-term middle atmosphere influence of very large solar proton events, J. Geophys. Res., 114, D11304, doi:10.1029/2008JD011415, 2009.

Karpechko, A. Yu., Gillett, N. P., Hassler, B., Rosenlof, K. H., and Rozanov, E.: Quantitative assessment of Southern Hemisphere ozone in chemistry-climate model simulations, Atmos. Chem. Phys., 10, 1385-1400, doi:10.5194/acp-10-1385-2010, 2010.

Keckhut, P., Cagnazzo, C., Chanin, M.-L., Claud, C., and Hauchecorne, A.: The 11-year solar-cycle effects on the temperature in the upper-stratosphere and mesosphere: Part IAssessment of observations, J. Atmos. Sol.-Terr. Phys., 67, 940947, doi:10.1016/j.jastp.2005.01.008, 2005.

Kodera, K.: Influence of stratospheric sudden warming on the equatorial troposphere, Geophys. Res. Lett., 33, L086804, doi:10.1029/2005GL024510, 2006.

Kodera, K. and Kuroda, Y.: Dynamical response to the solar cycle, J. Geophys. Res., 107, 4749, doi:10.1029/2002JD002224, 2002.

Kodera, K. and Shibata, K.: Solar influence on the tropical stratosphere and troposphere in the northern summer, Geophys. Res. Lett., 33, L19704, doi:10.1029/2006GL026659, 2006.

Kodera, K., Hori, M. E., Yukimoto, S., and Sigmond, M.: Solar modulation of the Northern Hemisphere winter trends and its implications with increasing $\mathrm{CO}_{2}$, Geophys. Res Lett., 35, L03704, doi:10.1029/2007GL031958, 2008.

Kondrashov, D. and Ghil, M.: Spatio-temporal filling of missing points in geophysical data sets, Nonlin. Processes Geophys., 13, 151-159, doi:10.5194/npg-13-151-2006, 2006.

Koshyk, J. N., Boville, B. A., Hamilton, K., Manzini, E., and Shibata, K.: Kinetic energy spectrum of horizontal motions in middle-atmosphere models, J. Geophys. Res., 104, 27,17727,190, doi:10.1029/1999JD900814, 1999.

Kuroda, Y. and Kodera, K.: Effect of the solar cycle on the Polar- 
night jet oscillation, J. Met. Soc. Japan, 80, 973-984, 2002.

Lamarque, J.-F., Brasseur, G., Hess, P., and Müller, J.-F.: Threedimensional study of the relative contributions of the different nitrogen sources in the troposphere, J. Geophys. Res., 101, 2295522968, doi:10.1029/96JD02160, 1996.

Langematz, U., Grenfell, J. L., Matthes, K., Mieth, P., Kunze, M., Steil, B., and Brühl, C.: Chemical effects in 11-year solar cycle simulations with the Freie Universität Berlin Climate Middle Atmosphere Model with online chemistry (FUB-CMAM-CHEM), Geophys. Res. Lett., 32, L13803, doi:10.1029/2005GL022686, 2005.

Liu, H.-L., Foster, B. T., Hagan, M. E., McInerney, J. M., Maute, A., Qian, L., Richmond, A. D., Roble, R. G., Solomon, S. C., Garcia, R. R., Kinnison, D., Marsh, D. R., Smith, A. K., Richter, J., Sassi, F., and Oberheide, J.: Thermosphere extension of the Whole Atmosphere Community Climate Model, J. Geophys. Res., 115, A12302, doi:10.1029/2010JA015586, 2010.

López-Puertas, M., Funke, B., Gil-Lopéz, S., von Clarmann, T., Stiller, G. P., Hopfner, M., Kellmann, S., Fischer, H., and Jackman, C. H.: Observation of $\mathrm{NO}_{\mathrm{x}}$ enhancement and ozone depletion in the Northern and Southern Hemispheres after the OctoberNovember 2003 solar proton events, J. Geophys. Res., 110, A09S43, doi:10.1029/2005JA011050, 2005.

Manzini, E., Matthes, K., Blume, C., Bodeker, G., Cagnazzo, C., Calvo, N., Charlton-Perrez, A., Douglass, A., Fogli, P. G., Gray, L., Kim, J., Kodera, K., Kunze, M., Pena Ortiz, C., Randel, W., Reichler, T., Stenchikov, G., Timmreck, C., Toohey, M., and Yoden, S.: Chapter 8: Natural Variability of Stratospheric Ozone, in: SPARC CCMVal Report on the Evaluation of ChemistryClimate Models, edited by Eyring, V., Shepherd, T. G., and Waugh, D. W., SPARC, Toronto, Ontario, Canada, Tech. Rep. WCRP-132/WMO/TD-1526/SPARC Rep. 5, 2010.

Marsh, D. R., Garcia, R. R., Kinnison, D. E., Boville, B. A., Sassi, F., Solomon, S. C., and Matthes, K.: Modeling the whole atmosphere response to solar cycle changes in radiative and geomagnetic forcing, J. Geophys. Res., 112, D23306, doi:10.1029/2006JD008306, 2007.

Matthes, K., Marsh, D. R., Garcia, R. R., Kinnison, D. E., Sassi, F., and Walters, S.: Role of the QBO in modulating the influence of the 11 year solar cycle on the atmosphere using constant forcings, J. Geophys. Res., 115, D18110, doi:10.1029/2009JD013020, 2010.

McLandress, C. and Shepherd, T. G.: Impact of climate change on stratospheric sudden warmings as simulated by the Canadian Middle Atmosphere Model, J. Clim., 22, 5449-5463, doi:10.1175/2009JCLI3069.1, 2009.

McLandress, C., Ward, W. E., Fomichev, V. I., Semeniuk, K., Beagley, S. R., McFarlane, N. A., and Shepherd, T. G.: Large-scale dynamics of the mesosphere and lower thermosphere: An analysis using the extended Canadian Middle Atmosphere Model, J. Geophys. Res., 111, D17111, doi:10.1029/2005JD006776, 2006.

McLinden, C. A., Tegtmeier, S., and Fioletov, V.: Technical Note: A SAGE-corrected SBUV zonal-mean ozone data set, Atmos. Chem. Phys., 9, 7963-7972, doi:10.5194/acp-9-7963-2009, 2009.

Megner, L.: Funneling of meteoric material into the polar vortex, in: Nucleation and Atmospheric Aerosols, edited by: O'Dowd, C. D. and Wagner, P. E., Springer, The Netherlands, 860-864, doi:10.1007/978-1-4020-6475-3_170, 2007.
Melo, S. M. L., Blatherwick, R., Davies, J., Fogal, P., de Grandpré, J., McConnell, J., McElroy, C. T., McLandress, C., Murcray, F. J., Olson, J. R., Semeniuk, K., Shepherd, T. G., Strong, K., Tarasick, D., and Williams-Rioux, B. J.: Summertime stratospheric processes at northern mid-latitudes: comparisons between MANTRA balloon measurements and the Canadian Middle Atmosphere Model, Atmos. Chem. Phys., 8, 2057-2071, doi:10.5194/acp-8-2057-2008, 2008.

Müller, R., Tilmes, S., Konopka, P., Grooß, J.-U., and Jost, H.J.: Impact of mixing and chemical change on ozone-tracer relations in the polar vortex, Atmos. Chem. Phys., 5, 3139-3151, doi:10.5194/acp-5-3139-2005, 2005.

Newman, P. A., Daniel, J. S., Waugh, D. W., and Nash, E. R.: A new formulation of equivalent effective stratospheric chlorine (EESC), Atmos. Chem. Phys., 7, 4537-4552, doi:10.5194/acp7-4537-2007, 2007.

Nissen, K. M., Matthes, K., Langematz, U., and Mayer, B.: Towards a better representation of the solar cycle in general circulation models, Atmos. Chem. Phys., 7, 5391-5400, doi:10.5194/acp-75391-2007, 2007.

NOAA/POES website: http://ngdc.noaa.gov/stp/satellite/poes/ index.html, last access: 24 January, 2008.

Orsolini, Y. J.: Long-lived tracer patterns in the summer polar stratosphere, Geophys. Res. Lett., 28, 3855-3858, doi:10.1029/2001GL013103, 2001.

Orsolini, Y. J., Eskes, H., Hansen, G., Hoppe, U.-P., Kylling, A., Kyrö, E., Notholt, J., Van der A, R., and von der Gathen, P.: Summertime low-ozone episodes at northern high latitudes, Q. J. Roy. Meteor. Soc., 129, 3265-3275, doi:10.1256/qj.02.211, 2003.

Orsolini, Y. J., Manney, G. L., Santee M., and Randall, C. E.: An upper stratospheric layer of enhanced $\mathrm{HNO}_{3}$ following exceptional solar storms, Geophys. Res. Lett., 32, L12S01, doi:10.1029/2004GL021588, 2005.

Orsolini, Y. J., Urban, J., and Murtagh, D. P.: Nitric acid in the stratosphere based on Odin observations from 2001 to $2009-$ Part 2: High-altitude polar enhancements, Atmos. Chem. Phys., 9, 7045-7052, doi:10.5194/acp-9-7045-2009, 2009.

Pallé, E., Butler, C. J., and O'Brien, K.: The possible connection between ionization in the atmosphere by cosmic rays and low level clouds, J. Atmos. Sol-Terr. Phys., 66, 1779-1790, doi:10.1016/j.jastp.2004.07.041, 2004.

Pancheva, D., Mukhtarov, P., Mitchell, N. J., Merzlyakov, E., Smith, A. K., Andonov, B., Singer, W., Hocking, W., Meek, C., Manson, A., and Murayama, Y.: Planetary waves in coupling the stratosphere and mesosphere during the major stratospheric warming in 2003/2004, J. Geophys. Res., 113, D12105, doi:10.1029/2007JD009011, 2008.

Polvani, L. M. and Kushner, P. J.: Tropospheric response to stratospheric perturbations in relatively simple general circulation model, Geophys. Res. Lett., 29, 1114, doi:10.1029/2001GL014284, 2002.

Porter, H. S., Jackman, C. H., and Green, A. E. S.: Efficiencies for production of atomic nitrogen and oxygen by relativistic proton impact in air, J. Chem. Phys., 65, 154-167, doi:10.1063/1.432812, 1976.

Randall, C., Rusch, D., Bevilacqua, R., Hoppel, K., and Lumpe, J.: Polar Ozone and Aerosol Measurement (POAM) II stratospheric $\mathrm{NO}_{2}$, 1993-1996, J. Geophys. Res., 103, 28361-28371, doi:10.1029/98JD02092, 1998. 
Randall, C. E., Siskind, D. E., and Bevilacqua, R. M.: Stratospheric $\mathrm{NO}_{\mathrm{x}}$ enhancement in the Southern Hemisphere vortex in winter/spring of 2000, Geophys. Res. Lett., 28, 2385-2388, doi:10.1029/2000GL012746, 2001.

Randall, C. E., Harvey, V. L., Manney, G. L., Orsolini, Y., Codrescu, M., Sioris, C., Brohede, S., Haley, C. S., Gordley, L. L., Zawodny, J. M., and Russell III, J. M.: Stratospheric effects of energetic particle precipitation in 2003-2004, Geophys. Res. Lett., 32, L05802, doi:10.1029/2004GL022003, 2005.

Randall, C. E., Harvey, V. L., Siskind, D., France, J., Bernath, P., Boone, C., and Walker, K.: $\mathrm{NO}_{\mathrm{x}}$ descent in the Arctic middle atmosphere in early 2009, Geophys. Res. Lett., 36, L18811, doi:10.1029/2009GL039706, 2009.

Randel, W. J. and Wu, F.: A stratospheric ozone profile data set for 1979-2005: Variability, trends, and comparisons with column ozone data, J. Geophys. Res., 112, D06313, doi:10.1029/2006JD007339, 2007.

Randel, W. J., Shine, K. P., Austin, J., Barnett, J., Claud, C., Gillett, N. P., Keckhut, P., Langematz, U., Lin, R., Long, C., Mears, C., Miller, A., Nash, J., Seidel, D. J., Thompson, D. W. J., Wu, F., and Yoden, S.: An update of observed stratospheric temperature trends, J. Geophys. Res., 114, D02107, doi:10.1029/2008JD010421, 2009.

Reddmann, T., Ruhnke, R., Versick, S., and Kouker, W.: Modeling disturbed stratospheric chemistry during solar-induced $\mathrm{NO}_{\mathrm{x}}$ enhancements observed with MIPAS/ENVISAT, J. Geophys. Res., 115, D00I11, doi:10.1029/2009JD012569, 2010.

Rees, M. H.: Physics and chemistry of the upper atmosphere, Cambridge University Press, Cambridge, UK, 289 pp., 1989.

Rind, D., Lean, J., Lerner, J., Lonergan, P., and Leboissitier, A.: Exploring the stratospheric/tropospheric response to solar forcing, J. Geophys. Res., 113, D24103, doi:10.1029/2008JD010114, 2008.

Rinsland, C. P., Gunson, M. R., Salawitch, R. J., Newchurch, M. J., Zander, R., Abbas, M. M., Abrams, M. C., Manney, G. L., Michelsen, H. A., Chang, A. Y., and Goldman, A.: ATMOS measurements of $\mathrm{H}_{2} \mathrm{O}+2 \mathrm{CH}_{4}$ and total reactive nitrogen in the November 1994 Antarctic stratosphere: Dehydration and denitrification in the vortex, Geophys. Res. Lett., 23, 2397-2400, doi:10.1029/96GL00048, 1996.

Roy, I. and Haigh, J. D.: Solar cycle signals in sea level pressure and sea surface temperature, Atmos. Chem. Phys., 10, 3147-3153, doi:10.5194/acp-10-3147-2010, 2010.

Rozanov, E., Callis, L., Schlesinger, M., Yang, F., Andronova, N., and Zubov, V.: Atmospheric response to $\mathrm{NO}_{\mathrm{y}}$ source due to energetic electron precipitation, Geophys. Res. Lett., 32, L14811, doi:10.1029/2005GL023041, 2005.

Russell, J. M., Solomon, S., Gordley, L. L., Remsberg, E. E., and Callis, L. B.: The variability of stratospheric and mesospheric $\mathrm{NO}_{2}$ in the polar winter night observed by LIMS, J. Geophys. Res., 89, 7267-7275, doi:10.1029/JD089iD05p07267, 1984.

Sandford, D. J., Schwartz, M. J., and Mitchell, N. J.: The wintertime two-day wave in the polar stratosphere, mesosphere and lower thermosphere, Atmos. Chem. Phys., 8, 749-755, doi:10.5194/acp-8-749-2008, 2008.

Schmidt, H.: Numerical simulation of the MLT response to natural and anthropogenic forcing for the period 1960 to 2006, The 6th IAGA/ICMA/CAWSES workshop on Long-Term Changes and Trends in the Atmosphere, NCAR, Boulder, Colorado, USA, 15-
18 June, 2010.

Schmidt, H., Brasseur, G. P., Charron, M., Manzini, E., Giorgetta, M. A., Diehl, T., Fomichev, V. I., Kinnison, D., Marsh, D., and Walters, S.: The HAMMONIA chemistry climate model: sensitivity to the mesopause region to the 11 years solar cycle and $\mathrm{CO}_{2}$ doubling, J. Clim., 19, 3903-3931, 2006.

Scinocca, J. F., McFarlane, N. A., Lazare, M., Li, J., and Plummer, D.: Technical Note: The CCCma third generation AGCM and its extension into the middle atmosphere, Atmos. Chem. Phys., 8, 7055-7074, doi:10.5194/acp-8-7055-2008, 2008.

Seale, R. A. and Bushnell, R. H.: TIROS-N/NOAA A-J space environment monitor subsystem, NOAA technical memorandum ERL SEL;75, National Oceanic and Atmospheric Administration, Environmental Research Laboratories, Space Environment Laboratory, Boulder, Colorado, USA, 1987.

Semeniuk, K., McConnell, J. C., Jin, J. J., Jarosz, J. R., Boone, C. D., and Bernath, P. F.: $\mathrm{N}_{2} \mathrm{O}$ production by high energy auroral electron precipitation, J. Geophys. Res., 113, D16302, doi:10.1029/2007JD009690, 2008.

Seppälä, A., Randall, C. E., Clilverd, M. A., Rozanov, E., and Rodger, C. J.: Geomagnetic activity and polar surface air temperature variability, J. Geophys. Res., 114, A10312, doi:10.1029/2008JA014029, 2009.

Shindell, D., Rind, D., Balachandran, N., Lean, J., and Lonergan, P.: Solar cycle variability, ozone, and climate, Science, 284, 305308, doi:10.1126/science.284.5412.305, 1999.

Siskind, D. E.: On the coupling between middle and upper atmospheric odd nitrogen, in: Atmospheric Science Across the Stratopause, Geophys. Monogr. Ser., vol. 123, edited by: Siskind, D. E., Eckermann, S. D., and Summers, M. E., 101116, AGU, Washington, DC, USA, 2000.

SOLARIS website: http://www.geo.fu-berlin.de/en/met/ag/strat/ forschung/SOLARIS/Input_data, last access: 17 March, 2008.

Solomon, S. and Crutzen, P. J.: Analysis of the August 1972 solar proton event including chlorine chemistry, J. Geophys. Res., 86, 1140-1146, doi:10.1029/JC086iC02p01140, 1981.

Solomon, S., Rusch, D. W., Gerard, J. C., Reid, G. C., and Crutzen, P. J.: The effect of particle precipitation events on the neutral and ion chemistry of the middle atmosphere, 2, Odd hydrogen, Planet. Space Sci., 29, 885-893, doi:10.1016/00320633(81)90078-7, 1981.

Solomon, S., Reid, G. C., Rusch, D. W., and Thomas, R. J.: Mesospheric ozone depletion during the solar proton event of July 13, 1982, 2, Comparison between theory and measurements, Geophys. Res. Lett., 10, 257-260, 1983.

Solomon, S., Rosenlof, K. H., Portmann, R. W., Daniel, J. S., Davis, S. M., Sanford, T. J., and Plattner, G.-K.: Contributions of stratospheric water vapor to decadal changes in the rate of global warming, Science, 327, 1219-1223, doi:10.1126/science.1182488, 2010.

Soukharev, B. E. and Hood, L. L.: Solar cycle variation of stratospheric ozone: Multiple regression analysis of long-term satellite data sets and comparison with models, J. Geophys. Res., 111, D20314, doi:10.1029/2006JD007107, 2006.

SPARC CCMVal 2010: SPARC Report on the Evaluation of Chemistry-Climate Models, edited by Eyring, V., Shepherd, T. G., and Waugh, D. W., SPARC, Toronto, Ontario, Canada, Tech. Rep. WCRP-132/WMO/TD-1526/SPARC Rep. 5, available at: http://www.atmosp.physics.utoronto.ca/SPARC, 2010. 
Starkov, G. V.: Statistical dependences between the magnetic activity indices, Geomagn. Aeronomy, 34, 101-103, 1994.

Stiller, G. P., Tsidu, G. M., von Clarmann, T., Glatthor, N., Höpfner, M., Kellman, S., Linden, A., Ruhnke, R., Fischer, H., López-Puertas, M., Funke, B., and Gil-Lopéz, S.: An enhanced $\mathrm{HNO}_{3}$ second maximum in the Antarctic midwinter upper stratosphere 2003, J. Geophys. Res., 110, D20303, doi:10.1029/2005JD006011, 2005.

Swider, W. and Keneshea, T. J.: Decrease of ozone and atomic oxygen in the lower mesosphere during a PCA event, Planet. Space Sci., 21, 1969-1973, doi:10.1016/0032-0633(73)90126-8, 1973.

Tiao, G. C., Reinsel, G. C., Xu, D., Pedrick, J. H., Zhu, X., Miller, A. J., DeLuisi, J. J., Mateer, C. L., and Wuebbles, D. J.: Effects of autocorrelation and temporal sampling schemes on estimates of trend and spatial correlation, J. Geophys. Res., 95, 2050720517, doi:10.1029/JD095iD12p20507, 1990.

Tsyganenko, N. A., Usmanov, A. V., Papitashvili, V. O., Papitashvili, N. E., and Popov, V.: Software for computations of geomagnetic field and related coordinate systems, Special report, Soviet Geophysical Committee, Moscow, USSR, 58 pp., 1987.

Tunbrige, V. M., and Mitchell, N. J.: The two-day wave in the Antarctic and Arctic mesosphere and lower thermosphere, Atmos. Chem. Phys., 9, 6377-6388, doi:10.5194/acp-9-6377-2009, 2009.

Urban, J., Pommier, M., Murtagh, D. P., Santee, M. L., and Orsolini, Y. J.: Nitric acid in the stratosphere based on Odin observations from 2001 to 2009 - Part 1: A global climatology, Atmos. Chem. Phys., 9, 7031-7044, doi:10.5194/acp-9-7031-2009, 2009.

Usoskin, I. G. and Kovaltsov, G. A.: Cosmic ray induced ionization in the atmosphere: Full modeling and practical applications, J. Geophys. Res., 111, D21206, doi:10.1029/2006JD007150, 2006.

Usoskin, I. G., Alanko-Huotari, K., Kovaltsov, G. A., and Mursula, K.: Hemispheric modulation of cosmic rays: monthly reconstruction for 1951-2004, J. Geophys. Res., 110, A12108, doi:10.1029/2005JA011250, 2005.
Usoskin, I. G., Kovaltsov, G. A., and Mironova, I. A.: Cosmic ray induced ionization model CRAC:CRII: An extension to the upper atmosphere, J. Geophys. Res., 115, D10302, doi:10.1029/2009JD013142, 2010.

Verronen, P. T., Seppälä, A., Kyrölä, E., Tamminen, J., Pickett, H. M., and Turunen, E.: Production of odd hydrogen in the mesosphere during the January 2005 solar proton event, Geophys. Res. Lett., 33, L24811, doi:10.1029/2006GL028115, 2006.

Vogel, B., Konopka, P., Grooß, J.-U., Müller, R., Funke, B., LópezPuertas, M., Reddmann, T., Stiller, G., von Clarmann, T., and Riese, M.: Model simulations of stratospheric ozone loss caused by enhanced mesospheric $\mathrm{NO}_{\mathrm{x}}$ during Arctic Winter 2003/2004, Atmos. Chem. Phys., 8, 5279-5293, doi:10.5194/acp-8-52792008, 2008.

Warneck, P.: Cosmic radiation as a source of odd nitrogen in the stratosphere, J. Geophys. Res., 77, 6589-6591, doi:10.1029/JC077i033p06589, 1972.

WDC website: http://wdc.kugi.kyoto-u.ac.jp last access: 20 March 2008.

White, W. B.: Response of tropical global ocean temperature to the Sun's quasi-decadal UV radiative forcing of the stratosphere, J. Geophys. Res., 111, C09020, doi:10.1029/2004JC002552, 2006.

White, W. B., Lean, J., Cayan, D. R., and Dettinger, M. D.: Response of global upper ocean temperature to changing solar irradiance, J. Geophys. Res., 102, 3255-3266, doi:10.1029/96JC03549, 1997.

World Meteorological Organization (WMO)/United Nations Environment Programme (UNEP): Scientific Assessment of Ozone Depletion: 2002, Global Research and Monitoring Project - Report No. 47, Geneva, Switzerland, 489 pp., 2003.

Wolter, K. and Timlin, M. S.: Measuring the strength of ENSO events: How does 1997/98 rank?, Weather, 53, 315-324, 1998.

Yoden, S., Taguchi, M., and Naito, Y.: Numerical studies on time variations of the troposphere-stratosphere coupled system, J. Met. Soc. Japan, 80, 811-830, 2002. 